Evaluating the Effectiveness of Three Dimensional Geovisualization Tools in Communicating Climate Change Impacts

A PEI Case Study

by

Laura Salisbury

A thesis submitted to the Faculty of Graduate and Post Doctoral Affairs in partial fulfillment of the requirements for the degree of

Master of Science

in

Geography

Carleton University

Ottawa, Ottawa

(C) 2015

Laura Salisbury 


\title{
Preliminary Section
}

\begin{abstract}
Three-dimensional geographic visualization (3D geovisualization) tools have been praised as a solution to the challenge of communicating climate change impacts by capturing public interest, making the issues more personal, and motivating users to take action. However, evaluation methods are not standardized, especially with novice and expert users. Using a combination of workshop surveying and usability testing, I addressed this issue by studying the Coastal Impact Visualization Environment (CLIVE) tool, which allows users to visualize potential sea-level rise and coastal erosion scenarios on PEI (Prince Edward Island). I found that geovisualization tools have the capability to educate and engage users about potential climate change impacts, but generally fade from the users' memories over time, leading to a lack of overall motivation to take climate change action. This has paved the way for the development of a pilot cybercartographic atlas to keep the discussion about climate change impacts accessible.
\end{abstract}




\section{Acknowledgements}

I would like to thank my supervisors Dr. Fraser Taylor, Dr. Scott Mitchell, my advisors Dr. Bruce Tsuji, and Dr. Adam Fenech, and my committee members Dr. Shawn Donaldson and Dr. Stephen Sheppard for all their guidance, suggestions, and contributions. A major thank you to all the members of the Climate Research Lab at UPEI, especially D. Ellis, A. Doiron, D. Jardine, and M. Maheed, with special thanks to Dr. David Lieske for the kind words of advice and encouragement. My sincere thanks to the folks in the Department of Geography and Environmental Studies and the Graduate Student Association at Carleton University. One final thank you to my family, to the Glenoran roommates, and to LB. 


\section{Contents}

1 Introduction $\quad 1$

1.1 Brief Outline . . . . . . . . . . . . . . . . . . 1

1.2 Climate Change Impacts . . . . . . . . . . . . . 2

1.3 Background ................... 4

1.3.1 Geovisualization ............... 4

1.3.2 Three-Dimensional (3D) Geovisualization . . . . . . . . . 9

1.3.3 Evaluating Effectiveness . . . . . . . . . . . . . . 19

1.4 Summary of Chapter . . . . . . . . . . . . . . . 23

1.5 Going Forward . . . . . . . . . . . . . . . . 25

1.5.1 Research Questions . . . . . . . . . . . . . . . 25

1.5 .2 Hypotheses ................... 26

1.5 .3 Justification . . . . . . . . . . . . . . 27

2 Methodology 28

2.1 Background . . . . . . . . . . . . . . . . . . . . 29

2.1.1 Climate Change Effects on Prince Edward Island . . . . . 29

2.1.2 Coastal Impact Visualization Environment (CLIVE) . . . 30

2.2 Methodology .................... 33

2.2.1 Workshop Phase. . . . . . . . . . . . . . . 34

2.2.2 Usability Testing Phase . . . . . . . . . . . . . . 38

3 Results \& Discussion $\quad 46$

3.1 Workshop Phase . . . . . . . . . . . . . . . . 46

3.1.1 Summary of Participants . . . . . . . . . . . . . . . . 49

3.1 .2 Survey Responses . . . . . . . . . . . . . . . . . 51

3.2 Usability Testing Phase . . . . . . . . . . . . . . . . . . . 58

3.2 .1 Ease of Use . . . . . . . . . . . . . . . . . 58

3.2 .2 Usefulness . . . . . . . . . . . . . . . . . 62 
4 Moving Forward $\quad 70$

4.1 Summary of Findings . . . . . . . . . . . . . . . . . 70

4.1 .1 Ease of Use . . . . . . . . . . . . . . . . . . . . 70

4.1 .2 Usefulness . . . . . . . . . . . . . . . . . . . . 71

4.1 .3 Novices vs. Experts . . . . . . . . . . . . . . . . 73

$4.1 .43 \mathrm{D} \ldots \ldots \ldots \ldots \ldots \ldots \ldots \ldots \ldots \ldots$

4.2 Limitations . . . . . . . . . . . . . . . . . . . . . . 74

4.2 .1 Case Study . . . . . . . . . . . . . . . . . . . . . . . 74

4.2 .2 Workshop Phase. . . . . . . . . . . . . . . . 75

4.2 .3 Usability Testing Phase . . . . . . . . . . . . . . . 76

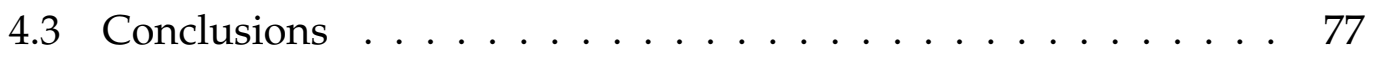

4.4 Ideas for Further Research . . . . . . . . . . . . . . . . 80

4.4 .1 Pilot Atlas . . . . . . . . . . . . . . . . . . 80

4.4 .2 Other Directions . . . . . . . . . . . . . . . . . . . . . . 85

4.5 Final Statements . . . . . . . . . . . . . . . . . . . 86 


\section{List of Figures}

1.1 The Cartography Cube (MacEachren and Taylor 1994). . . . . 6

1.2 Screenshot of 'Earth: An Animated Map' (Beccario 2013). . . . . 11

1.3 Depiction of world population data (Google Data Arts Team 2013). . . . . . . . . . . . . . . . . . . 12

1.4 A 3D city model (Pasewaldt 2012) . . . . . . . . . . . . . . 13

1.5 A 3D model used to archive a digital record of 17 th century Olomouc (Popelka and Brychtova 2011) . . . . . . . . . . . . 14

1.6 A 3D geovisualization tool used to model landscapes for navigational purposes (Schobesberger and Patterson 2008). . . . . . 15

1.7 An example of a 3D geovisualization used for risk communication (Lieske 2012) . . . . . . . . . . . . . . . . . . 17

2.1 An example of a home at risk from coastal erosion (Ellis 2014). . 29

2.2 The CLIVE home screen (provided by the CRL). . . . . . . . . 31

2.3 A scene from CLIVE (provided by the CRL) . . . . . . . . . . . 32

2.4 An example of coastline change scenarios 30,60, and 90 years from 2010 (provided by the CRL) . . . . . . . . . . . . . . 33

2.5 Example of a dramatic sea level rise scenario (provided by the CRL). . . . . . . . . . . . . . . . . . . 34

2.6 Locations of CLIVE roadshow workshops. Location names correspond to numbers in Table 2.1. (Ellis 2014). . . . . . . . . . . . 35

2.7 The CLIVE roadshow poster (Ellis 2014). . . . . . . . . . . . 36

3.1 Charlottetown workshop, photographed by Don Jardine (Ellis 2014). . . . . . . . . . . . . . . . . . . 4 48

3.2 Souris workshop, photographed by Don Jardine (Ellis 2014). . . 48

3.3 Age distribution of workshop participants compared to that of the whole province in the 2011 census. . . . . . . . . . . . . 49

3.4 Gender of participants at all workshops. . . . . . . . . . . . 50 
3.5 Education level of workshop participants. . . . . . . . . . . 50

3.6 All responses to "Are you concerned about the sea causing damage to the shoreline." . . . . . . . . . . . . . . . 51

3.7 Proportion of participants no more or less concerned. Note that all participants are accounted for, as well as each community. . . 52

3.8 Proportion of participants less concerned about the sea causing damage to the shoreline. Note that all participants are accounted for, as well as each community. . . . . . . . . . . . . 52

3.9 Proportion of participants more concerned about the sea causing damage. Note that all participants are accounted for, as well as each community. . . . . . . . . . . . . . . . . . . . 52

4.1 Overview of the Geovisualization Module. The cursor is hovering over the geovisualization tool CLIVE. . . . . . . . . . 82

4.2 Comments made by CLIVE Road Show Participants shown in the PEI Module. . . . . . . . . . . . . . . . . . . . . . 83

4.3 Comments near Cable Head. The cursor is hovering over a comment made by user ' $R A^{\prime}$ ' who is remembering the impacts from storms past. Clustering of comments is seen in this screenshot. . . . . . . . . . . . . . . . . . . 83

4.4 Comments in Alberton. The cursor is hovering over a comment made by user 'Troutshore', who is concerned about future impacts of coastal erosion. . . . . . . . . . . . . . . . 84 


\section{List of Tables}

2.1 Workshop locations and dates. . . . . . . . . . . . 36

2.2 Usability Test Participants, all conducted in 2014. . . . . . . . . 41

3.1 CLIVE roadshow workshop attendance. . . . . . . . . . . 47

3.2 Issues and recommendations for game controls. . . . . . . . . 59

3.3 Issues and recommendations for navigation. . . . . . . . . 59

3.4 Issues and recommendations for layout. . . . . . . . . . . 59

3.5 Issues and recommendations for data. . . . . . . . . . . . 60

3.6 Suggestions and recommendations for future directions. . . . . 61 


\section{Appendices}

Appendix A: Pre CLIVE roadshow workshop questionnaire. . . . . . . 99

Appendix B: Post CLIVE roadshow workshop questionnaire. . . . . . . . 100

Appendix C: Email invitation to participate in the usability study - expert user. . . . . . . . . . . . . . . . . . . . . 101

Appendix D: Usability study interview consent form. . . . . . . . . . 102

Appendix E: Pre usability test questionnaire. . . . . . . . . . . . . 106

Appendix F: Usability testing notes, tasks, and interview questions. . . . 107

Appendix G: Post usability test questionnaire. . . . . . . . . . . . 113

Appendix H: Follow up Email interview Questions: ‘Expert Template'. . 116 


\section{List of Abbrieviations}

BC British Columbia

CFAs Come From Aways

CGV Commission on GeoVisualization

CRL Climate Research Lab

CLIVE CoastaL Impact Visualization Environment

GCRC Geomatics and Cartographic Research Centre

GHG Greenhouse Gas

GIS Geographic Information Systems

HCI Human Computer Interaction

ICA International Cartographic Association

IPCC International Panel on Climate Change

LiDAR Light Detection And Ranging

PEI Prince Edward Island

SFU Simon Fraser University

UCD User-Centered Design

UPEI University of Prince Edward Island

VGI Volunteered Geographic Information

WAMBY What About My Back Yard? 


\section{Chapter 1}

\section{Introduction}

\subsection{Brief Outline}

This thesis will test the argument that 3D geovisualization tools are an effective way of communicating climate change impacts. This will be accomplished by testing the effectiveness of an existing 3D geovisualization tool using a case study.

First, a background and history of the use of 3D geovisualization tools will be provided, as well as examples of geovisualization tools designed to communicate climate change impacts. Additionally, an overview of the methods commonly used to measure the effectiveness of geovisualization tools will be provided.

The second chapter is devoted entirely to the the Coastal Impact Visualization Environment (CLIVE) case study. This tool was developed by the Climate Research Lab (CRL) at the University of Prince Edward Island and the Spatial Interface Lab of Simon Fraser University. Similar to a video game, CLIVE allows users to visualize potential sea-level rise and coastal erosion scenarios on Prince Edward Island (PEI), a Canadian province that is particularly vulnerable to the effects of climate change. I am evaluating CLIVE's effectiveness using two distinct, empirically driven methods: workshop surveying, and usability testing to explore the tool's utility and usability. I will also explore how both novices and experts react to this geographic visualization. 
Results of this research will be discussed in the third chapter. I have also added on to the project by developing a pilot cybercartographic atlas of climate change effects on PEI, which I will discuss in the fourth chapter. This pilot atlas will includes the discussion points generated by the workshop and usability testing phases of my research. This final chapter also includes my conclusions.

\subsection{Climate Change Impacts}

Climate change is a major issue that has received significant exposure in the scientific community as well as the general public. Even if all global greenhouse gas emissions stopped on the day of the publication of this thesis, the impacts of climate change would affect the world for many years to come due to a delayed warming response known as a climate-lag (Mann 2014). As International Governmental Panel on Climate Change (IPCC) report Co-Chair Thomas Stocker stated: “...we are committed to climate change and effects will persist for many centuries." (Williamson 2013).

In Canada alone, the current and potential effects of climate change are

widespread, ranging from coast, to coast, to coast. Some impacts include: water stress (either too much, or too little precipitation), increased damage from extreme flooding and storms, changes in species distribution, and increases in the severity of disease and insect outbreaks, among more. These effects are increasingly affecting Canadians by impacting our natural environment, economic sector, and our health (Natural Resources Canada 2015).

While action to reduce greenhouse gas (GHG) emissions is a necessary response to climate change, adaptation is seen as just as necessary. A report published by Natural Resources Canada states that we as Canadians must “... make adjustments in our activities and decisions in order to reduce risks." The report also calls for continued community adaptation and engagement to "... build capacity, address information needs, and overcome challenges" (Natural Resources Canada 2015). To build economic and social resilience, the Canadian public must be prepared.

To properly prepare for the impacts of global climate change and make in- 
formed decisions regarding the risks these effects might entail, people must be well informed. A stronger and more accurate understanding of these effects should lead to better decision-making, which will both reduce behaviours that feed climate change, as well as mitigate the risks the public will face because of it.

This requires clear communication and education, which is generally accomplished through the usual channels of news reports, articles, reports, and books. These are passive learning processes and are not as effective teaching tools as active learning processes (Wolff et al. 2015; Taylor and Lauriault 2014). For example, the Intergovernmental Panel on Climate Change (IPCC), a group evaluating the risk of human-caused climate change, has written several highly scientific reports with all the information we need. Unfortunately, the information is sometimes lost in scientific jargon before it reaches the public.

To engage the widest audience possible, we must take advantage of all possible communication techniques and technologies. One opportunity to explore is geovisualization (geographic visualization), a set of tools and techniques supporting the visualization of geographic data. Of particular interest to geovisualization researchers are three-dimensional (3D) geographic visualization tools, which have increased dramatically in the 21st century.

The research field of geovisualization places a particular emphasis on the importance of data interaction, which can stimulate knowledge construction: the process of creating rather than revealing knowledge. This can help a user to uncover otherwise hidden patterns, relationships, anomalies, and trends in a dataset.

Knowledge construction may have more of an impact when attempting to motivate the public, as opposed to 'simple' (or passive) infomation transmission. It is an 'authentic' (or 'active') learning process (Galarneau 2005), which have a retention rate far greater than those of passive learning processes (Wolff et al. 2015), which may help Canadians to truly realize and act upon incoming effects of climate change.

These tools have expanded the potential for creating interactive, engaging, informative and effective presentations for communicating geospatial infor- 
mation. But it can be difficult to measure the overall effectiveness of these novel and innovative tools, and they often require large amounts of resources to develop. Before investing time and energy into producing geovisualization tools that may or may not produce their intended result, we must test the effectiveness of these geovisualization tools. Are they an effective mean to communicate climate change impacts?

In addition, we must be careful about the audience to whice we are showcasing geovisualization tools. At its inception, the research field of geovisualization intended experts (and experts alone) to use said tools, which will be discussed in Section 1.3. Now geovisualization tools are more and more likely to be shown and distributed to novice users across digital networks. Are these tools an effective means of communicating the intended information to both novice and expert users?

\subsection{Background}

The purpose of this section is to paint the reader an overall picture of the history of geovisualization: significant uses, types, and examples of geovisualization tools, to describe the benefits and downfalls of three-dimensional geovisualization, to discuss the difference between novice and expert users, to provide an overview of methods to measure a geovisualization tool's effectiveness, and to provide context for the importance of my research.

\subsubsection{Geovisualization}

"When something is visualized (made visible), even if only by illumination in a dark room, the viewer is brought closer to understanding it."

- Michael Wood, 1994

At its root, all problem solving relies on processing, interpreting, and analyzing data. Visualizations are extremely important in this cognitive process, allowing important patterns to emerge that were once invisible. Improving 
visualizations substantially improves the performance of any problem solver, be it a city planner, a politician, or the everyday non-expert.

Two essential components of data visualization in the 21st century are computers and maps (MacEachren and Taylor 1994). Computers have vastly improved visualization potential, while maps are arguably one of the single most important visualization tools of all time (Ware 2012). Since their passage from the paper realm to the digital, maps have greatly expanded capabilities of portraying spatial information that their traditional predecessors could have never offered. These digital maps (or web maps) can include public participation and crowd sourcing in their construction and presentation, can incorporate a wide range of graphic representations of spatial data using animation and dynamic mapping, as well as embrace immersive and interactive environments and interfaces developed by cutting edge technologies.

These technological advancements and the interest and excitement they have generated have led to creation of the research field of geovisualization: "... a loosely bounded domain that addresses the visual exploration, analysis, synthesis, and presentation of geospatial data by integrating approaches from various disciplines including cartography with those from scientific visualization, image analysis, information visualization, exploratory data analysis, visual analytics, and GI Science" (Kraak 2009). In laymen's terms, geovisualization simply means the visualization of spatial data, and is an extension of traditional cartography, though a great emphasis is placed on varying levels of interactivity.

An entirely digital field, geovisualization first developed in the late 1980s, branching from various fields including scientific visualization (McCormick 1988) and information visualization (Card et al. 1999), and was encouraged directly by the increase in sophistication and amount of digital web-mapping, sometimes referred to as the geospatial revolution (Pennsylvania State University 2010). This revolution, which is and has led to the increased prevalence of all geographic information science, has encouraged the increase in geovisualization techniques, refinement, and cost and ease of production. The field has since expanded, leading to textbooks, conferences, and working groups entirely devoted to the subject. In the early 21 st century, the field of geovisualization has been one of the leading areas of applied cartographic research 
(Dodge et al. 2008; Dykes 2005).

The use of geovisualization can be visualized itself by the cartography cube as seen in Figure 1.1. This figure shows the differing ways in which geovisualizations are used, incorporating relationships of human-map interaction, presenting knowns and revealing unknowns, the difference between private and public consumption, and the difference between information visualization and information communication.

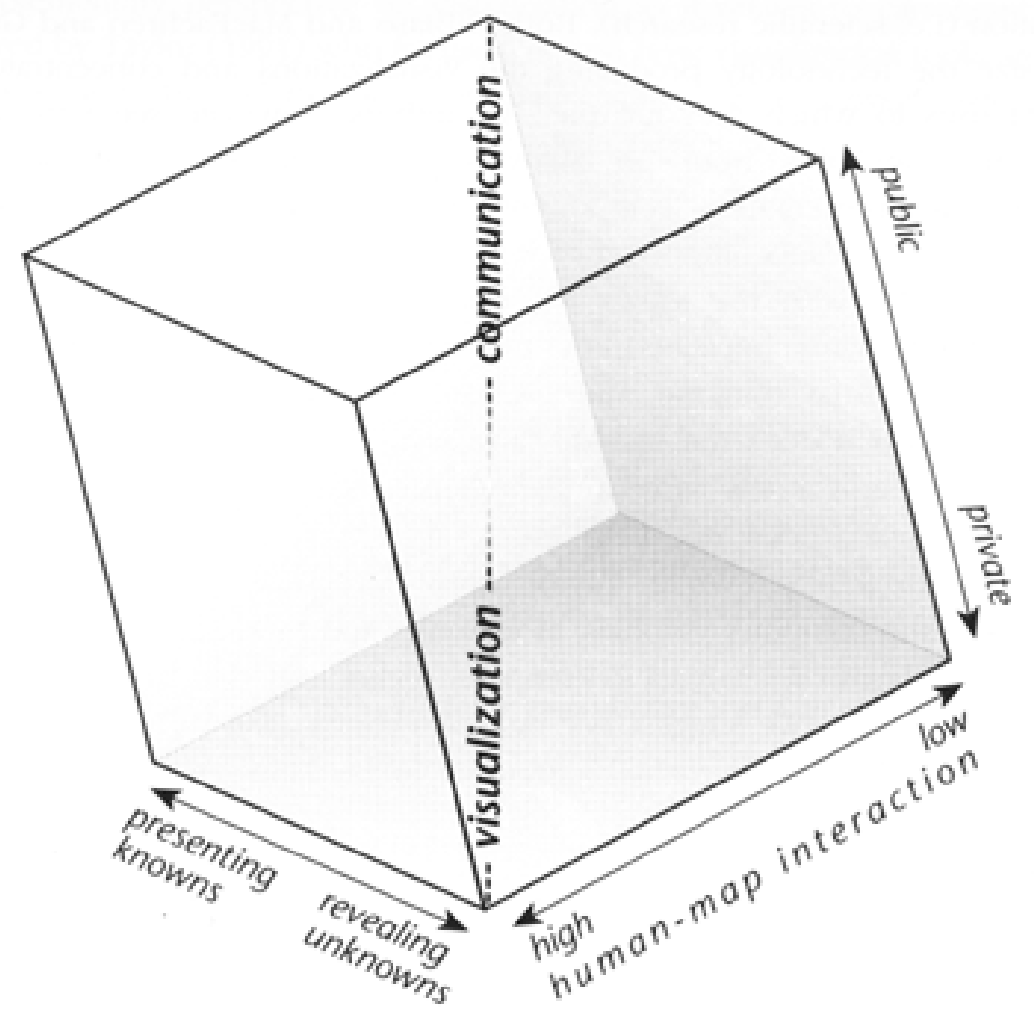

Figure 1.1: The Cartography Cube (MacEachren and Taylor 1994).

DiBase argues that geovisualization holds two major roles in research: the 'analysis end' which facilitates private visual thinking and exploration of data, and the 'communication end' which focuses on public visual communication of results (MacEachren and Taylor 1994). Early geovisualization development attempts were typically designed for use by scientists involved in analysis end of the geovisualization 'spectrum', which would fall on the front corner of the cube in Figure 1.1.

Brodersen argues that the domain of geographic information systems (GIS), cartography, and geo-information is facing a paradigm shift from a geometric 
positioning discipline to a communication discipline (2007). In other words, modern maps (including geovisualization tools) are becoming increasingly more focused on displaying information or knowledge. This shift is apparent in the research field of geovisualization, with interactive maps being used widely for research and education throughout the public sector and through accessible media and technologies. This is occurring in a variety of disciplines and applications all over the world (Kraak 2009).

In other words, interactive maps were originally produced and used by experts, but are now being used by a wide and largely unknown audience, which we can likely assume to be made up of some 'novices' in the subject matter of the visualization. As Montello argues, the success of the interpretation of maps is heavily influenced by a person's prior knowledge and experience, meaning that digitally distributed communication tools can be interpreted very differently between novices and experts in the subject matter of the visualization (Montello 2009). This issue is of interest to the Commission on GeoVisualization $(\mathrm{CGV})^{1}$, leading to the need to study, contribute, and learn from the development and use of interactive maps within all user groups.

Due to this democratization ${ }^{2}$ of $3 \mathrm{D}$ geovisualization techniques, novice users are being exposed to visualizations that were traditionally designed for use by experts and professionals. On the one hand, these geovisualization tools should be understandable by as many people as possible in their target audience (including novice users) so that the intended information can be communicated widely and quickly. On the other hand, these geovisualization tools should not simplify issues to the point where information can be misinterpreted or the whole picture is not conveyed properly. It is not known to what extent expertise levels alter a geovisualization tool's usefulness and ease of use. This is one branch of the geovisualization research field that has not been explored to its full potential.

\footnotetext{
${ }^{1}$ The Commission on GeoVisualization (CGV) of the International Cartographic Association (ICA) was founded in 1995 by the ICA's Commission on Visualization and Virtual Environments. The CGV has been actively developing the field by conducting expert workshops for defining key issues, promising research directions, opportune goals, as well as developing, publishing, and logging related undertaken research.

${ }^{2}$ Democratization means to make accessible to everyone.
} 


\section{Importance of Geovisualization}

So far we've seen that geovisualization techniques tend to focus on revealing unknowns in the data (as opposed to communicating known information), involve a high degree of human-map interaction, and are generally meant for a private audience (as opposed to the wider general public) (Kraak 2009). But what makes geovisualization so different from web maps, or traditional maps for that matter?

New discoveries, ideas, hypotheses, and conclusions are often formed when using geovisualization tools and techniques. When users interact with geospatial information from a new and different perspective, a process called exploratory visual thinking can be stimulated, allowing users to uncover otherwise hidden patterns, relationships, anomalies, and trends in the dataset. In turn, this act of searching for the unknown can lead to theory generation and knowledge construction (Dykes 2005; Tobon 2005; Roth 2013; Kraak and MacEachren 2005; Andrienko et al. 2002; Dodge et al. 2008). In the research field of geovisualization, this construction of knowledge is emphasized over knowledge storage or transmission (MacEachren et al. 2004). Knowledge construction is an active learning process, which is a more effective teaching tool when compared to passive learning approaches (Wolff et al. 2015).

Often users find interactive maps novel and exciting, prompting engagement with an otherwise possibly dull subject. As Bredl et. al (2012) suggest, threedimensional geovisualization can be a tool to steer students towards wanting to learn a subject and away from them feeling like they have to learn a subject. As well, geovisualization techniques can be used to engage the emotions of users and provide an overall captivating experience, similar to the effect of cinema, video games, and 'serious games' (Aitken and Craine 2006).

This engagement is generally thought to come from the feeling of being immersed within the geovisualization tool. Immersion is described by Witmer \& Singer in 1998 as the "...psychological state characterized by perceiving oneself to be enveloped by, included in, and interacting with an environment." It is also described as a sense of being in a world generated by the computer instead of just using a computer (Lombard and Ditton 1997). Simply put, immersion can described as 'feeling present', which shares a lot of commonalities 
with 'flow' experiences (Ermi and Frans 2005). Flow describes the state of immersion in a user, and the production of this state is tied to user enjoyment and the feeling of being challenged (Buchanan and Csikszentmihalyi 1991).

Spatial problems (like climate change adaptation) are generally large, complex, and difficult to tackle (Andrienko et al. 2007). Geovisualization can help to build a synergy between humans and computers in solving these wideranging and intricate problems. With our knowledge, flexible thinking, imagination, as well as our capacity for thought, these systems require human minds. But we humans are not without our faults, which is where the advantages of computer systems come in. That being said, little empirical evidence supports the claims that geovisualization tools facilitate decision making in real world practice, though many researchers are extremely interested in this possibility.

\subsubsection{Three-Dimensional (3D) Geovisualization}

Recent technological and societal developments have acted as a positive stimulus for map creation and use. This has lead to the democratization of the geovisualization development field, as well as experimentation with technological developments leading to a wide range of geovisualization techniques and concepts ranking from static two-dimensional (2D) maps to extremely interactive three-dimensional (3D) interfaces.

There are two main categories when discussing 3D visualization: 'pseudo' and 'true'. Pseudo 3D, also called two-and-a-half-dimensional or 3/4 perspective, is any sort of perspective view that simulates the appearance of being three-dimensional (MacEachren 1995). Stereoscopic images viewed using special viewing devices (such as glasses) are characteristic of true 3D. While true 3D technologies are growing (Johnson et al. 2006), pseudo 3D is far more popular and established. I will be focusing solely on pseudo 3D visualization which I will refer to simply as '3D'.

As it is such a new and growing field, there are not many design standards for digital 3D maps. Work by Haberling has begun to address the need for 3D cartographic design and presentation principles (2008). Pegg (2012) laid out some 
guidelines and design techniques to help the 3D mapping professional, including rendering, illumination, abstraction, generalization, and viewing angles. As basic principles are established, specific design issues relating to 3D modeling can be researched, including general visualization of building models (Baig and Rahman 2013), camera angle and control (Klimke et al. 2013), label placement, the integration of mobile devices (Trujillo et al. 2013), rendering performance (Ellul 2013), quality management (Wagner et al. 2013), general data management and structure (Breunig et al. 2013; Ledoux and Meijers 2013)), and potential crowd sourcing options (Uden and Zipf 2013).

It should be noted that what I refer to as 3D geovisualization tools are also sometimes called geospatial virtual environments (GeoVEs), 3D computerbased simulations of real or imagined environments that users are able to navigate through and interact with (Slocum et al. 2009). They can also be referred to as 'virtual geographical environments' (VGE) by the video game industry (Shepherd and Bleasdale-Shepherd 2008), as 'landscape visualizations' by geographers (Sheppard et al. 2013), and as 'virtual globes' by planners (Schroth et al. 2015, 2011; Sheppard and Cizek 2009). We can also turn to the 'serious games' research field (Henriksen 2013; Foster 2008), which share many ties with 3D geovisualization tools.

\section{Common Uses}

The most suitable method of visualization of an idea or a problem depends on the situation, but 3D visualization adds a connection to reality, be it the visualization of geospatial data, urban areas, landscapes, or simulations of natural disasters.

Data Visualization The role of geovisualization for data visualization has great potential to provide new ways to facilitate understanding of complex issues, especially for children, as well as to support research in children's spatial cognition that is difficult or impossible to do in the real world. An example is the 'Earth: an Animated Map' (see Figure 1.2), which is an interactive geovisualization tool showcasing global air and ocean circulation patterns and temperatures, created by Beccario (2013). Figure 1.3 showcases another data 
visualization example: a portrayal of world population data created by the Google Data Arts Team in 2013.

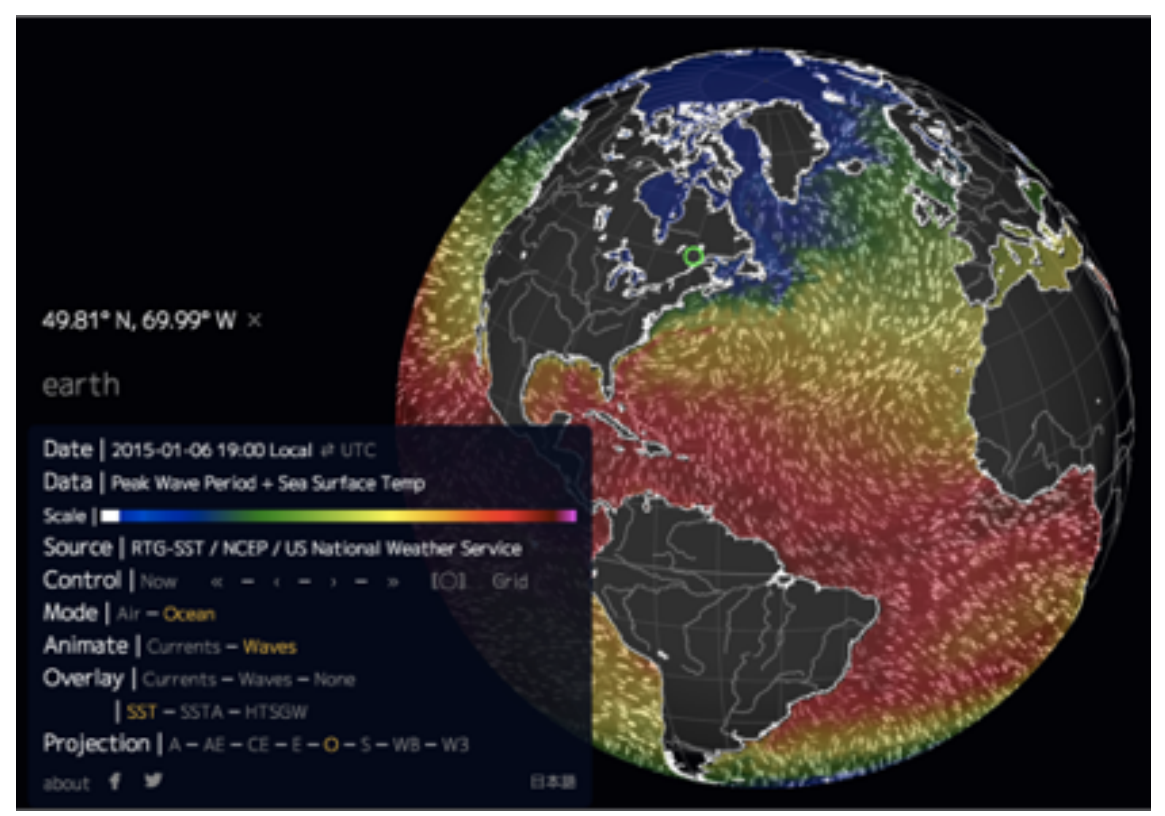

Figure 1.2: Screenshot of 'Earth: An Animated Map' (Beccario 2013). 


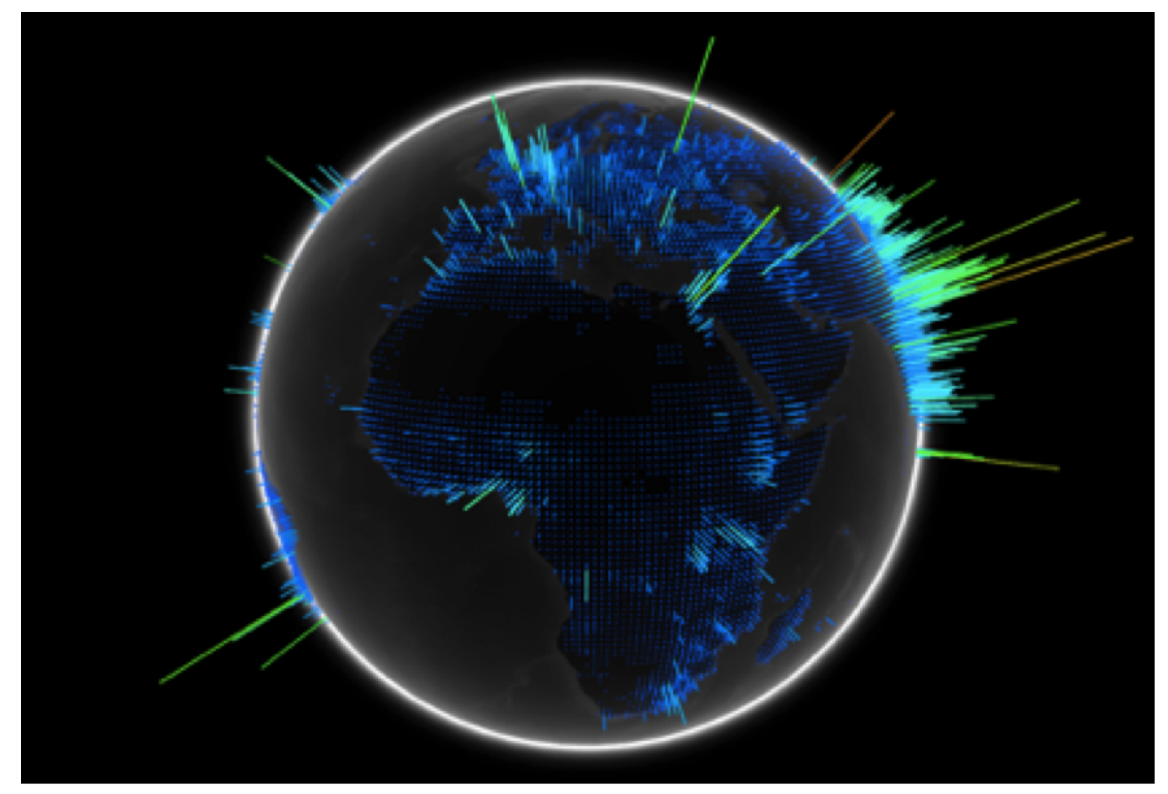

Figure 1.3: Depiction of world population data (Google Data Arts Team 2013). 
Urban Modelling Interactive 3D city models are becoming more popular, which can be designed and produced for navigational purposes, tourism related reasons, or even for indoor navigation (Brown et al. 2013). Design teams are exploring the many different facets of 3D city models, such as appropriate levels of realism (Semmo et al. 2012). The effective modelling of cities using $3 \mathrm{D}$ geoinformation is necessary for analysis in the fields of urban planning, city administration, among other urban 'issues' (Baig and Rahman 2013). These topics could be related to urban space and planning, critical infrastructure use, or below-ground features (Becker et al. 2013). Models can be used to explore energy consumption in buildings (Kaden and Kolbe 2013), or to visualize heat island effects (Danahy et al. 2015). See Figure 1.4 for an example of urban modelling.

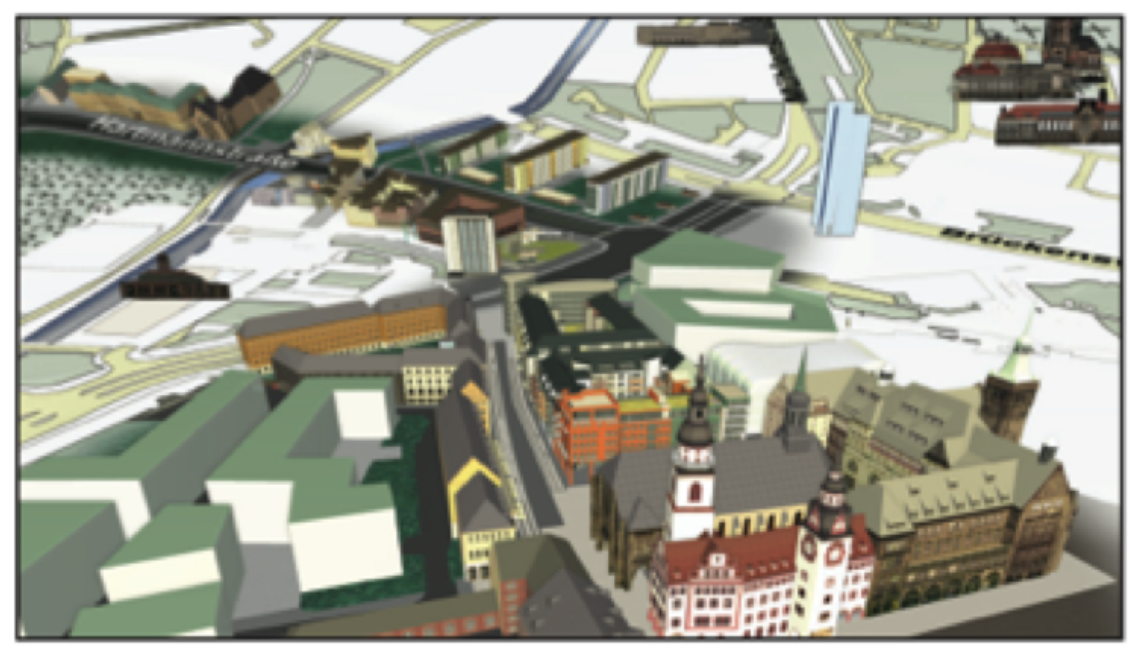

Figure 1.4: A 3D city model (Pasewaldt 2012)

Virtual rendering of historical cities can archive digital records, and present cultural heritage and landscape information to the public (for an example, see Figure 1.5). Many research groups are interested in this purpose, particularly in the field of archaeology. In the context of preserving heritage, many meticulous details are being explored by research groups, including the potential of non-photorealistic rendering of virtual historic landscapes, or the most effective way to mix realistic and abstract data in representations (de Boer 2010). 


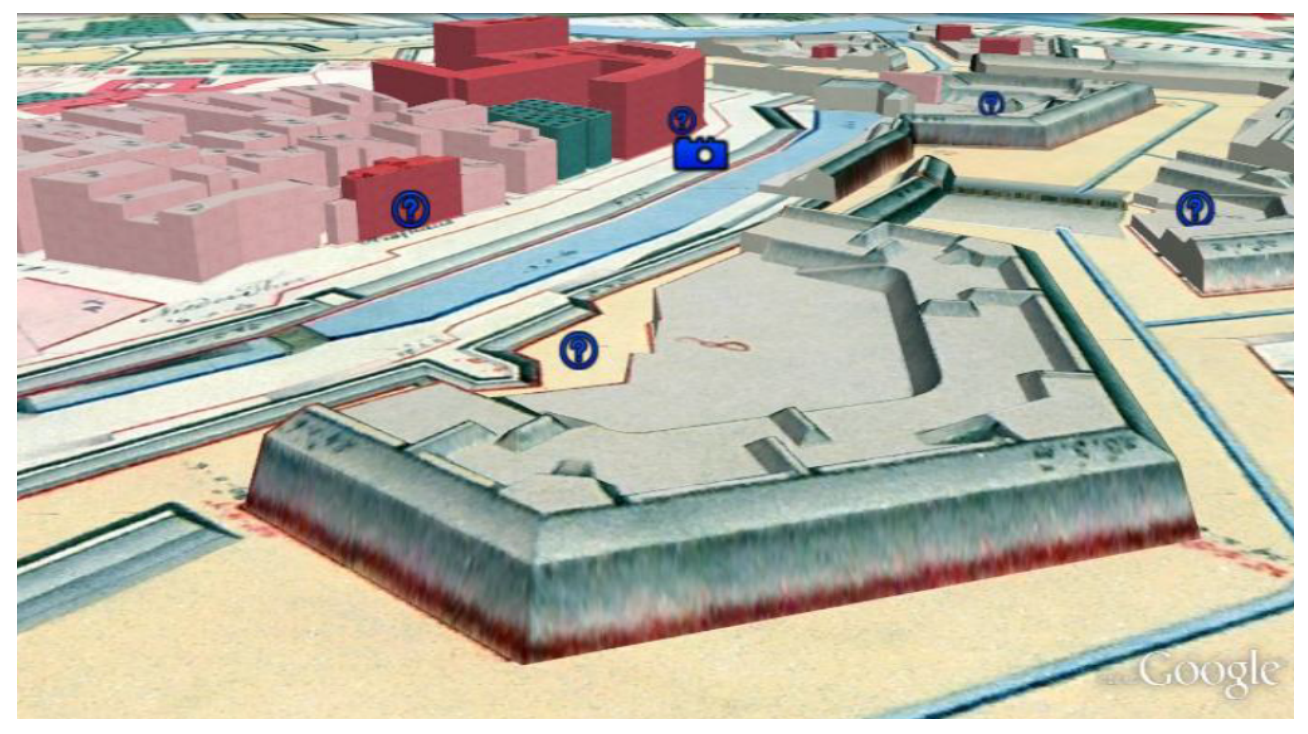

Figure 1.5: A 3D model used to archive a digital record of 17th century Olomouc (Popelka and Brychtova 2011) 
Landscape Modelling Researchers are very interested in modelling landscapes using 3D geovisualization, be it for navigational purposes, resource management (Buecken and Rossman 2013), or for research in the field of geomorphology (the study of the change of natural landforms) (Lowner 2013). There is growing interest in using digital landscapes to visualize future environmental scenarios, which will be explored full in the following section.
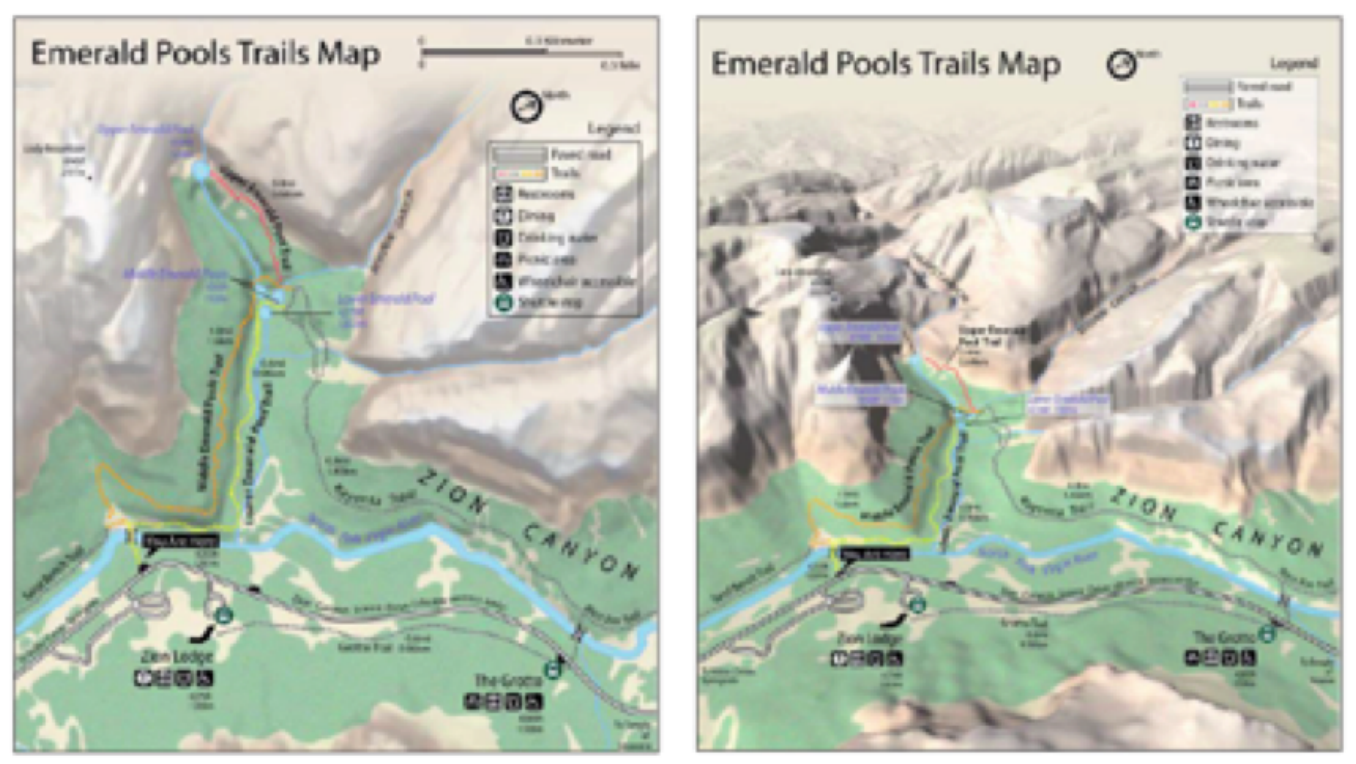

Figure 1.6: A 3D geovisualization tool used to model landscapes for navigational purposes (Schobesberger and Patterson 2008).

Simulations Simulations (the imitations of real world processes using models) are important in risk communication, leading from research that shows that previous experience is known to strongly affect risk perception (Tversky and Kahnman 1974, Grothmann and Pan 2005, Burningham et al. 2008). 3D geovisualization tools are used for many types of simulations, generally relating to risk communication of natural disasters, as exemplified by the German disaster management program called 'Lukex' (Bredl et al. 2012). Simulations of disasters such as flooding (before, during, and after) may benefit vulnerable users (Atila et al. 2013). In 2012, Lieske simulated flooding from a potential dyke breach (see Figure 1.7). Sheppard (2013) showed members of a BC coastal community at risk of flooding projections of their community with a typical storm surge scenario with no adaptive measures, and the same projection with intensive mitigation strategies. In 2013, Benoy and others examined 
the possibility of 3D geovisualization tools to showcase hurricane storm surge scenarios. Other environmental issues are being depicted using geovisualization tools, as shown by another study conducted by Sheppard (2013) that outlined a semi-realistic landscape visualization of the community of Kimberley showing susceptibility to Pine Beetle infestation. Another study focused on the British Columbian city of Delta, explored the potential of 'visioning packages' to show dike breach events, future sea level rise, storm surges, and future adaptation scenarios (Barron et al. 2012).

As seen, communicating environmental issues (including those under the 'climate change' umbrella) using 3D geovisualization techniques is of great interest (Dransch et al. 2010). Sheppard (2013) says that we must turn to these techniques to help accelerate informed and effective responses to climate change, as well as to enhance the overall sense of urgency. In this respect, the localized nature of simulations is important, as exemplified by Nicholson-Cole (2005) showing that we react more to national, local, and personal imagery versus international imagery. Localized geovisualization tools can tap into this emotional attachment to place quickly and memorably. For example, Daniel and Meitner (2001) found that visualizations can produce both positive and negative emotional reactions in users. Following this logic, Sheppard et al. (2011) have developed a conceptual framework to develop visualization materials for to build climate change awareness and agency.

As Kostelnick et al. (2013) suggest, geographic information scientists can provide an important contribution by creating maps and geovisualization tools that depict predicted consequences of risks, but these bring along limitations and uncertainties. They can oversimplify the issue, can use overly ambiguous data sets, and can mislead users by over or under-predicting the geographic extent of a hazard zone (Kostelnick et al. 2013). It has also been found that visualizations with dire predictions can lead to maladaptive practices (Lieske 2012; O'Neill and Nicholson-Cole 2009; Moser and Dilling 2007). It also has been shown that telling someone that they should act differently does not convince them to do so, and simply leads them to mental blocking (Morss et al. 2008), although it can be argued that telling is not the same as showing visually. As Lieske (2012) describes, the effectiveness of 3D geovisulization tools in public communication remain to be demonstrated. 


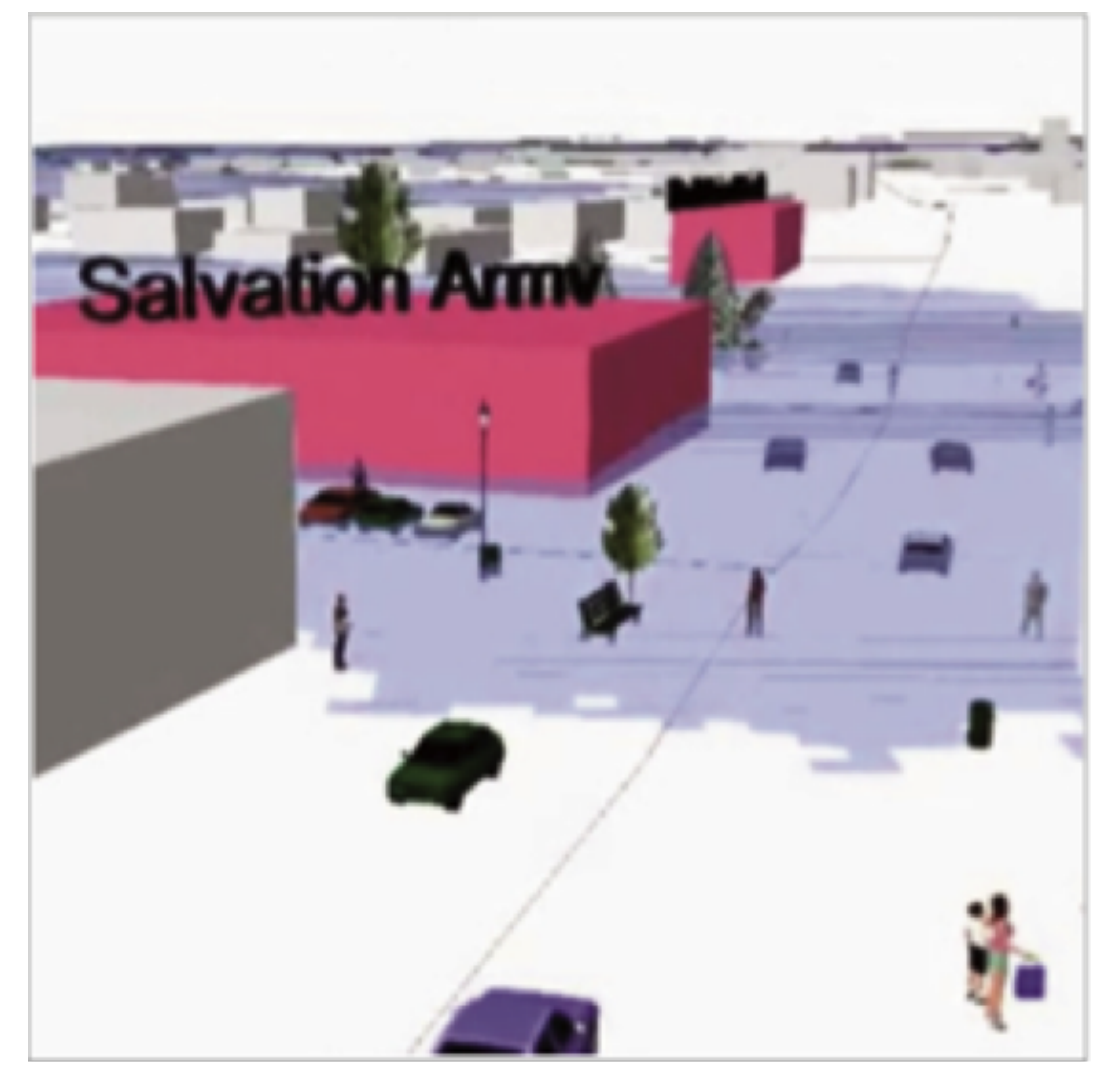

Figure 1.7: An example of a 3D geovisualization used for risk communication (Lieske 2012).

\section{$2 \mathrm{D}$ vs. $3 \mathrm{D}$}

Due to the sudden popularity of 3D geovisualization tools in the past 15 years, interest regarding the effectiveness of this technique is growing. Kraak (2009) raises a pertinent question: are developments in the geovisualization field "... moti-vated by known requirements and the need for solutions, or developing possibilities and the desire to explore and apply them". Are these 3D visualizations simply being produced because developers have the desire to explore new technological capabilities, or are they an effective method of displaying geographical information?

Using 3D in visualization holds many benefits. They can be dimensionally accurate representations, and require a lesser cognitive load for interpretation when compared to 2D (Bunch and Lloyd 2006). Popelka \& Brychtova (2011) stated that "... from the user perspective, it is much more efficient to use methods with higher visualization potential, despite increasing costs. From this 
point of view, the best method seems to be 3D maps." 3D visualization creates additional displace space, additional data variables, provides a familiar view of the world by generally using a top down view, allowing for a stronger sense of place and location to be obtained. This final point may explain why environmental problems and issues are generally better communicated to the public with 3D more effectively than 2D maps (Hudson-Smith 2008).

The benefits and downfalls of 3D visualization can be evaluated using comparison studies. When comparing the effectiveness of $2 \mathrm{D}$ and $3 \mathrm{D}$ visualization using eye tracking technologies, the majority of studies find that 3D visualizations allow participants to understand topography either as or more accurately than traditional 2D maps (Irvankoski 2012; Popelka and Brychtova 2013; Schobesberger and Patterson 2008; Petrovic and Masera 2006; Fuhrmann et al. 2009; Savage et al. 2004). While participants performed better when asked about elevation, in some studies they performed poorly when asked non-elevation related questions, suggesting that the more realistic components of the maps may be detracting from the map's overall value by distracting users (Schobesberger and Patterson 2008; Savage et al. 2004). This shows that 3D visualization can detract from the overall message, effectively leading to 'cognition overload' (Harrower 2007). As well, navigating in 3D worlds can be extremely difficult and frustrating for some users, even for simple tasks (Sayers 2004). As Shepherd (2008) puts when evaluating the 3D geovisualization technique: "Just because it can be done does not mean that it should be done; some 3D effects are of questionable analytical value, and 3D is not always better than 2D for visualizing data".

Even when overwhelming to the user according to test results, 3D geovisualization tools are generally preferred over their 2D counterparts. With the exception of older generations (e.g. seniors), users generally prefer 3D maps (Popelka and Brychtova 2013; Hegarty et al. 2008). Interestingly, users still prefer these maps even when they display extraneous non-task related information, which substantially slows response time and task performance, perhaps attributed to a 'fun' factor (Kray et al. 2003). Notwithstanding a basic principle that graphics should not provide more information than is needed by the user, users seem to prefer these cluttered materials (Hegarty et al. 2008). This introduces the concept of naive realism: the faith that increasingly real- 
istic depictions are completely accurate, when they may be actually highly error-prone. This leads to users receiving flawed and imprecise representations of reality (Smallman and St. John 2005). Again, Shepherd (2008) succinctly captures this idea: "We may all have been born into a 3D world, but we need to be continually aware that our virtual 3D worlds are sometimes more challenging than the real thing".

The potential for emotion manipulation using geovisualization tools is considerable (Craine and Aitken 2009), and the use of 3D seems to hold an even greater potential. A study looking at the effectiveness of flood risk communication using 2D traditional flood maps and a 3D simulation of the flooded town found that both materials were equally at effective at communicating risk. However, there was an interesting user reaction attributed to the 3D animations: those shown the 3D animation were more likely to express anger, concern, or want to take political action (Lieske 2012). This suggests that some sort of 'wow' factor can be attributed to 3D visualization. If incorporated into geographical educational materials, 3D geovisualization has the possibility of adding to the 'three key pleasures' of electronic storytelling described by Platt in 1995 (Cartwright 2006), those being: immersion (the sense of being transported to another reality), rapture (entranced attachment to the objects in that reality), and agency (the delight when a player can interact with said world).

In summary, 3D geovisualization tools have been known to be overwhelming to the user due to too much interaction or complexity, undermining one purpose of geovisualization: to enable learning and to impart information. Although these media are not necessarily the best format for visualizing all geographic information, it is always worthwhile to continue to investigate these more 'advanced' maps and their possible uses (Petrovic and Masera 2006), especially when they can complement digital storytelling.

\subsubsection{Evaluating Effectiveness}

As part of the CGV, Slocum and others argued in 2001 that geovisualization tools are of little use if their effectiveness is not iteratively tested. If they are not assessed, they can not be deemed as acceptable or adding to the field. But how do we test effectiveness? To brand a geovisualization tool as either 'ef- 
fective' or 'ineffective', we must measure whether or not its goals are being achieved (Sheppard et al. 2013; Fuhrmann and Pike 2005). Comparative analysis is generally used (when two versions of similar maps are tested using two groups), but because of time and resource constraints, many times this method is not possible. This is when usability testing, a method described in the section below, acts well to evaluate the effectiveness of geovisualization tools.

\section{Usability Testing}

The usability of a program refers to its fitness for use and its ability to facilitate the users' potential tasks at hand, which can be boiled down to the program's ease of use (Davis 1989). A program's usability can be measured in a process called usability testing, which is a central component of the research discipline of Human-Computer Interaction (HCI) (Bhowmick et al. 2008). HCI researchers are interested in the physical, organizational, and social interplay between computer systems and humans, and are quite focused on studying and improving the usability of these systems, focusing on a process called user-centered design ${ }^{3}$ (Bowen and Reeves 2008).

Usability testing involves participants completing defined tasks that users in the real world would be expected to complete. This testing is undergone to uncover the product's most critical problems, as well as its most delightful aspects. The evaluation of these products must take place with participants who are representative of the target user-population (Kushniruk and Patel 2004). It is generally recommended to test with 8-10 participants to discover major problems and flaws (Kushniruk 2002). They are generally one-on-one sessions, though group sessions can take place. Visual and audio recording of whole session is usually captured as well. These records of the user's movements and comments can used later on for user behaviour analysis. Questionnaires or discussion at the end of the session can be useful to complement in test comments (Dumas and Loring 2008).

\footnotetext{
${ }^{3}$ Computer systems are now generally developed using user-centered design (UCD), a process that requires the early involvement of potential users and an iterative cycle of interaction between users and tool designers with the purpose of developing tools that are useful and appropriate for the target domain. It considers the user at all stages of development to ensure that technology is appropriate, functional, and useful to complete tasks
} 
The behaviour of the moderator is a key part of usability testing. The moderator observes and notes the behaviours of the users, and reminds them to continually 'think aloud.' Implementation of the think aloud method is criti$\mathrm{cal}$, in which the user is asked to talk about their experience with the interface, including their thought-process, problems, questions, or comments (Jaspers et al. 2004). By continually reminding the user to think aloud, the moderator can uncover more rich information than simply from surveys. It is also extremely important for the moderator to remain impartial, and to not help struggling users (which is a common mistake for beginner moderators) (Dumas and Loring 2008).

Test results can reveal simple design flaws previously unnoticed by the developer, problems associated with user comprehension, and problems with the tool's usefulness. The testing can focus on generating quantitative data, qualitative data, or a combination of both. With a quantitative focus, an emphasis is placed on measuring objective goals. While the user completes a specified task by the tester, one could note the time taken, the number of errors, the number of abandons, the percentage completed, user satisfaction scores using Likert scales, or to test the ability or 'non-ability' to find certain key pieces of information. Quantitative analysis is generally preferred in summative studies $^{4}$, or when measures of success or failure can be compared to competitors or different versions of the product (Dumas and Loring 2008). With a qualitative focus, we can hone in on user perception about the system, which is also quite valuable. Such a focus allows for a lot more freedom and openness (Fuhrmann et al. 2009). Qualitative analysis is generally preferred in formative studies, as they are used to diagnose broad and general problems (Dumas and Loring 2008).

Usability testing promotes a convergence of the user, the technology, and the developer. It is now an essential aspect of software design, testing, implementation, acceptance, and uptake (Norman and Panizzi 2006). This includes geovisualization tools, as discussed in the following section.

\footnotetext{
${ }^{4} \mathrm{~A}$ formative study simply means that the product is at the beginning stages of being tested, as opposed to a summative test, which is the last stage before shipping the product.
} 
Geovisualization and Usability Testing As Shepherd points out, it is not enough to design clever and sophisticated programs without giving serious thought to how users will interact with them, meaning that the interface of the program is just as important as the content (Shepherd 2009). Usability testing is one way to ensure an interface is working effectively, and has been useful for creating and implementing web-based mapping systems in many fields, such as public health (Cinnamon, Rinner, Cusomano, Marshall, Bekele, Hernandez, Glazier, and Chipman Cinnamon et al.; Maclachlan et al. 2007). Some researchers in the geovisualization field are using usability testing (Tobon 2005; Slocum et al. 2009; Nivala et al. 2007; Slocum et al. 2001). Brauen (2011) conducted usability tests to explore the use of 'sound-maps' which are a part of the realm of geovisualization.

A suitable usability testing methodology requires a very clear specification of goals and tasks, which lends itself well to quantitative analysis. Due to the exploratory and interactive nature of geovisualization, this standard specification of tasks and users is very difficult to decide upon, and often even not possible (Slocum et al. 2001). For example, visual exploration is most easily achieved when data exploration goals are ill-defined (Keim 2001), but very defined goals are a necessary condition when using usability evaluation methods. This means that evaluations and tasks must be tailored to each and every geovisualization (Tobon 2005).

It is pertinent to include mixed evaluation methods in geovisualization research, as argued by Tobon (2005). She posits that a combination of evaluation methods can help elucidate information about a system's usability that strictly quantitative or qualitative methods cannot find alone. According to Peake (2012), there has been an increase in the use of qualitative methods by cartographic researchers following the increase in private map creation. Schobesberger (2009) argues that quantitative and qualitative methods are necessary for understanding human interaction with maps. van Elzakker and Wealands (2007) argue that it is difficult to formulate hypotheses for testing by means of quantitative techniques, since "... in many cases we do not yet know enough about how maps or Multimedia Cartography products work for knowledge construction or geospatial problem-solving." 
Evaluating Pure Concepts Geovisualization researchers often want to evaluate a certain technique or concept as opposed to a specific program, which is very difficult to isolate to be tested for usability and effectiveness. Unfortunately, 'pure' concepts have to be implemented in a software tool, which will be tested rather than the concept itself. As Andrienko and others describe (2002), usability test outcomes must be interpreted cautiously before abandoning a pure concept or technique.

Let me provide a hypothetical example: a usability test is conducted on a system - a visualization of the transportation system of the City of Ottawa. The developers of this visualization have incorporated a novel new concept - 3D visualization - and wish to determine if it is effective or not. The developers conduct usability testing, and their users uncover major issues including flaws in the system controls, general bugs within the system, and slow performance. All these usability issues leave the users with a negative impression of the geovisualization tool, and they may associate the pure concept (3D visualization) in a negative way.

It is not accurate to say that the 3D visualization technique is ineffective, because the usability issues were all from the system's poor performance, and not the actual visualization technique. Negative results do not necessarily imply that a certain technique or concept is a poor one, though in general, positive results will favour the technique or concept (as well as demonstrate that the implementation of the interface was well done).

If results are negative, such as in our example, redesign of the interface, the improvement of performance, and debugging of the system may be necessary in order to test the concept or technique more appropriately (Andrienko et al. 2002).

\subsection{Summary of Chapter}

3D Geovisualization The democratization (meaning to make accessible to everyone), of geographic information sciences has led to the widespread access and use of geovisualization production techniques, including the use of 
'3D'. As we've seen, the development and incorporation of 3D geovisualizations into information communication tools is valuable. These visualizations add an emotional component to such materials, which can be used to the advantage of a geographic storyteller. As well, they can substantially improve representation, especially when it comes to elevation. At the same time, visualization from a different perspective may reveal new understandings of the data at hand, including uncovering invisible patterns.

Although there are many benefits to these visualization tools, they hold some downfalls. As previous research suggests, 3D geovisualization tools can be overwhelming to the user, and the information originally intended to be communicated is simply not transferred. Despite all of this, the popularity of these tools is growing. This shows a need to remain proactive in measuring the effectiveness of 3D geovisualization tools.

Novices and Experts When creating geovisualization tools, questions arise regarding the relationship between the user, these technology and the developer; especially regarding the appropriateness of new geovisualization methods for the target user audience. Due to the democratization of 3D geovisualizations distributed over digital networks, novice users are being exposed to visualizations that were traditionally designed for use by experts and professionals. Although a small but growing body of research considering the potential and effectiveness of 3D geovisualization is emerging, one branch that has not been explored to its full potential is the user's expertise with the subject matter at hand. These expertise levels can alter a geovisualization tool's usefulness and ease of use.

I am concerned with the difference in perceptions between novice and expert users. On the one hand, these geovisualization tools should be understandable by as many people as possible in their target audience (including novice users) so that the intended information can be communicated widely and quickly. On the other hand, these geovisualization tools should not simplify issues to the point where information can be misinterpreted or the whole picture is not conveyed properly.

This leads to another broad question: 'does the public understand the infor- 
mation that is intended to be communicated?' as well as several other questions. Do the experts find that 3D geovisualizations over-simplify the subject matter at hand, by either misrepresenting the subject matter, or not communicating the entire issue? If this is the case, do experts hold a negative impression of the visualization in terms of both its usability and usefulness? Do the novices find that 3D geovisualization tools are impressive in terms of utility no matter the subject matter? Do they feel that they are learning about the subject matter at hand? Do novices feel that 3D geovisualization tools are over-simplifying or over-complicating the subject matter at hand?

Measuring Effectiveness To break down the term 'effective', we may deem a product effective if it is both successful in producing its desired or intended result (useful), while a usable tool is easy to use (usable). Currently, the most accepted method of measuring this effectiveness is usability testing. Along with discovering specific usability problems, this method give the researcher an idea of how the user reacts to a number of components of visualization: data cognition and awareness, emotional impact, motivational or behavioural change, and the level of active or passive learning. It also provides a general impression of the user's overall experience with the tool.

\subsection{Going Forward}

\subsubsection{Research Questions}

This chapter has lead us to one broad overarching question: "Are 3D geovisualization tools an effective means of communicating climate change impacts?"

To break down the term 'effective', I argue that a geovisualization tool is effective when it is both useful and usable. A useful tool is successful in producing its desired or intended result, while a usable tool is easy to use. With that being said, our overarching question can be further refined: "Are these $3 D$ geovisualization tools successful in producing the desired or intended result of educating, engaging, and motivating users to take action against climate change and its potential effects, as well as being easy to use?" 
I am also concerned with the difference in perceptions between novice and expert users, meaning that I will expand my question one final time. "Are these $3 D$ geovisualization tools successful in producing the desired or intended result of educating, engaging, and motivating users to take action against climate change and its potential effects, as well as being easy to use, for both novice and expert users?"

\subsubsection{Hypotheses}

As Slocum and others suggested in 2001, the development of an effective geovisualization requires evaluation using usability engineering principles. Swienty et al. (2008) suggest that geovisualization systems must take usefulness and usability into account, which are both often overlooked. Using these principles applied to a case study, I will evaluate a 3D geovisualization tool depicting climate change impacts. Additionally, I will build upon this even further by examining the differences between novices and experts in the subject matter of the visualization.

I hypothesize that 3D geovisualization tools are an effective means of communicating climate change impacts. I argue that although these tools have the potential to education, engage, and motivate users to take action against climate change and its potential risks, but that they are simply stepping stones in the right direction.

I also think that novices will find 3D geovisualization tools to be more effective than experts. In terms of usability, I believe that novices will find the visualizations more engaging and easy to use as compared to the experts. This may be because of the 'wow' factor attributed to these visualizations. Novices could become more overwhelmed than the experts, as they will be less used to processing the same data that the experts will already have some experience with, leading to a less effective and less usable tool. In terms of usefulness, I believe that experts will find the visualizations less useful than novices, as they will be able to see 'beyond' the wow factor and question the integrity and validity of the visualization's message. 


\subsubsection{Justification}

3D Geovisualization Design Principles Where geovisualization used to be a 'private' affair, it is becoming more of a public display, leading to the need to investigate and validate design options and choices. I believe that both groups (novices and experts) will have different ideas and perceptions surrounding 3D geovisualizations, and these differing opinions could inform design choices in the future. This will be useful in choosing effective geovisualization display and development methods and tools.

Climate Change Impacts It can be argued that some members of the public are slow to act and adapt to human induced climate change, especially those who are affected by long-term and gradual impacts. The source of motivation to adapt is a complicated idea to address, but 3D geovisualization tools have the potential to help us move towards possible solutions to a lack of motivation.

Climate change impacts are being communicated to a wider audience using 3D geovisualization, but there is a shortage of research on the effectiveness of these tools. This research is not only important to further the geovisualization research field, but to better our ability to create resilient and well-informed members of the public. It will help to understand whether or not it is worth pursuing 3D geovisualization technologies, or if they are a waste of our time and resources. 


\section{Chapter 2}

\section{Methodology}

This chapter gives an overview of the need for climate change impact awareness on Prince Edward Island (PEI), a description of the Coastal Impact Visualization Environment (CLIVE) tool, as well as an overview of how I measured its effectiveness. 


\subsection{Background}

\subsubsection{Climate Change Effects on Prince Edward Island}

For a variety of reasons including its geologic makeup, decreasing winter ice cover, rising sea levels, and more frequent and intense storm surges, the Canadian province of Prince Edward Island is at risk from sea level rise and coastal erosion.

Sea level rise from thermal expansion and melting snow and ice pack is one risk directly linked to climate change. 450 million people live in the coastal zone within $20 \mathrm{~km}$ of the coastline as well as $20 \mathrm{~m}$ or less above sea level, meaning that sea level rise will have a huge impact on human communities (Kostelnick et al. 2013).

A study conducted by Webster and Brydon in 2013 found that between 1968 and 2010, the annual rate of coastal erosion on PEI was $28 \mathrm{~cm}$ per metre of shoreline retreating. Using this rate, it can be calculated that in 90 years, 30 square kilometres of PEI will have eroded away, leaving much at risk including: 1,000 homes and cottages, 17 lighthouses, 10 footbridges, and 146 commercial buildings. This adds up to an estimated $\$ 150$ million in Island real estate and \$45 million in road infrastructure at risk (Webster and Brydon 2013).

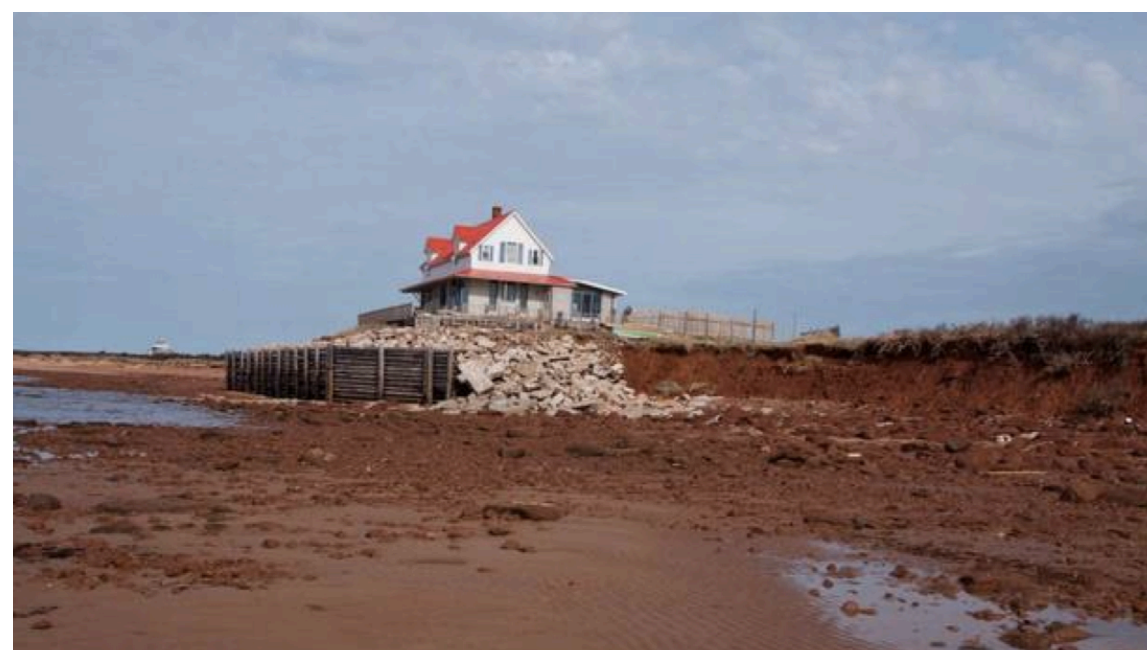

Figure 2.1: An example of a home at risk from coastal erosion (Ellis 2014).

Living in an area that is losing land, either from wave action or rising sea 
levels, is chock-full of risk. These risks are important to be continually communicated to the public, be it for general risk awareness, policy change support, or for personal action (see Figure 2.1). Flood risk maps, generally 2D and static, are often used as risk communication tools, and are often quite accessible through municipal government offices. This information is accessible to the public, but this does not mean that it is sought out.

Different ways of communicating information can target a larger audience, and one method to achieve this goal is by using the technique of 3D geovisualization. As discussed in the previous chapter, 3D geovisualizations have expanded the potential for creating interactive, engaging, informative and effective presentations for communicating geospatial information. They can also stimulate visual thinking and hypothesis formation, as well as give the user a new perspective.

\subsubsection{Coastal Impact Visualization Environment (CLIVE)}

Existing environmental change records and scenarios must be accessible, viewable, and understandable to community members on PEI in order for the public to be well-informed. This has led to the creation of the Coastal Impact Visualization Environment (CLIVE), a prime example of a 3D geographic visualization tool depicting climate change risk (see Figures 2.2 and 2.3). Developed jointly by the Climate Research Lab (CRL) at UPEI and the Spatial Interface Lab at Simon Fraser University (SFU), CLIVE allows users to visualize coastal erosion and sea level rise scenarios combining historic data and models used by the Intergovernmental Panel on Climate Change (IPCC) and state of the art geovisualization technologies.

CLIVE allows users to view scientific data in an interactive interface, and explore climate change projections that would otherwise be 'locked up' in charts and mathematical equations. The concepts that CLIVE allows the user to explore are often abstract, but with this visualization tool, users can explore these data and scenarios at any scale in their own neighbourhoods, effectively turning an abstract idea into reality. Users can explore two distinct functions of the program: coastline change scenarios, and sea level rise scenarios, and 


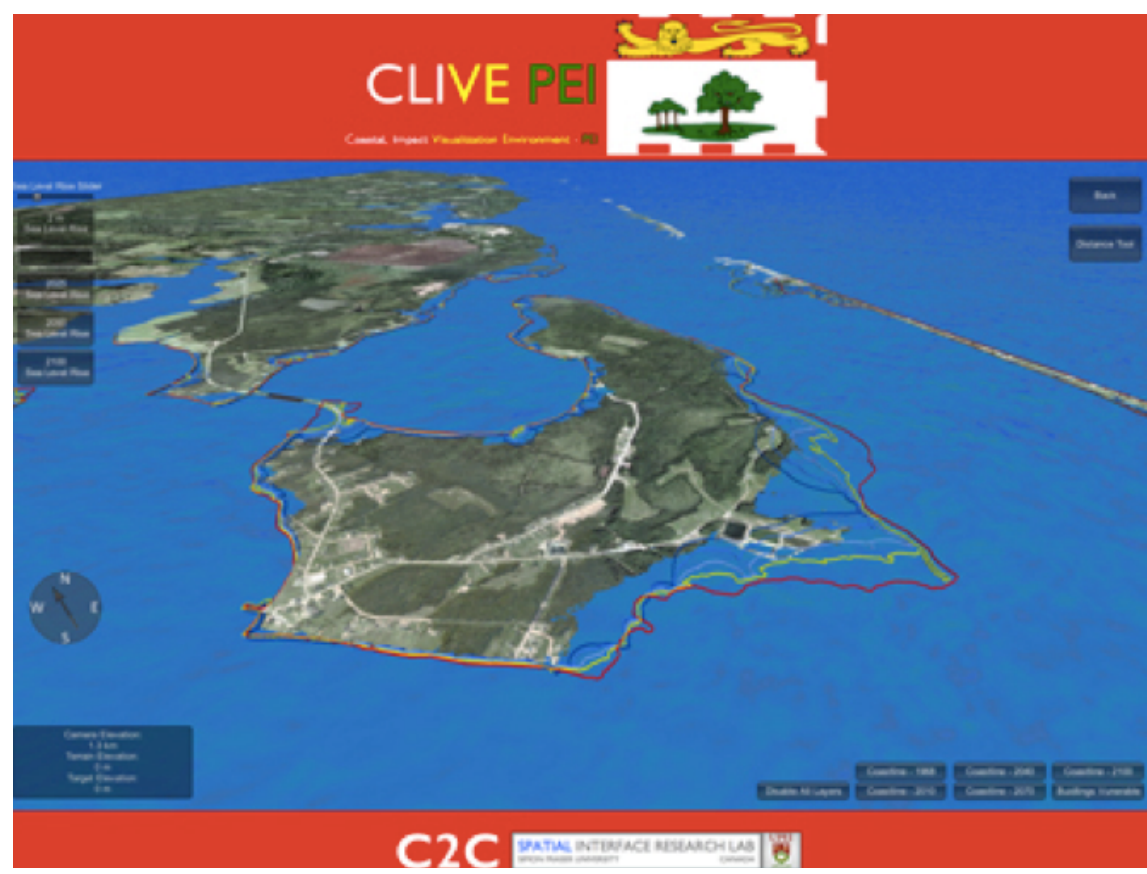

Figure 2.2: The CLIVE home screen (provided by the CRL).

although these two components cannot interact with each other, they may be overlaid on top of each other.

The coastline change scenarios were generated by calculating erosion rates for every metre of the shoreline by examining any change between provincial aerial photographs from 1968, to provincial orthographic images taken in 2010. Using these erosion rates, potential coastlines were generated for the years 2040, 2070, 2100. It is important to note that these scenarios are only taking into account these current rates of erosion, and do not account for the predicted accelerated erosion rates or for sea level rise (see Figure 2.4).

The sea level scenarios available in CLIVE are for the years 2050, 2075, and 2100 , which correspond to a rise in sea level of $0.43 \pm 0.15 \mathrm{~m}, 0.83 \pm 0.36 \mathrm{~m}$, and $1.06 \pm 0.48 \mathrm{~m}$. These scenarios were chosen from a report commissioned by the Atlantic Climate Adaptation Solutions Association outlining climate change scenarios in Nova Scotia and Prince Edward Island (Richards and Daigle 2011). This report was based on the A2 and A1B emission scenarios published by the Intergovernmental Panel on Climate Change (IPCC) in 2007. It is important to note that these are conservative estimates, so the developers of CLIVE included the capability to increase the sea level rise to 8 metres above the current level (see Figure 2.5). 


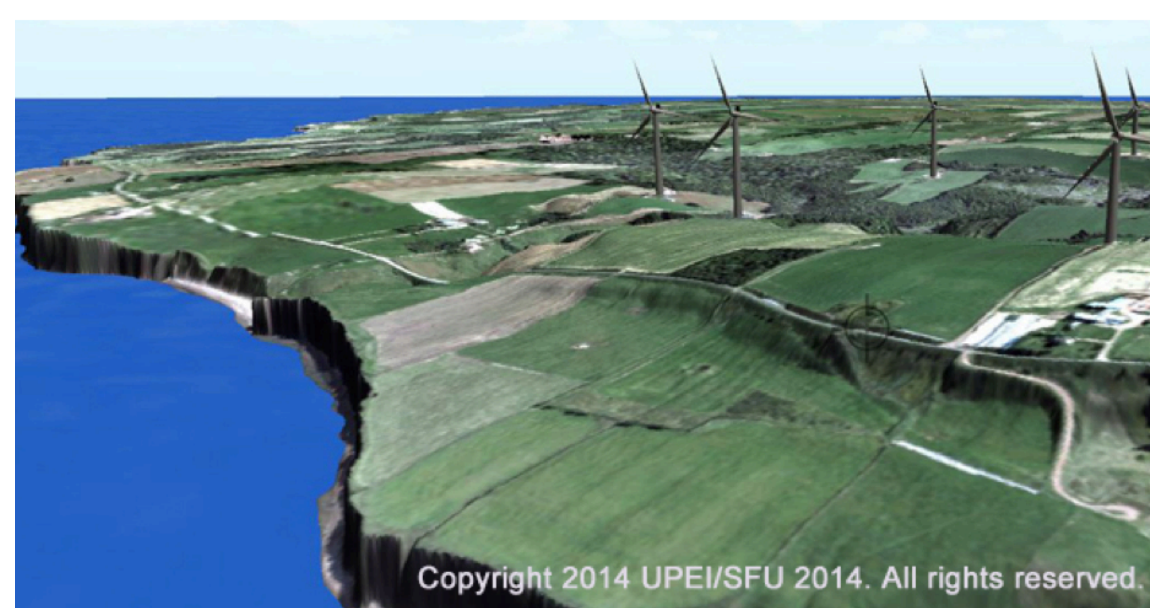

Figure 2.3: A scene from CLIVE (provided by the CRL).

The engine used to develop CLIVE is called Unity (Unity Technologies 2015), a game creation system. Using an Xbox controller, the user can fly over Prince Edward Island in its entirety, following its dips and hills to a maximum height of 400 metres. These high-resolution elevation data were derived from Light Detection And Ranging (LiDAR) data.

The goals of the entire research program include educating community members about coastal erosion and sea level rise, as well as planning for adaptation measures. To do this, a community and stakeholder engagement and outreach program named the CLIVE Road Show was organized by the Climate Research Lab, and funded by the Provincial Government.

As seen, CLIVE is an impressive geovisualization using state of art technology, new 3D techniques, and aims to make science accessible to the public in order for them to be able to take action against the effects of climate change. All together, these data provide the user with the ability to visualize potential coastal erosion and future sea-level rise scenarios, but does this translate into actually communicating climate change risks? Additionally, does it impact novices and experts to the same degree? In order to understand whether CLIVE is achieving its goals, studying its use and reception by stakeholders is very important. I began this process which is outlined in the following section. 


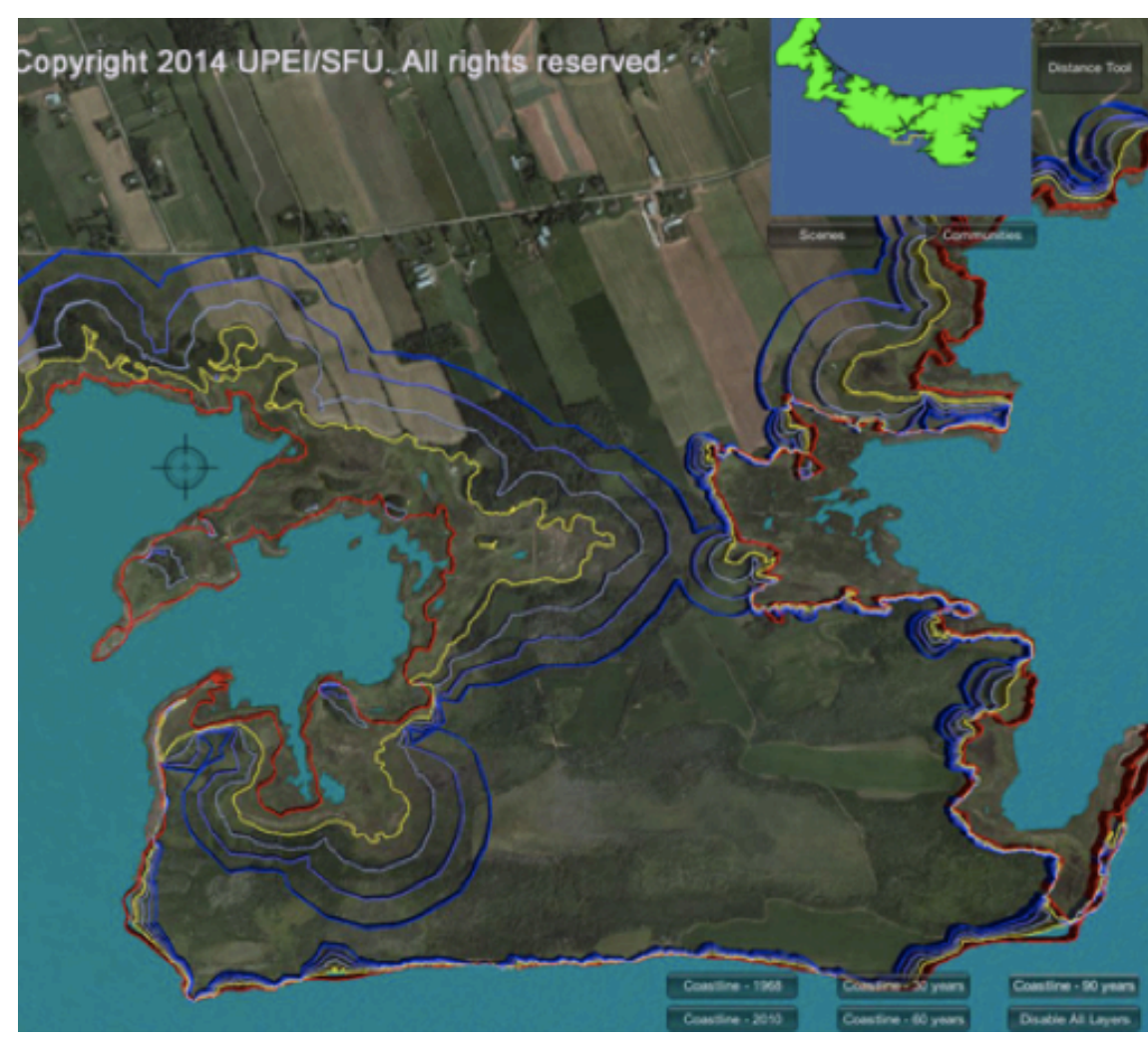

Figure 2.4: An example of coastline change scenarios 30, 60, and 90 years from 2010 (provided by the CRL).

\subsection{Methodology}

A geovisualization tool is effective if it is useful and easy to use. I evaluated the effectiveness of the geovisualization tool CLIVE by measuring its usefulness and usability. This was done by undertaking two distinct empirically driven methods: workshop surveying, and usability testing. These phases ran con-currently, and both address each of CLIVE's goals: 1) educate users about coastal erosion and sea level rise; 2 ) engage them; and 3) motivate them to take some sort of action. They also address the tool's ease of use by examining its performance in the usability testing phase. I conducted a pilot test run of both phases to ensure that each phase would proceed smoothly. 


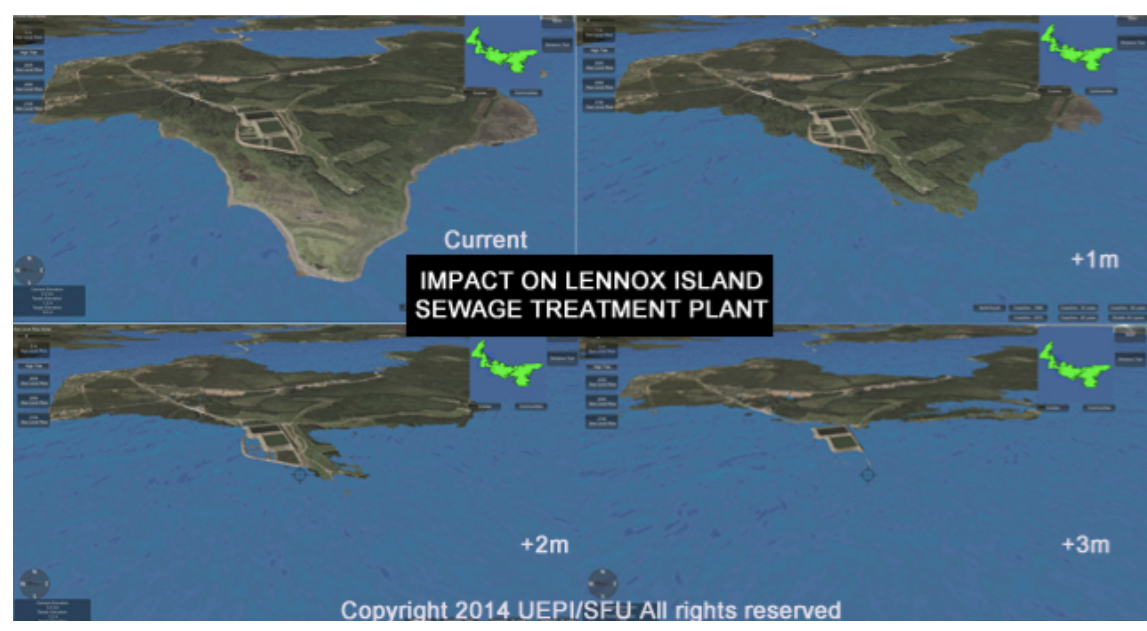

Figure 2.5: Example of a dramatic sea level rise scenario (provided by the CRL).

\subsubsection{Workshop Phase}

The workshop surveying phase was conducted to measure participants' level of concern regarding climate change impacts (specifically coastal erosion and sea level rise risks) on PEI before and after a demonstration of CLIVE. Following methods outlined by Lieske (2012) and Sheppard (2013), levels of concern were measured by linking up before and after surveys, designed with repeated questions. These surveys were conducted at all eight of the CLIVE Road Show workshops and were used to determine general changes in attitudes and knowledge about climate change impacts after a demonstration of CLIVE. Another goal of this phase was to assess user feedback on the usefulness of the visualization, which addresses my central argument that 3D geovisulization tools are effective in communicating climate change impacts.

\section{The Road Show}

The CLIVE Road Show was toured and showcased in eight different communities on PEI, with the goals of educating Islanders about coastal erosion and sea level rise from climate change, as well as creating a discussion surrounding adaptation to climate change on PEI. These workshops were planned, advertised, and conducted by researchers at the Climate Research Lab at UPEI, with support from the provincial government. The workshop dates and lo- 


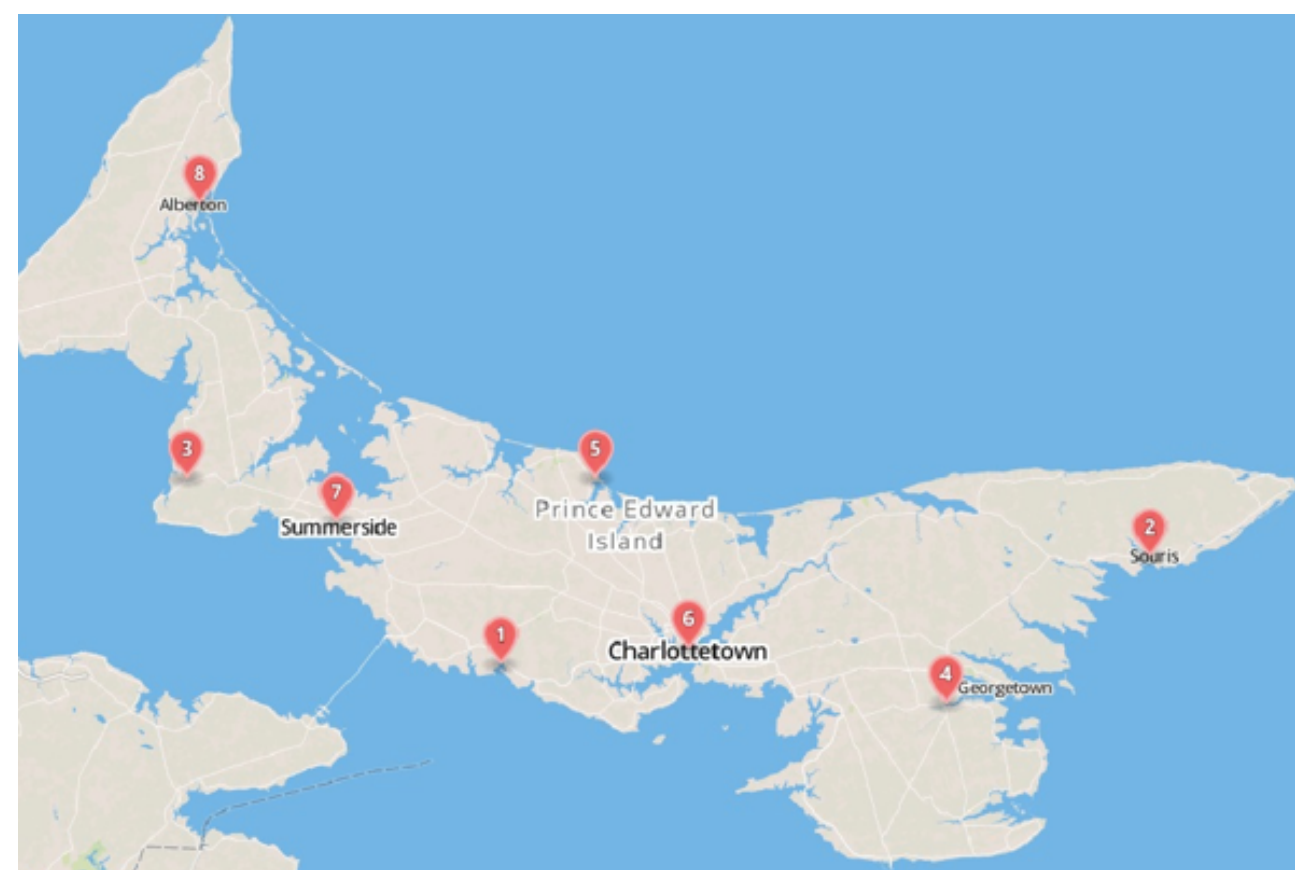

Figure 2.6: Locations of CLIVE roadshow workshops. Location names correspond to numbers in Table 2.1. (Ellis 2014).

cations are listed in Table 2.1 (see also Figure 2.6 for locations), and they all lasted between one and two and a half hours.

The workshops consisted of a brief presentation on coastal erosion and sealevel rise on PEI, a demonstration of the actual tool emphasizing areas of local concern, and a semi-structured discussion about coastal erosion and sea-level rise and its risk to homes, cottages, transportation infrastructure, and communities. Participants were encouraged to share feedback, opinions, and ideas about possible adaptation and mitigation strategies. Climate Research Lab staff reached out to town councils, watershed groups, local media outlets, and several cottage associations in the days leading up to each workshop, and distributed posters (see Figure 2.7) in all eight communities and surrounding towns and villages. 
Table 2.1: Workshop locations and dates.

\begin{tabular}{||ccc||}
\hline Number & Location & Date \\
\hline \hline 1 & Victoria & July 8, 2014 \\
\hline 2 & Souris & July 9, 2014 \\
\hline 3 & Abram's Village & July 15, 2014 \\
\hline 4 & Montague & July 17, 2014 \\
\hline 5 & North Rustico & July 22, 2014 \\
\hline 6 & Charlottetown & July 23, 2014 \\
\hline 7 & Summerside & July 24, 2014 \\
\hline 8 & Alberton & July 30, 2014 \\
\hline \hline
\end{tabular}

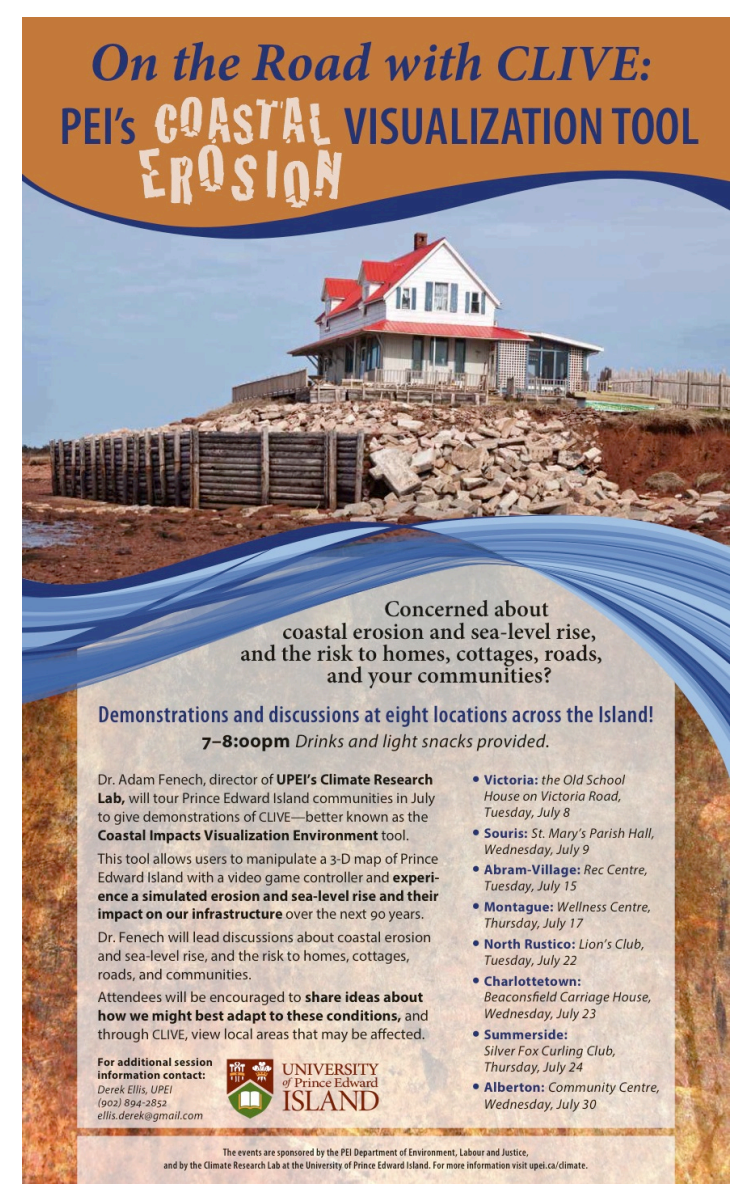

Figure 2.7: The CLIVE roadshow poster (Ellis 2014).

\section{Surveys}

Workshop participants filled out surveys before (see Appendix A) and after (see Appendix B) the workshop to gage how the session changed their views 
on coastal erosion and sea level rise on PEI, if at all. Participants were asked to think of a code word in order to link up both of their surveys, and to keep the surveys anonymous and confidential.

The surveys included a combination of open and closed questions. Questions were direct, simplified, clear, and tuned to Islanders, while leading and loaded questions were avoided. My design takes the possibility of measurement bias (the tendency for a respondent's answer to differ from their true value) into account and avoids it by the careful design of the questions. It was also pretested before the CLIVE Road Show workshops with students. In the following section, I will describe all questions on the survey and explain why they were used.

Key demographic information about the participants was acquired (ex: age, gender, and education). This information was included to determine if different demographic groups found CLIVE more or less effective. I also asked what kind of computer technologies the participant was familiar with (i.e. email, typing up documents, Excel spreadsheets, general internet browsing, Google Maps, GPS units, programming, and video games). This was done to determine if participants with different computer skill levels were more or less likely to be be impacted by the demonstration of CLIVE.

Question 2 ("Do you notice the sea causing damage to the shoreline of Prince Edward Island?") was included to see whether or not participants were aware of the problem, and if they or their neighbours are currently at risk (as seen in Appendix A). Question 3 ("Are you concerned about the sea causing damage to the shoreline?") was included to understand whether or not the participant was concerned with the matter at hand. If the participant was 'not at all' concerned about the issues, they would circle the value of ' 1 '. If they were 'very much concerned', they would circle the value of '7'. This was linked with Question 1 in the post test (as seen in Appendix B) to determine if their response changed, if at all.

Question 4 ("Are you currently protecting your land against the sea?") was included to see if participants were protecting their land with sea walls, rocks or other materials, by relocating themselves, or in other ways. Question 5 builds upon this by asking if participants "... are planning on protecting [their] land 
against the sea..." Question 3 on the post test (see Appendix B) builds upon this theme even further by seeing if participants are planning on protecting their land against the sea after the demonstration.

In the post test survey (see Appendix B), two open ended questions were included. "Do you feel that the visualization (CLIVE) helped you to better understand how the sea affects the shoreline? Please explain why or why not" is included to directly ask if the user learned about coastal erosion and sea level rise on PEI. "Do you have any suggestions to improve CLIVE?" was included to learn of any general usability issues. Uncovering true and in-depth usability issues were reserved for the usability testing phase, though I included this last question because I thought it was worth getting a grasp of the opinion of a broad cross section of PEI.

\subsubsection{Usability Testing Phase}

The usability testing phase was conducted to measure the tool's usefulness and usability. These measures were evaluated by thematically analysing qualitative data generated during formative usability testing. I conducted these tests with two groups: novices and experts in the subject matter of climate change risks on PEI.

The goals of this phase were as follows:

1) Identify CLIVE usability issues and provide recommendations to developers.

2) Examine CLIVE's usefulness; does the tool educate, engage, and motivate users to take action against climate change impacts?)

3) Speculate upon the effectiveness of the use of the $3 \mathrm{D}$ technique in geovisualization.

4) Determine how the experience of both novice and expert users differ by revealing the true amount of knowledge concerning coastal erosion and sea level rise on PEI gained. 
1) Usability Following guidelines used by Tobon (2005) and by Brauen (2011), this exploratory study is aimed at inspecting features and functionalities that either facilitated or impeded with the user tasks designed in the methodology. In order to tease out main usability issues, six participants were targeted in each group (novices and experts). This was decided in light of the study conducted by Brauen (2011) that recommends testing six participants to uncover flaws and problems within the product.

Directly from this study, all specific recommendations regarding the improvement of functionalities for CLIVE were be made available for the developers, which is consistent with the core values of usability testing and user-centered design, two important components of HCI. The results from this study can also serve as a baseline for future CLIVE usability tests.

2) Usefulness CLIVE is designed to allow users to explore and learn about coastal erosion and sea level rise scenarios on PEI, engage users, and motivate them to take action to adapt to these risks. The usability test was designed to see whether or not CLIVE achieves these goals. By studying how users interact with CLIVE while performing specified user tasks, we can see how users explore the program. Having the users fill out a pre and post survey, we can glean some insight about the potential of climate change education. By following up with the users six months after the test, we can see if CLIVE has left a lasting impression on the user.

3) The 3D Technique Another goal is to test the effectiveness of $3 \mathrm{D}$ as a general technique. Ideally, a comparative study of 2D vs. 3D would have been carried out to isolate this technique (Lieske 2012), but this was not possible in my case. However, there are other ways of interpreting the effectiveness of the $3 \mathrm{D}$ technique, without any comparative studies at all.

When it comes to testing the 3D technique, the first step is to decide whether or not CLIVE is an effective climate change risk communication tool in general. If CLIVE is an effective tool, it can be assumed that the technique of 3D is not ineffective. If CLIVE is ineffective, it could suggest that $3 \mathrm{D}$ is not an effective means of geovisualization, but again, this is difficult to determine, 
as many other factors could cause CLIVE to be ineffective. If it is found that CLIVE is an ineffective geovisualization, then a second round of usability testing is recommended after improving any interface, system performance, or visualization issues (Tobon 2005). This second round will be more likely to determine whether or not $3 \mathrm{D}$ visualization is effective or ineffective.

4) Recruiting Novices vs. Experts The evaluation of a geovisualization tool must take place with participants who are representative of the target userpopulation (Kushniruk and Patel 2004). In our case, CLIVE is designed to communicate climate change risks to all residents and visitors of Prince Edward Island. This means thats our desired user target was quite broad: any resident or visitor to the Island. It was of interest to recruit participants from a range of fields, and who did not necessarily have a solid foundation of knowledge of geography or GIS. It was also of interest to recruit participants from a broad range of ages.

Based on the eye tracking study of Ooms and others (2012), experts are defined as having at least a master's degree in the subject matter of the geovisualization (in our case, climate change sciences). I extended this further to include professionals who work in the subject matter. Novices are defined as knowing very little about the subject matter of the information that the geovisualization is depicting.

The experts were recruited from a list of involved partners who are interested in testing out the latest version of CLIVE. These participants are already familiar with the project and program from the nature of their work and expertise. The snowball method was used to target the novices starting at the CLIVE Road Show, as well as through networking at the CLIVE Road Show workshops. I discussed the project with interested novices, and they were all were officially invited to participate with a formal email (see Appendix H). Participants were awarded either a $\$ 10$ gift card or a weather calendar published by researchers at the University of Prince Edward Island. There were no exclusionary criteria, and the consent form can be seen in Appendix D. See Table 2.1 for a list of participants. 
Table 2.2: Usability Test Participants, all conducted in 2014.

\begin{tabular}{||cccccc||}
\hline User & Date & Gender & Age & Occupation & Expertise Level \\
\hline \hline 1 & July 9 & Male & $35-44$ & GIS Technician & Expert \\
\hline 2 & July 11 & Male & $/$ & Government & Expert \\
\hline 3 & July 13 & Female & $35-44$ & Government & Expert \\
\hline 4 & July 14 & Male & $55-64$ & Custodian & Novice \\
\hline 5 & July 15 & Male & $45-54$ & GIS Technician & Expert \\
\hline 6 & July 16 & Male & $25-34$ & Student & Novice \\
\hline 7 & July 17 & Female & $18-24$ & Student & Novice \\
\hline 8 & July 17 & Male & $18-24$ & Student & Novice \\
\hline 9 & July 22 & Male & $55-64$ & Climate Researcher & Expert \\
\hline 10 & July 23 & Male & $35-44$ & Government & Expert \\
\hline 11 & July 24 & Male & $25-34$ & Landscaper & Novice \\
\hline 12 & July 28 & Female & $18-24$ & Student & Novice \\
\hline 13 & July 28 & Female & $45-54$ & Educator & Novice \\
\hline \hline
\end{tabular}

\section{The Usability Test}

Generally, usability testing includes measuring the quantifiable performance rates of the users using the program. These performance rates can be measured in a number of ways, such as assessing time to complete a specific task, or the number of errors the user makes while attempting to complete this specific task. These performance measures will help the developer improve the program's ease of use. For example, if our user is given the specific task to click on the 'login' button in the new website we are testing, if the user takes an extremely long amount of time to find this button, this indicates to the developer that the 'login' button must changed to become more visible, or placed in a more prominent area.

In the context of geovisualization, long task completion times may not be indicative of poor ease of use (such as our previous example). Long times could show that the user is having a difficult time completing a task (such as finding the 'login' button), but it also may be from users simply investigating a detail on the map. Though the same could be said for any program that is undergoing usability testing, this is particularly true for geovisualization tools from their exploratory nature.

For this reason, I focused on generating qualitative data during the usability 
tests. A strength of this approach is that its openness and flexibility allow for the opportunity to uncover a variety of rich information that would never be discovered if we were focusing on generating quantitative data (e.g. time to complete a certain task, number of errors in a test sequence, etc.). By focusing on qualitative data, we can identify areas of the product that would be improved as it documents users' goals, expectations, areas of confusion, and unproductive paths (Dumas and Loring 2008).

Weaknesses of usability testing include the fact that researcher biases may come into play. I avoided these biases as much as possible by being clear that I was not part of the CLIVE development team, and that I would not be offended if the user did not enjoy their experience with CLIVE. I also tried to create the most 'neutral' testing space as possible ${ }^{1}$.

A visual and audio recording of the screen recorded the user's movements using a screen capture software called CamStudio. Transcriptions of each session were created and used in thematic analysis outlined by Dunn (2000). These one-on-one sessions lasted between 30 and 60 minutes, and were divided into a few components: 1) The Pre-Test, 2) The Test, and 3). The Post-Test. These components are described below.

1) Pre-Usability Test Each session began in the same way: users were greeted, asked to sign an informed consent form (as seen in Appendix D), given their compensation, and asked to fill out a pre-usability test (as seen in Appendix E). This was followed by a brief explanation of the purpose of the session, a short presentation of the effects of climate change on PEI, and the geovisualization tool CLIVE.

On the pre-survey, questions regarding demographic data, users' experience with technology, and users' thoughts and opinions with climate change impacts on PEI were asked, just like the workshop pre-survey. Key demographic

\footnotetext{
${ }^{1}$ All but two evaluations were conducted in the large boardroom of the Regis and Duffy Research Centre at the University of Prince Edward Island, affectionately nicknamed 'the Fish Bowl'. One evaluation was held in a small private boardroom in the same building. Much to my dissatisfaction, one evaluation was held in the Climate Research Lab. It should be noted that these tests are best conducted in a neutral venue (such as an empty boardroom or another quiet and private area), but the participant asked to remain in the Climate Research Lab because they felt more comfortable there.
} 
information about the users was acquired (ex: age, gender, and education) to gain a general understanding on my sample. I also asked what kind of computer technologies the participant was familiar with (i.e. email, typing up documents, Excel spreadsheets, general internet browsing, Google Maps, GPS units, programming, video games). This was done to determine if participants with different computer skill levels were more or less likely to understand CLIVE and its interface. Question 2 ("Do you notice the sea causing damage to the shoreline of Prince Edward Island?") was asked to see whether or not users were aware of the problem, and if they or their neighbours are currently at risk. Exactly like the pre-workshop survey, Question 3 ("Are you concerned about the sea causing damage to the shoreline?") was asked to understand the user's level of concern. This was linked with Question 1 in the post test (as seen in Appendix $\mathrm{G}$ ) to see if users changed their level of concern. Question 4 ("Are you currently protecting your land against the sea?") was asked to see if users were protecting their land with sea walls, rocks or other materials, by relocating themselves, or in other ways. Question 5 builds upon this by asking if users "... are planning on protecting [their] land against the sea...". A question in the interview stage (see Appendix F) builds upon this theme even further by asking if users were planning on protecting their land against the sea after experiencing CLIVE. This may not apply to students.

HCI principles generally emphasize the need for intuitive user interfaces without the need for explanation or tutorials (Norman and Panizzi 2006). In this case, this version of CLIVE was must be demonstrated with a member of the development team. In order to mimic the current real world application of CLIVE, a tutorial on the game controls was given to all participants, as well as some prompts to practice these controls. This tutorial allows them to concentrate on the tasks given later on, as opposed to figuring out the controls 'blindly.'

2) The Test Due to the very definition of geovisualization, it is difficult to define tasks for usability testing because there is often no set usability testing practice for dynamic geovisualization (Slocum et al. 2001). When designing a usability test for a geovisualization tool, we must decide upon tasks that reflect upon possible work processes, but are also conducive to the main goals of 
geovisualization: the gaining of insight and knowledge construction (Tobon 2005). The emphasis we place on the exploratory nature of geovisualization can be brushed aside if we are firm with deciding upon specific tasks. This is why all designed tasks are quite flexible in nature, and were chosen so that the participant could fully explore coastal erosion and sea level rise scenarios by using the different tool sets available in the program. User tasks were chosen in consultation with the lead developer.

Once they felt ready, participants were asked to perform these specific tasks. Each task will be explained briefly below (see Appendix F for full list). The 'think aloud method' was used, wherein the user is asked to talk about their experience with the interface. This includes their thought-process, problems, experiences, expectations, questions, or simply general preference or comments (Jaspers et al. 2004). In being asked to think out loud, a participant may reveal more about their thinking process than can be recorded in a written questionnaire.

Task 1 was to find the user's home town, starting from the main menu. This was asked to see if the user could place themselves in CLIVE. If the user was not from $\mathrm{PEI}^{2}$, I asked them to find Charlottetown. To follow-up with this theme, Task 2 was to find their home, or a local landmark. If they were using Charlottetown, I asked them to find the University.

Task 3 was to place a flag on the landmark using the 'flag tool.' After the flag was placed, I asked them to read the elevation of the landmark. Task 4 was to measure the landmark to the coastline using the 'ruler tool.' After the distance is measured, I asked them to read the distance back to me. Both Tasks 3 and 4 were designed to explore the ease of use of the 'flag' and 'ruler' tools.

Task 5 was to change the sea level scenarios. I asked them to change the scenarios in both possible ways (using the 'side' buttons as well as the 'back' buttons). Task 6 was to change the coastal erosion scenarios. I asked them to add each coast line one by one, as well as remove them one by one. Both Tasks 5 and 6 were designed to explore the ease of use of the sea level rise and coastal erosion scenarios.

\footnotetext{
${ }^{2}$ One participant was a visitor to PEI. All others were residents.
} 
3) The Post-Test User reactions, or user's subjective views and preferences about the geovisualization tool, can be gathered through interviews (Koua and Kraak 2005). After all tasks are performed, participants were allowed a free exploration of the system. While they explored CLIVE, I conducted a semi-structured interview to gather information about participants' perceptions of climate change, and how they would improve CLIVE in terms of its use and usefulness. This took an average of 20 minutes. Questions in full can be seen in Appendix F.

The questions asked were based around the two main themes: climate change risks, and the usefulness of CLIVE. The users were asked if they felt they learned about coastal erosion and sea level rise, if they were now more concerned about these issues, and if they will take any new measures against the issues. These questions linked up directly with two questions on the pre usability test survey. The users were then asked what they liked most about CLIVE, what they liked least about CLIVE, any suggestions for improvement, and what their overall or 'take home' message was.

Questionnaires or discussion at the end of the session can be useful to complement test comments, even when they are asking the same questions that the interviewer had already brought up. I administered a post-survey designed to inspect aspects of CLIVE. This took the form of a Likert scale (Davis 1989), where statements were presented and participants were asked to express their agreement or disagreement according to a scale. In this case, strong levels of agreement with a statement were assigned to a value of 7 , while strong levels of disagreement were assigned a value of 1 , while the middle of the scale was assigned a value of 4 and reserved for an 'undecided' view. These values can be added all together to provide a rough overall satisfaction score. Questions can be seen in Appendix F.

Six months later, I conducted follow-up email interviews to see if users have changed their actions in the last six months. Questions were designed around the theme of 'motivation' (meaning are the users taking any sort of action to protect themselves against climate change impacts) and can be seen in Appendix $\mathrm{H}$. 


\section{Chapter 3}

\section{Results \& Discussion}

This chapter outlines results from the workshop and usability testing phases, results from the usability testing phase, project limitations, as well as a summary of findings.

\subsection{Workshop Phase}

This section includes a descriptive summary of the survey sample, as well as a summary of survey responses segmented by theme. In total, 234 participants attended the workshops (see Table 3.1 for participant numbers). See Figures 3.1 and 3.2 for a small sample of photographs. Quotations are identified by the code word the participant used to match up their pre and post survey. 
Table 3.1: CLIVE roadshow workshop attendance.

\begin{tabular}{||cccc||}
\hline Number & Location & Date & Attendees \\
\hline \hline 1 & Victoria & July 8, 2014 & 30 \\
\hline 2 & Souris & July 9, 2014 & 6 \\
\hline 3 & Abram's Village & July 15, 2014 & 9 \\
\hline 4 & Montague & July 17, 2014 & 21 \\
\hline 5 & North Rustico & July 22, 2014 & 55 \\
\hline 6 & Charlottetown & July 23, 2014 & 38 \\
\hline 7 & Summerside & July 24, 2014 & 48 \\
\hline 8 & Alberton & July 30, 2014 & 27 \\
\hline \hline
\end{tabular}




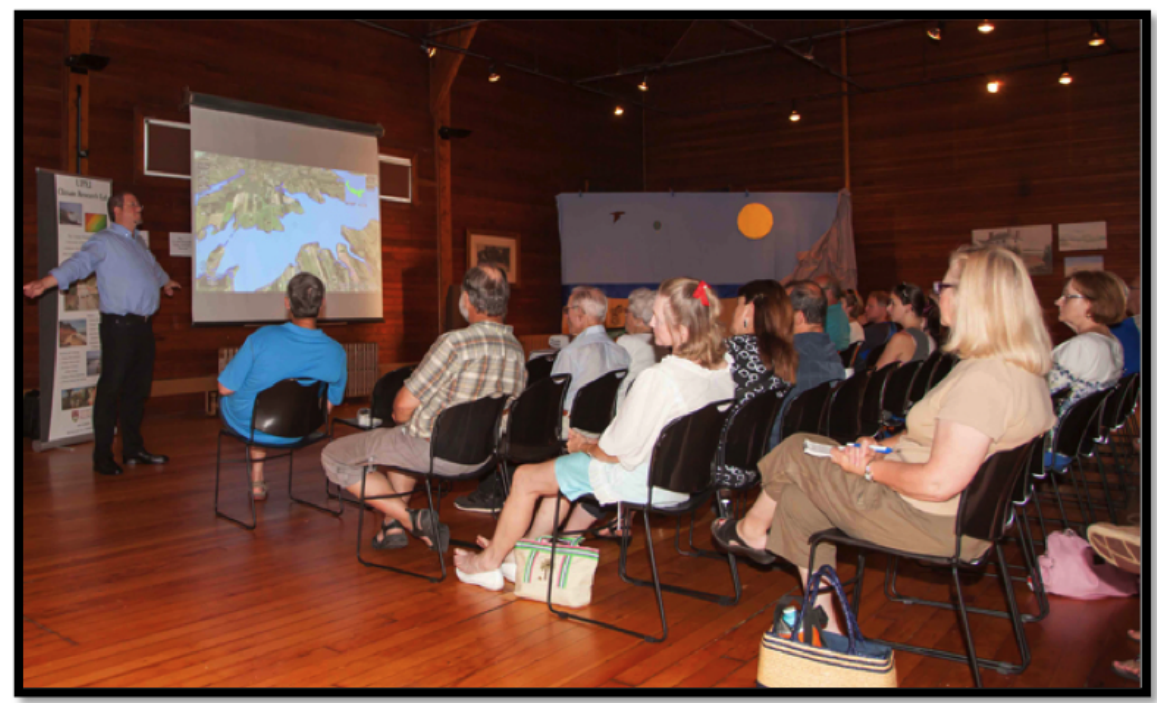

Figure 3.1: Charlottetown workshop, photographed by Don Jardine (Ellis 2014).

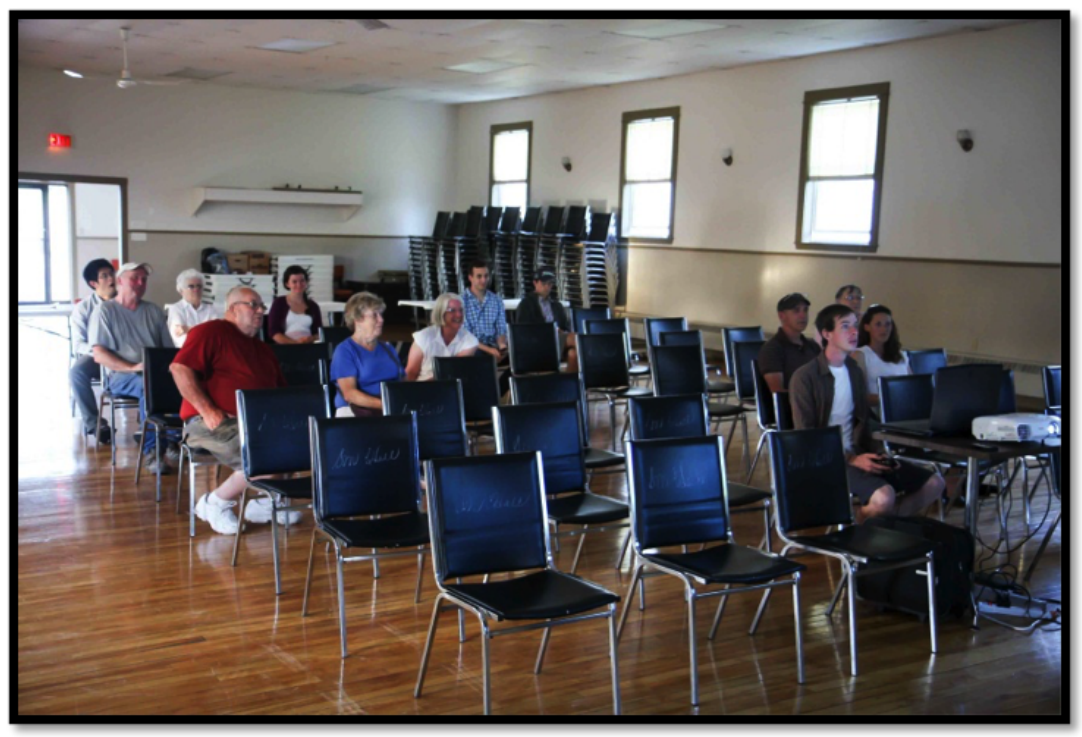

Figure 3.2: Souris workshop, photographed by Don Jardine (Ellis 2014). 


\subsubsection{Summary of Participants}

Age Almost half of workshop attendees were between the ages of 55 and 74 . When looking Prince Edward Island's population as a whole, we note that this is not an accurate representation of the population of the province according to the 2011 Census population data (see Figure 3.3) (Statistics Canada 2011). On the same figure, we also see that very few youth attended the workshops.

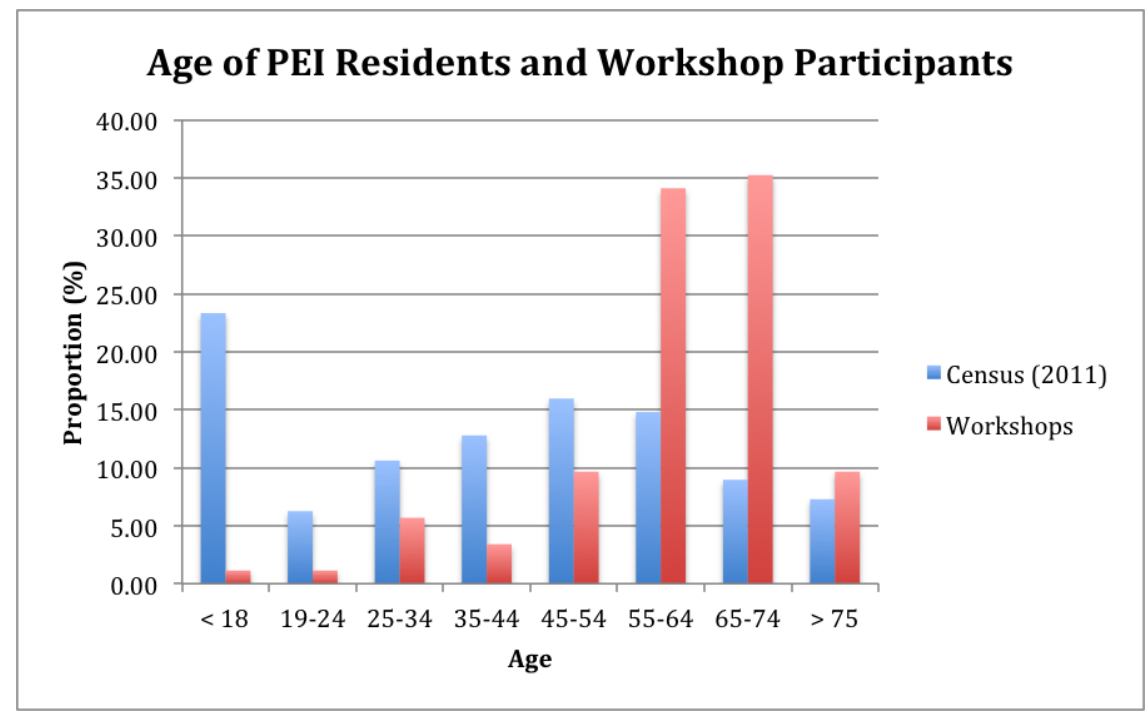

Figure 3.3: Age distribution of workshop participants compared to that of the whole province in the 2011 census.

Gender Most workshop attendees were male at $53.49 \%$ of participants. This is comparable to the 2011 Census data, which records $48.22 \%$ of residents as males and $51.78 \%$ as female. See Figure 3.4 for a more detailed look at the gender composition of the workshops.

Education The vast majority (over $90 \%$ ) of workshop participants had college or university level education (see Figure 3.5). Only 2 participants had no high school education, and they were both in North Rustico. When looking Prince Edward Island's population as a whole, one may note this is not an accurate representation of the population of the province according to the 2011 Census data, which recorded that only $47 \%$ of the population between the ages of 25 to 64 had achieved college or university level education. More 


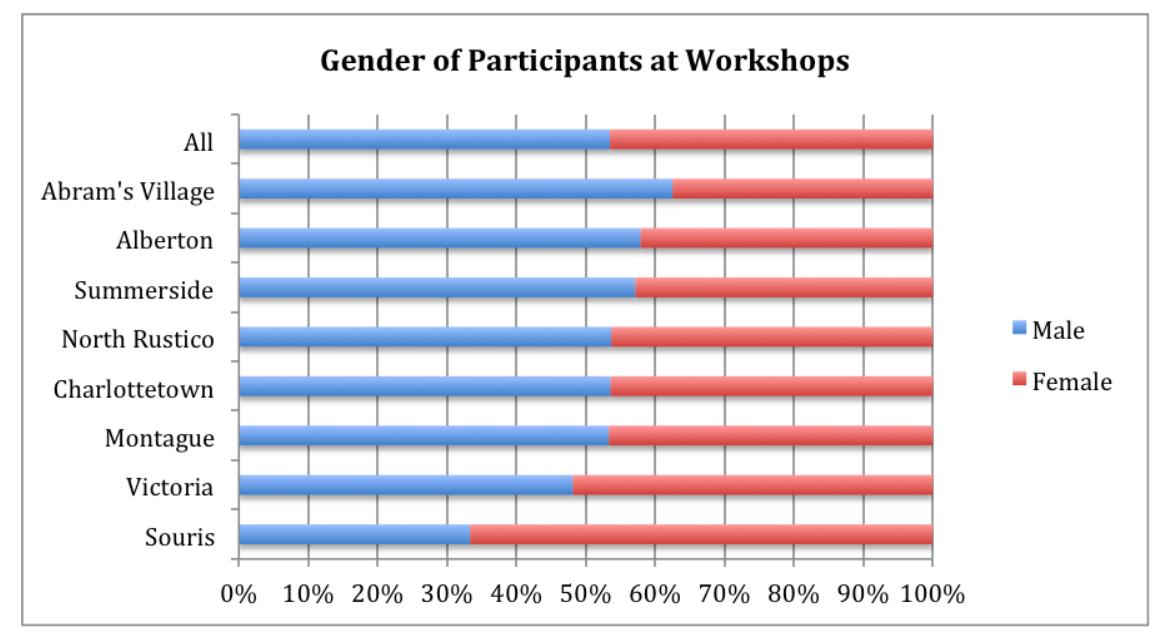

Figure 3.4: Gender of participants at all workshops.

than half of Souris workshop attendees only had high school education, but the sample size was low $(n=6)$.

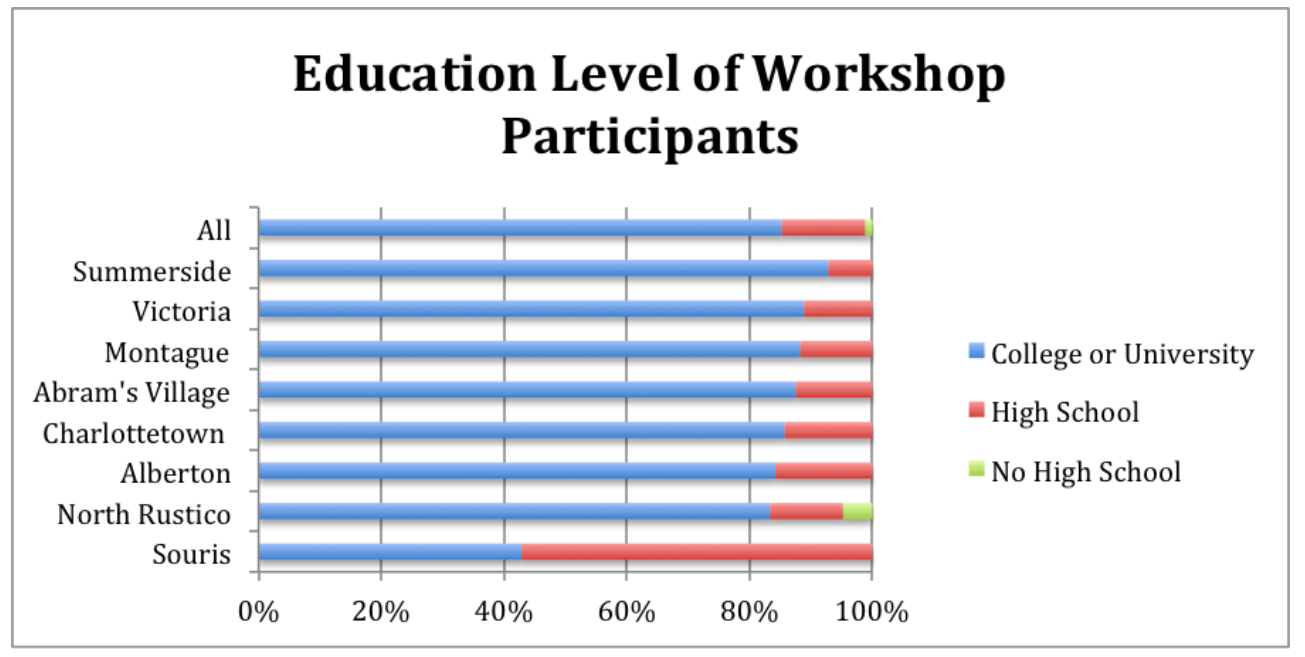

Figure 3.5: Education level of workshop participants. 


\subsubsection{Survey Responses}

\section{Level of Concern}

It is clear from the CLIVE meetings that Islanders are already very much aware of the impacts of coastal erosion and sea level rise, though rates were relatively unknown. When asked: "Are you concerned about the sea causing damage to the shoreline" (see Appendix A), no participants answered below '4' (see Figure 3.6). In the post survey, when asked: "Are you concerned about the sea causing damage to the shoreline" the majority of participants did not change their responses (see Figure 3.7), but a small percentage (1.89\% of all participants) became less concerned (see Figure 3.8). As well, a small percentage (12.58\% of all participants) became more concerned (see Figure 3.9). There was no significant difference between the means of both groups.

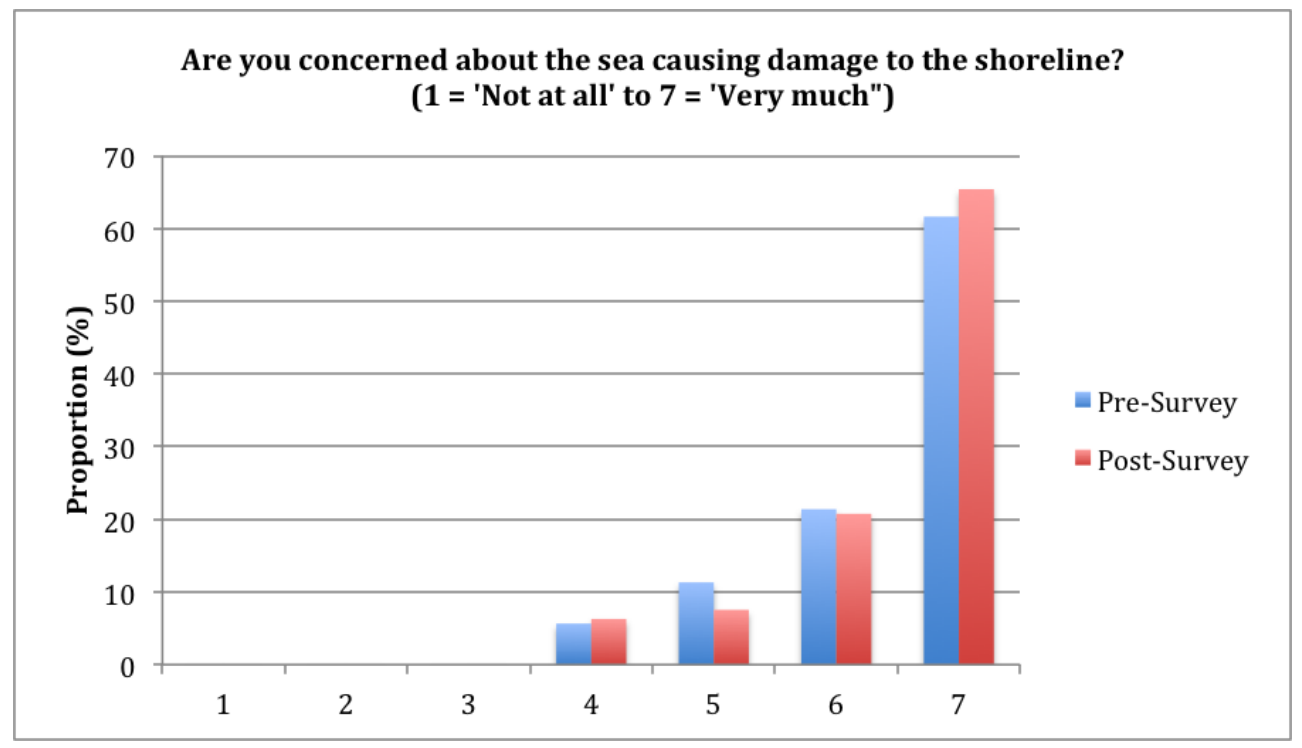

Figure 3.6: All responses to "Are you concerned about the sea causing damage to the shoreline."

It also is important to note that Islanders with cottages and property on the coastline were concerned about these valuable assets. Unfortunately, survey respondents could not be identified as 'at risk' or 'not at risk', as surveys did not include specific questions regarding coastal property. 


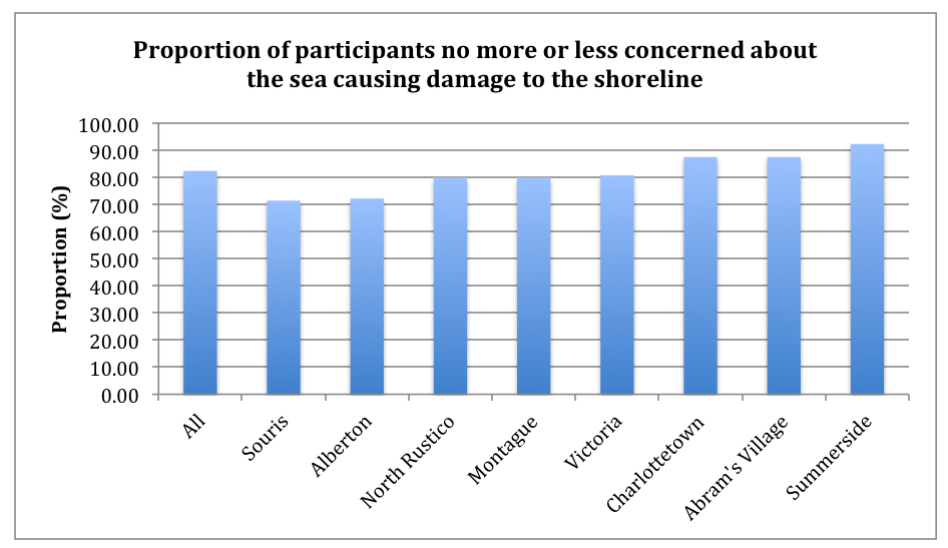

Figure 3.7: Proportion of participants no more or less concerned. Note that all participants are accounted for, as well as each community.

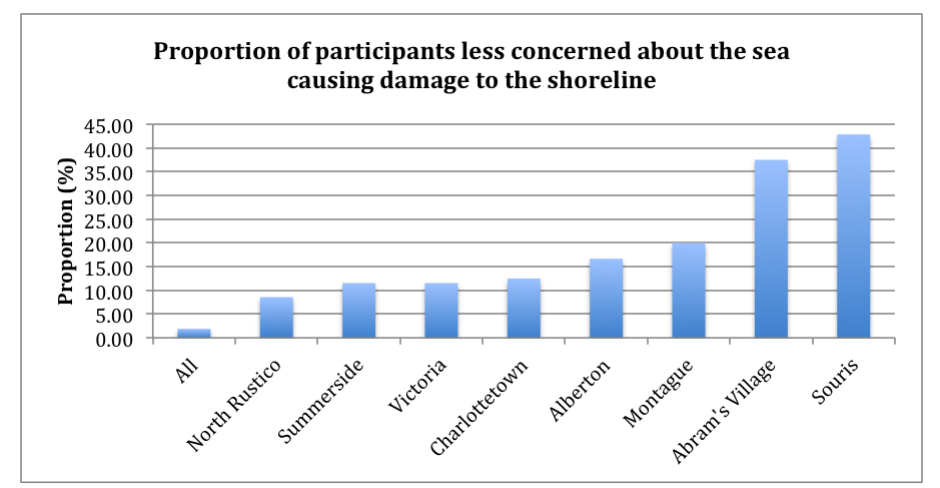

Figure 3.8: Proportion of participants less concerned about the sea causing damage to the shoreline. Note that all participants are accounted for, as well as each community.

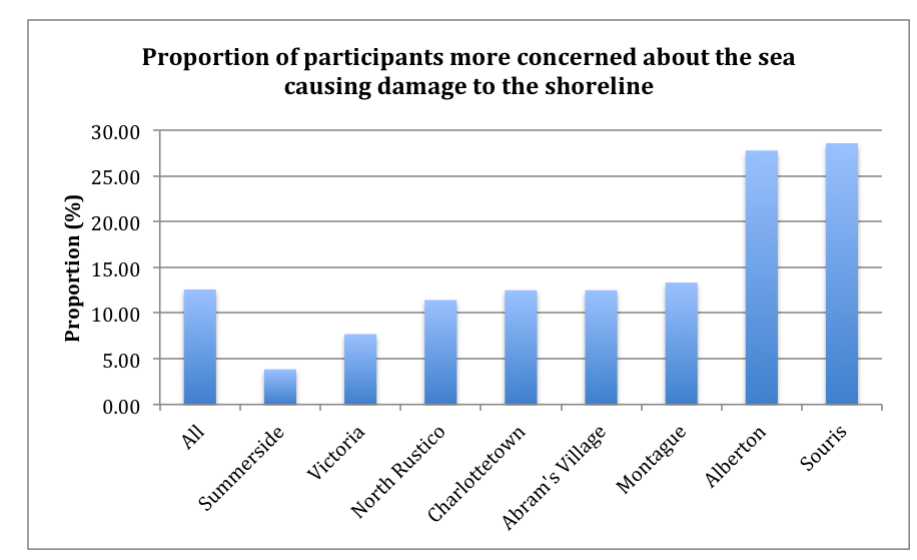

Figure 3.9: Proportion of participants more concerned about the sea causing damage. Note that all participants are accounted for, as well as each community. 


\section{Protection Measures}

According to the pre-survey, some protection against coastal erosion and sea level rise is already in place. When asked "Do you currently take measures against the sea?', 40 participants (or $20.30 \%$ of all workshop participants) responded that they do currently take measures against coastal erosion. Of those responses, 13 respondents have sea walls in place, 31 use rocks or other materials, and 2 have relocated because of the sea. The number of participants who live on the coast is unknown. Even though many participants did not have protection in place at the time, there were some future plans for protection. When asked 'Do you plan on taking measures against the sea?', of those who aren't currently taking measures against the sea, 8.93\% (or 15 respondents) say they plan on doing so in the future. These 15 respondents mentioned that they would protect themselves by placing rocks and other materials 7 times, and mentioned relocation 6 times.

It is clear that the presentation garnered some interest in implementing protection measures. After the workshop, 32 participants had changed their mind and decided that they would take measures against the sea. That is $16.24 \%$ of all workshop participants. When asked how they would take measures, sea walls were mentioned 4 times, placement of rocks and other materials were mentioned 6 times, and relocation was mentioned 8 times. Many participants mentioned wanting to develop 'living shorelines' to protect themselves, including planting rose bushes, trees, shrubs, and even bamboo. Others mentioned extending and creating living shorelines. As a last resort, participants would sell their house. Sandtucket mentioned they might install gabion baskets.

\section{Other Measures}

Implementing typical protection methods (including contructing sea walls or placement of rocks or other materials) is not the only measure participants can take against coastal erosion and sea level rise. After the workshop, when asked if the participants would take measures other than typical engineering methods, more than half (108 respondents, or $63.36 \%$ of surveys) replied that 
they would. 'Educating yourself' was mentioned 93 times, 'Spreading the word to friends and family' was mentioned 66 times, 'by writing a letter to the local government' was mentioned 27 times, and relocation was mentioned 20 times. Jasper had another idea for other measures, writing: "Through my classroom." Some participants will put pressure on the government such as Participant \#11, who will: "Encourage the province to develop and implement long term planning to mitigate the issue," or Tobin who will: "Put pressure on federal government to make better decisions to protect our environment not just the coastal erosion."

On the other hand, some participants were not planning on taking any sort of action, as they thought there was no point. CAKB provided an example: "Unless governments come to an agreement to limit climate change, planning to adjust seems like an exercise in futility - i.e. just live with it and adjust as it becomes unavoidable." In accordance, Lighthouse said: "I don't think there is much we can do," while Participant \#107 said: "It won't affect me or my grandchildren." This apathetic viewpoint was not common among the participants, but it is present and should be addressed when designing future engagement sessions. 


\section{Usefulness}

According to the workshop participants, it is clear that CLIVE is helpful. Out of 168 participants who answered the question: "Is CLIVE helpful? Why or why not?" 164 replied: 'Yes' and four (4) replied: 'I don't know.' This means that $85.86 \%$ of all respondents think that CLIVE is helpful, which is including those who did not answer the question. Participants described CLIVE as 'a great simulation tool', 'effective', 'wonderful', 'nice', 'interesting', 'excellent', and 'easy to understand'. The presentation was described as 'very interesting', 'very informative', 'excellent', 'well presented and explained', and 'great.' Many participants thanked the CLIVE team.

Other than general positive feedback, several themes emerged from the written responses outlining the reasons why the participants found CLIVE useful. These themes are as follows:

1) Visualization

2) A Learning Tool

3) Motivation

1) Visualization CLIVE has an ability to help its viewers visualize coastal erosion and sea level rise scenarios. World Cup summarized what many participants described: "...as they say, a picture tells a thousand words. There is nothing like seeing your own property slowly get inundated with rising sea level. Amazing! And very motivating to start planning now." As well, Barr Colony said that they liked that they were able "... to compare past, present, and future - and see all at once." Hampton Hills said: "It helps to see a visual of the effects and how it will affect ourselves and our children," while GIS says: "It is more effective to see the change rather than just hear about the rise." Finally, Bowie mentioned: "Visualization of effects on known geographical sites is very persuasive." As was seen in the surveys, most participants are very aware of the issues at hand, but participants were still pleased to see the issue portrayed in a new and different way. Kol described the experience of many participants very well: "Instead of wondering or worrying about erosion, now I can see the reality of it. This has validated my concern." Checkeres said: "I knew what was happening but nice to see 
the visual," while CAKB said: "It shows close up what we've seen in the media already." Wombat said: "a graphic rendition of what is likely to happen always helps to put some flesh to the argument". Participant \#171 mentioned: "It makes it more realistic and important when you see homes and large portions of land get eaten up."

2) A Learning Tool CLIVE helps its viewers better understand the impacts of coastal erosion and sea level rise on PEI. Many participants mentioned this, including Came in late, who mentioned: "Fantastic imagery that brings abstract concepts close to home." Hamilton2006 wrote: "Learned a lot! Was surprised to see the scalloping and the effect of run off in low lying areas. Had not thought previously about including sea levels." NA said: "This is a fantastic tool to educate people who may not be able to envision the reality of rising levels or erosion. I would love to see this tool in use in schools, available to community groups, etc." Some participants even believe that CLIVE could a great land-use planning tool. Baccer said that they will be "...taking erosion into account on future plans to purchase property." Tobin said that CLIVE helped them to think about: "...where we purchase. Where we (as community) put our government facilities." Bowie thought that CLIVE "... should be a must for someone who intends to build (something) close to shore (or anywhere really)."

3) Motivation CLIVE excites its viewers to take more measures against coastal erosion and sea level rise. Participates noted this like Dusty who summarized: "Actually seeing what would happen to specific properties kind of makes you want to act to protect your property!!" Troutshore described CLIVE as a "... very good wake up call for people.". These statements are supported by the sheer number of participants who wrote that they would be interested in taking measures against the issues at hand.

\section{Criticisms \& Suggestions for Improvement}

Some participants gave suggestions for improvement. These suggestions include further zooming ability (to get closer to their houses), to fix certain 'dead zones' (areas of the Island that CLIVE can not access), to add buildings and street names, to add the specific years to the coastline scenarios, to include 
shorter time frames (such as 10,20 and 30 year scenarios), to add the potential impact of armouring, and to continue to update and reflect current advances in science (such as glacier melt rates).

The vast majority of responses included a request to put CLIVE online and accessible to the general public. N/A summarized this well: "Perhaps if CLIVE was available on line for private viewing it would allow individuals more time to clearly view specific parts of the Island - may create more and better feedback." Sandtucket had an idea: "Try to tie it in with actual civic addresses. Set it up to allow you to log in and type in your address and look at your property in various scenarios." Other requests include putting CLIVE in publicly accessible places, such as libraries, specific groups, or science centres. As Kol said, "Everyone in PEI should experience this." Participants also encouraged the team to continue to give more presentations and demonstrations to educate more residents, and as Highview said, "Take to as many towns as you can!"

Two percent of participants mentioned that the presentation lacked information about specific actions and strategies. Cottage described this well: "More info regarding mediation techniques would be great." Muffin said they "...don't know how to handle the situation." Zoey would have liked to "discuss mitigation and visualize adaptation strategies and scenarios." This is especially important to include, because CLIVE made some participants (one percent) quite concerned, including ART FREAK who said: "The consequences looked quite frightening if nothing is done. It is something I will be thinking about." Dusty agreed, saying: "Things sound so ominous and non-reversible." Commons said: "Very informative but I fear there is nothing really that we can do." Other criticisms included that the estimates were too conservative, that maps must be updated, that the presentation should have included more information on how and why climate change is happening, and that there is a lack of information on other elements affecting erosion. 


\subsection{Usability Testing Phase}

This phase is split into two subsections: ease of use and usefulness. The first subsection holds all content related to usability issues, including recommendations. The second subsection covers everything pertaining to CLIVE's usefulness, including all questions referring to potential change of user behaviour when it comes to protecting themselves against sea level rise. Segments of both sections were submitted to the Climate Research Lab in October 2014 as a report compiling all issues, comments, suggestions, and positive feedback generated from the usability sessions. This document serves as a resource for the developers to refer to when time and/or resources become available to improve the usefulness and ease of use of CLIVE.

\subsubsection{Ease of Use}

The following summarizes all usability issues that users discovered, as well as any recommendations for improvement. The discussed issues are divided into categories as follow:

1) Game Controls

2) Navigation

3) Layout

4) Potential for Misinterpretation

5) Future Directions

\section{1) Game Controls}

The Xbox game controller was a source of delight for most participants. Many commented that the controller let them feel very immersed in the world of CLIVE, even if the user did not have experience with the specific controller. However, some suggestions regarding the improvement of CLIVE's usability involved the game controls. These suggestions divided into subcategories are highlighted in Table 3.2. 
Table 3.2: Issues and recommendations for game controls.

\begin{tabular}{||cc||}
\hline Issue & Recommendation \\
\hline \hline Joystick Sensitivity & Reduce joystick sensitivity. \\
\hline Drift & Remove drifting effect. \\
\hline The Exit Button & Create an "Are you sure?" prompt \\
& when user exits. \\
\hline The East/West Button & Modify or simplify the East/West button. \\
\hline
\end{tabular}

\section{2) Navigation}

All users became quite comfortable with the programs navigation after some practice. This includes island, layout, and scene navigation as seen in the Table 3.3. Most recommendations from users were quite minor, including adding labels for easier way finding, streamlining the interface, and adding a more prominent compass for helping to orient the user.

Table 3.3: Issues and recommendations for navigation.

\begin{tabular}{||cc||}
\hline Issue & Recommendation \\
\hline \hline General Navigation & Add city, street, and landmark labels. \\
\hline Layout Navigation & Create one column of buttons. \\
\hline Scenes and Communities & $\begin{array}{l}\text { Ensure camera faces north } \\
\text { when the program begins. }\end{array}$ \\
\hline \hline
\end{tabular}

\section{3) Layout}

Many usability issues arose with the button and tool values, as seen in the Table 3.4. Recommendations were minor and included making more distinct highlighting and streamlining the interface for easier access and use.

Table 3.4: Issues and recommendations for layout.

\begin{tabular}{||cc||}
\hline Issue & Recommendation \\
\hline \hline Button & Make highlight on the selected button more distinct. \\
\hline Tool Values & $\begin{array}{c}\text { Move tool values into common 'toolbar' } \\
\text { with three sections: sea level rise }\end{array}$ \\
& scenarios, coastline scenarios, and tool information \\
\hline \hline
\end{tabular}




\section{4) Potential for Misinterpretation}

All experts were concerned with potential for information misinterpretation, and this includes data issues (as seen in Table 3.5 below). Another concern from the experts was that the public would take the scenarios as fact, as opposed to scenarios tied with uncertainty. These issues were not described in the tutorial. Another concern was the fact that extreme and unlikely scenarios (ex: a rise in sea level of 8 metres) are possible to input into CLIVE, and without expert knowledge or atleast some guidance, these scenarios may alarm and frighten users.

Table 3.5: Issues and recommendations for data.

\begin{tabular}{||cc||}
\hline \multicolumn{1}{||c||}{ Issue } & Recommendation \\
\hline \hline Coastlines & $\begin{array}{c}\text { Make all coastline scenarios buttons } \\
\text { and lines the same colour. }\end{array}$ \\
\hline Crustal Subsidence & Verify data includes crustal subsidence. \\
\hline Validity and Accessibility of Data & $\begin{array}{c}\text { Ensure more information, a FAQ, } \\
\text { and reports are freely available. }\end{array}$ \\
\hline \hline
\end{tabular}

The experts might be worried for nothing. It may comfort them to know that my findings show that all novices understood that CLIVE was not showing fact, and they understand that the scenarios that CLIVE is showing can completely change in the coming decades. For example, more armouring could prevent the erosion that CLIVE is predicting from actually happening. That being said, some sample comments from both experts and non-experts relating to the concern that there would be a lack of expert guidance are provided below:

"With some of the data, there's still some interpretation... it's hard to give that kind of expert interpretation unless you're standing there with them... It's when people are left to their own devices that could be challenging for folks." - User \#3

"The other challenge you raise up sea level an enormous rate and show that to someone and... I'm curious... when they see a scenario that's not realistic. Whether they automatically start to dismiss the validity of the tool. 'That won't 
happen you're just trying to scare me. So I'm not going to put a lot of faith in what you're saying because I think your objective is to scare."' - User \#3

There is a split between what experts think the public wants and what the public actually wants. The experts thought that the novices would not care about specific CLIVE program details. My interview findings show that 'novice' and 'average' home owners do want this information. Novices and experts alike asked about how, when, and where the data was collected, and questioned its validity and integrity. In fact, all novice users suggested to add more information, such as a Frequently Asked Questions section, with more sections on climate change and why the seas are rising. Sample comments from novices summarize this below:

"I wouldn't just look at this and believe it if someone gave it to me. I need to know about where the data is coming from... I'd like to know that the rate of beach erosion used is justifiable to be depended upon because of the dynamic nature of beach erosion and accretion... You have to justify the data being used ... That's just the way science is. And I'm sure everyone knows that. Even what the numbers would be is still not agreed upon completely, globally." - User \#12 "... in some fashion there should be some sort of description of how [data] were collected without being too technical." User \#5

\section{5) Future Directions}

Many participants had suggestions for future improvements, as seen in Table 3.6. These suggestions include adding $3 \mathrm{D}$ buildings, more layers, and releasing CLIVE online.

Table 3.6: Suggestions and recommendations for future directions.

\begin{tabular}{||cc||}
\hline Issue & Recommendation \\
\hline \hline Added Realism & Add in 3D building models. \\
\hline Online Release & Release a version of CLIVE online. \\
\hline Other & Add more layers (ex: coastal protection infrastructure). \\
\hline \hline
\end{tabular}




\section{Summary of Ease of Use}

Overall, participants seemed extremely impressed with CLIVE and satisfied with their experience. When every participant gave suggestions for improvement, they made it clear that they were nitpicking. See Tables 3.2 to 3.6 for a summary of all issues and recommendations. By far the most common suggestion was to release a version of CLIVE online.

Participants were engaged and interested in learning more about coastal erosion and sea level rise, no matter their level of expertise. The opportunity to explore CLIVE on their own time, as well as referring their family and friends to such a tool, is important to them. The issues regarding the tool's controls, interface, navigation, and did not detract from the user's experience.

\subsubsection{Usefulness}

CLIVE is intended to engage, educate, and motivate users to take action against coastal erosion and sea level rise risks on PEI. The following outlines how CLIVE: 1) engages, 2) educates, and 3) motivates its audience.

\section{1) Engagement}

CLIVE scored very well on the satisfaction survey. All users rated CLIVE over 61 out of a possible 84 on the post-survey. The average score given for all users was $87.55 \%$, with novices giving an average score of $87.93 \%$ and experts giving an average score of $87.11 \%$. The following section outlines major subthemes users discussed that all fit under the main theme of 'engagement. They are listed as follows:

i) Accessible, Visible, and Immediate

ii) Immerses

iii) Exploration 
i) Accessible, Visible, and Immediate CLIVE was commended for making climate data accessible, visible, and immediate. Many times high precision data of interest to the public are buried in reports that are simply inaccessible. They can remain inaccessible by either being too physically difficult to obtain, or from the inclusion of highly scientific jargon that gets in the way of the reader. The producers of these reports simply do not have the time or resources to develop this type of interactive data visualization for a wider audience. Both experts and novices praised the developers of CLIVE for wrapping up all the scientific data used into a neat, compartmentalized, and easy to use package.

"... being able to very quickly and intuitively be able to use the data this way is a lot better than having it tied up in a GIS, and having to write scripts and run models..." - User \#1

"... if we wanted to go to this area here and say ' $\mathrm{OK}$, we really need to generate a map because someone is planning on building here, and we want to be able to tell them about what the risk is.' Then we'd send a request to our mapping folks and say: 'Hey - can you generate a food risk map for this based on this information based on so on and so forth,' and they'd send us one back but there's no immediacy to that, it would be... It may take a day depending on how busy they are. With this tool... you can see that information instantaneously... I do like [the immediacy]." - User \#3

CLIVE's visualization potential is very impressive to users. All participants expressed their delight with being able to visualize future coastal erosion and sea level rise scenarios, and be able to simply and immediately flip between these scenarios. Many users also really appreciated seeing the historical coastlines.

"It looks real. It's hard to compare that to a future reality that doesn't exist. And you can actually see the sea level rise up against land. It's kind of flying over it. It looks real. You're visualizing sea level rise." - User \#10

"Well it's like everything else, right? As soon as you can see something, it helps." 
“...nothing sets it in stone like a visual." - User \#7

ii) Immerses An interesting pattern that I like to call 'What About My Back Yard?' (WAMBY) emerged again and again. When we started the program but before the actual usability test, every single interviewee went immediately to his or her house, without any sort of prompt from me. This was not completely surprising, but should be noted, as developers may be able to use this to their advantage. This is a clear sign of the user feeling 'placed' (or immersed) within the world of CLIVE. Users enjoyed being able to see familiar places, such as dips and hills, streets, and moving water. This all added to the program's overall impact.

"And I've always said the first thing people want to do is look at their own house. It's the first thing people do when they get in a hotel room in a different city, they look in the phone book for someone with their same name." - User \#2 "[It] feels very local, that's a neat thing for sure. When do you ever see something like this? A game about where you live?" - User \#13

"It's very effective having the moving water. I felt that was really helpful. To sort of remind us that it's water." - User \#13

"... it makes it more real if you pick a place that you know. It definitely makes it more impactful." - User\#7

"I like that it's very interactive environment for people. I like the potential that it has for people to better understand these issues. It's meaningless to walk into a community and say sea level is going to rise by a meter. Absolutely meaningless unless you can give them a visual. Before CLIVE, the visual that we would give them would be a paper based map... And that's still better than saying 'Oh it's a metre'. But this is a more immersed environment for people. I think it will be interesting to see whether presented in this way, that it's more compelling to them." - User \#3

iii) Exploration CLIVE is a very fun tool to explore. While we talked, all users continually explored the program, changing locations and scenarios as 
they saw fit. They searched for low lying areas and bridges just to see them flood. They explored in a variety of ways including looking for their favourite places to play sports, finding where their friends lived, looking at lighthouses, checking out their favourite beaches, or even getting a good view of the most expensive house on PEI (valued at $\$ 7.75$ million in Cable Head East). There was a lot of interest in investigating vulnerable infrastructure between novices and experts alike. Some of these areas that users were interested in include: bridges, causeways, sewage lagoons, emergency services buildings, sewage lagoons, harbours, ferry ports, major shipping wharves, Lennox Island (a First Nations reserve), friends' houses and businesses, among more.

"I'm just having fun flying through this world. I think that's what the game developers want. I'm enjoying it. And the more I play with it, the easier the controls get. And the map looks pretty awesome. Well this is super cool." - User \#11

With no doubt, CLIVE enchanted the users. In fact, CLIVE continually battled with me for their attention. Often when trying to answer my questions, they would constantly interrupt themselves, noting some interesting new scene they just saw. My questions were interrupted and sometimes ignored, but the user was having a great time, engaged with the tool and truly exploring different areas and scenarios. CLIVE seemed to bring out the storyteller in some users. With an air of nostalgia, they told me stories of in filled bogs, and exactly how certain areas, land, beaches, and roads used to extend far beyond their current locations. They spoke of the large storms, weather and water level records. An example of an engaged user is summarized below.

"Oh yeah it's always nice to have something visualized for you, right? Like there's nothing... Wow look at that. Nothing beats... Look at that - that bridge is gone. And look at what happens to the Island there." - User \#4

\section{2) Education}

Sub-categories include:

i) Teaching Tool

ii) Level of Concern 
iii) Outreach

i) Teaching Tool In terms of a potential teaching tool, there were some differences in how CLIVE was viewed. When asked if they learned about coastal erosion and sea level rise, two novices did, though some thought it was more accurate to say that it helped them understand the impacts of coastal erosion and sea level rise. Most experts could not know for sure because they worked in the field. Also, erosion is very much on the mind of Islanders, so this was a difficult question to answer for all participants. Perhaps I was not asking the right questions - CLIVE can not take the place of a lesson in the mechanics of coastal erosion or sea level rise, especially where the inhabitants are constantly faced with the issues, but it can illustrate and illuminate their future impacts quite nicely and easily.

"The concept of [coastal erosion and sea level rise], no. But the potential realities, yes. The idea of coastal erosion... Seeing these lines didn't make me understand it any more or less than I already did. But in seeing the lines, I could kind of see... if coastal erosion continues at the rate that it does, what could potentially happen." - User \#6

"It's not anything that Islanders aren't already aware off. Anytime you go to the beach in the last...10 years, especially within the last 5 years, the amount of erosion that's happening, just in the National Park alone, is becoming very apparent. The storms in the winter, the lack of ice cover... and a couple of other factors like that... I think people are aware." - User \#1

"... not surprised by any of this. And I've always known that the Island was disappearing into the water... But I can see that it's a valuable tool for helping other people who don't quite get that kinda thing." - User \#4

ii) Level of Concern It was difficult for the experts to answer when I asked if CLIVE had made them more concerned about coastal erosion. The experts all work in fields require a high level of coastal erosion and sea level rise knowledge, though they all agreed that it is an interesting way to present the information to others who may not have the same level of knowledge. The novices 
all agreed that CLIVE made them more concerned, or at least more aware of the risks at hand, though they did find this question difficult to answer.

"Well, no. I say that not because I don't care, but because I did care before." -

\section{User \#6}

"I was pretty concerned at the beginning, but it's definitely shocked me a little bit." - User \#11

iii) Outreach CLIVE is very suitable for complementing educational programs about climate change. Many users felt that CLIVE will help to raise climate change risk awareness, and help to connect people to climate change. Others thought that CLIVE should be brought out to more community events all across the Island. Experts were particularly happy with the fact that CLIVE is being taken to communities, because people are beginning to see and understand issues that the experts have been dealing with for years. All other participants suggested applications of CLIVE to their line of work, or recommended CLIVE to their friends. Some users felt that CLIVE would be extremely very useful for certain groups such as the Transportation Department, policy makers, teenagers, or those who don't work with technology on a regular basis.

"If there was a kiosk that people could come up, and especially if they had a coach, I think you need that. People could move around and see their house and see what the impact is in their community." - User \#2

"If people get that that's what's connected to what human beings are doing, then they might feel like: 'Oh you really meant it when you said it was important for us to do $x, y$, and $z$. So we're now seeing some real possible impacts of this... Oh that's somebody's home, that's somebody's life."' - User \#13

"People hear climate change all the time and it's usually linked to global warming and carbon sequestration, CO2 levels and stuff like that. This just brings it right to your front door." - User \#2

"[CLIVE is] a good way to raise awareness and wake people up, even if it's not an extremely accurate reality. But to show that - look, this is conservative, this 
is change, you can see it here based on the rate of beach erosion, or if you have sea level of even half a metre fifty years from now. I think it's a good way to wake people up or perhaps motivate action. To be determined." - User \#12

\section{3) Motivation}

Sub-categories are as follows:

i) Measures

ii) Measures Six Months Later

i) Measures No users were taking measures against coastal erosion or sea level rise, because none owned coastline property. The only measures mentioned were that users are not planning on buying cottages on the coastline, as they understand that they will have to spend thousands on maintaining them. The only other measures that users are taking are simply being aware of the issues, bringing this knowledge to the education system, and letting local decision makers know about CLIVE.

"... I've always tried to be somewhat conscious of my actions and the repercussions of what they have on the environment... by the time major changes happen I won't be living here. So that doesn't change the fact that I should be conscious of what I'm doing... The conciousness of it is not going to go away and I'd like to think it will remain at the same level, but the visual that this game has given me, it makes it more of a real thing as opposed to just a concept that I'm aware of." - User \#6

"... I immediately thought I should find out who's teaching the secondary geography stuff because they should see this... They should show it to all the teachers... I think that will be really useful, because we have a lot of people who are teachers from rural communities who it would make a huge difference to see it." - User \#13 
ii) Measures Six Months Later After following up six months later, experts and novices had different responses when it came to adaptation strategies. While novices recalled having discussions about sea level rise, coastal erosion, and CLIVE with others, experts can recall having similar conversations, but these were directly related to their work and not with their experience with CLIVE. As User \#12 (a novice), points out, CLIVE is a good starting point for these sorts of discussions: "... it also made it easier for the people I was talking to understand the concepts of sea level rise, coastal erosion, and climate change in general."

Other than discussions with others, no users had mentioned any other measures that they had taken. The lack of action being taken seemed to stem from the feeling that my users could not combat these issues personally, or like User \#11 said: “... I don't own shoreline property, nor do I feel like I have the right to tell people what to do with theirs if they have it!" Although raising awareness through word-of-mouth is extremely important, it is not enough to motivate or encourage action. User \#10, an expert, raised a point about persistence and how it can help with motivation: "... the general public has an awareness or attention span that is constantly shifting, so if the goal is motivate or encourage action, CLIVE developers need to be persistent in getting their message out." 


\section{Chapter 4}

\section{Moving Forward}

This chapter includes a summary of findings, limitations, conclusions leading to the creation of a pilot cybercartographic atlas, ideas for further research, and my final thoughts.

\subsection{Summary of Findings}

\subsubsection{Ease of Use}

In terms of the workshops, participants were pleased with CLIVE's usability, and they had very few recommendations. No relationships between different demographic groups were deemed as important to explore further. From those who came to the workshops, developers should take note of potential aging problems, namely reduced vision capacity as a result of ageing, which may be a problem for CLIVE users. In summary, all those who experienced CLIVE found the tool very easy to use, including both novices and experts. This contributes to my central argument that $3 \mathrm{D}$ geovisualization tools may be an effective means of communicating climate change effects. 


\subsubsection{Usefulness}

I remind the reader that I am evaluating the tool's usefulness according to its three main goals: to engage, educate about climate change effects and motivate the user to take action against these effects. I will briefly describe CLIVE's performance according to each of these goals.

Engagement It is very clear from both the surveys and the usability testing that CLIVE is an enjoyable program, both to use and to watch others use. $86 \%$ of workshop participant agreed that CLIVE was helpful. Both novices and expert users gave CLIVE an average score of approxmately $87 \%$. Although these scores cannot be compared to another version or program, they do make it clear that users were very satisfied with CLIVE

Education It is difficult to determine to what extent both workshop participants and usability testing users actually learned, as it is very clear from both the surveys and the usability testing that Islanders are very much already aware of the impacts of coastal erosion and sea level rise on PEI. A surprise was that a small percentage (2.5\%) of workshop attendees became less concerned about the sea causing damage to the shoreline. This could be for a number of reasons, but I believe that these people took note of where their homes were located and saw that the impacts were either far into the future or not as dramatic as they had originally believed. The visualization allowed them to make decisions regarding the issues, and that is just as important. A larger percentage (15\%) of workshop attendees became more concerned about the sea causing damage to the shoreline, which was expected.

That being said, it is also very clear that participants feel that education about these issues is very important. Many encouraged the team to bring CLIVE to more communities and even to schools. As Kol put so well: "Everyone in PEI should experience this." Perhaps a school atmosphere is where CLIVE is best suited, where it will have an audience with less overall experience than those who attended the workshops - those who have properties on the Island and the majority of were over the age of 55 . Though I have no doubt that young people have an inherent understanding of the sea, but CLIVE will help 
solidify that understanding.

Motivation It is clear that CLIVE had some hand in motivating users to protect themselves against climate change impacts. A good portion (16\%) of all workshop participants decided that they will take measures against the sea, be it placement of sea walls, rocks, and other materials, installation of gabion baskets, growing a 'living shoreline', or as a last resort, relocation. Unfortunately, we have no way of following up with these participants to see if they followed through with their plans.

When focusing on results from the email interviews portion of the usability phase to check up on participants, I found that more novices (as compared to experts) changed their habits, recommended CLIVE, and discussed the issues with others. The issues seemed new and fresh to novices, while experts have seemingly become 'immune' to the issues. If the key goal is to motivate individuals to take action, this study shows a number of points: geovisualization tools should be targeted to novices in order to create the most impact, and CLIVE must be kept fresh in participants' minds.

After I conducted my study, Schroth et al. (2015) published a very similar one. The authors organized public engagement sessions demonstrating a 3D geovisualization (which they call a landscape visualization) tool that showed local climate change impacts in a rural town in British Columbia (BC). They surveyed audience members before and after the sessions, and evaluated the long term impacts on decision making in a retrospective evaluation 22 months after the fact. The retrospective evaluation showed that the visualizations were remembered, are being used, and did change the habits of the participants, but mostly through the actions of council. Another related study produced by Cormish (2013) supports this. This disagrees with my restrospective evaluation - in my case, less action against climate change had been taken with the usability testing subjects. However, the engagement sessions set up by the Schroth research team included more response options for participants, and the participants were given much more time to be 'allowed' to act (22 months vs. 6 months). I suspect that if the CLIVE presentations followed this formula, and if I checked up on participants in two years as opposed to six months, I would have seen more evidence for change. Nevertheless, This reinforces the 
necessity for outlining direct action that a user can take after any session with CLIVE, as well as a need to be able to revisit pertinent information.

\subsubsection{Novices vs. Experts}

The issues uncovered in this study led to interesting findings regarding the needs of novice and expert users. These needs were expected to be very different between the two groups, but my findings show that there are far more similarities than differences. Regardless of being a novice or an expert, all users wanted online access to CLIVE. And above all, both novices and experts want accessible information regarding data sources, and validity, though experts assumed that novices would not be interested in this. Including all this information over the Internet in a clear and succinct manner is a challenge, a well known fact in the geovisualization community (Andrienko et al. 2002). To help with this, developers should consider more reliance on 'Intelligent Agents', one of the four key ' $\mathrm{I}$ ' components of geospatial virtual environments, which could essentially act as a teacher to guide users through CLIVE.

Though this is good news for the designers of the program, it may emphasize the fact that we need to study perceptions of different target audiences. For example: upbringing may affect a user's perception more than their familiarity with coastal erosion and sea level rise, as I was focusing on. For instance, Victoria is not a typical fishing village in PEI: it is made up of mostly cottages who house summer residents. These property owners may not have traditionally grown up by the sea, and may not have an inherent understanding about what living by the sea really means. They may not understand that the sea is always changing, and exerts its influence on the land at its will, and they may be more likely to have an expectation that a piece of infrastructure should simply stay put. CLIVE may impact them much more than a typical fishing village in PEI, such as North Rustico. North Rustico is a similarly sized fishing community but with a significantly smaller proportion of 'Come From Aways' (CFAs). The people of North Rustico may be more familiar with the sea and how it functions and therefore a little less concerned at the dramatic scenarios CLIVE has to offer. As they have more of a close relationship with the sea, these people will simply have the understanding that this is what happens 
when living by the coast. Studying different groups and how they perceive CLIVE has huge potential for the new geovisualization researcher.

\subsubsection{D}

This study was specifically interested in the effectiveness of CLIVE as a general geovisualization tool, but I am also interested in the novelty of the 3D technique. My intention was to not only examine and evaluate CLIVE as a tool on its own, but also to evaluate the concept of '3D' and to observe how users might react to it. Unfortunately, the specific 3D technique is very difficult to isolate and evaluate. As a whole, this study can not clearly encourage or discourage using the 3D technique, but we did learn some useful things: not a single user complained about the use of 3D. That being said, the word '3D' was only mentioned once in all of the surveys and all of the interviews. This was not expected, though they could not view the tool in 2D (plain view).

What can be said is that the potential negative effects of 3D such as overwhelming the user did not occur, which is a very positive sign when evaluating this technique. Resulting from this study, the CRL team will have a better understanding of how to evaluate user tasks for CLIVE. This means that more tests in the future can be aimed at evaluating specific concepts or techniques (as outlined by Andrienko and others in 2002) such as the use of the 3D technique.

\subsection{Limitations}

\subsubsection{Case Study}

It is important to note that these findings are from one case study. These findings may not apply to all 3D geovisualization tools intended to communicate climate change impacts. That being said, CLIVE is a prime example of $3 \mathrm{D}$ geovisualization tool, and lessons learned from this study likely extend onwards. 


\subsubsection{Workshop Phase}

Survey Problems There were some problems matching up the code words on the pre and post-workshop surveys, even after close inspection of handwriting. This meant that some (20) surveys were not usable. In future workshops, I would be adamant about checking that the participants submitted all surveys with code words.

The questions on the surveys can be said to be quite simple. As Dumas and Redish point out (1993), an economic survey design is advantageous for generating survey data, as participants tend to be deterred by long and/or complicated tests. This is why the questions on the surveys were chosen to be quite simple, all so that the survey would be completed by participants. It was also relayed to me that the education level (and potentially the literacy rate) of the participants was not expected to be very high, which is another reason why I chose very simple questions. This led to the generation of quite simple demographic data. For example, there were only three options for education ('No high school', 'High school', and 'College or university'). This does not leave us with a very detailed view of our sample. In future surveys, if demographic data needs to be studied, I would use more detailed questions.

Biases A few biases may have occurred during the workshop phase. My sample all chose to arrive at a climate change workshop, meaning that a 'selection' bias has occurred - those who are worried about coastal erosion will attend a coastal erosion workshop. This is not a large problem for my study - my intention was not to study the population of Prince Edward Island, it was to study those who viewed and experienced CLIVE. I do consider this a general limitation, as the results of this study cannot be used to conclude much about the entire population of Prince Edward Island, which, in a way, is limiting in its own right. This raises the question of whether CLIVE would be effective if used by people who don't live on the coast (for example: novices in usability tests, if they were carefully chosen).

Non-response bias may have skewed the demographic statistics, but overall the demographic data made it clear that when compared to Canadian census population data, the subset of the population of PEI that came to the work- 
shops is not a representative sample of the population of the provinces. This is in regards to age and education level, as they were a very highly educated group, and the majority of which were over the age of 55.

\subsubsection{Usability Testing Phase}

Beginner Moderator Beginner usability testing moderators find the usability testing process very difficult to get used to. Many beginners have trouble with remaining impartial, which can lead to a higher overall score for the product. Beginner moderators also tend to help users who are struggling with the product (Dumas and Loring 2008).

As a beginner usability testing moderator, I took precautions to remain impartial and to let the user struggle, but it is possible that still I contributed to the users' 'desire to please'. If conducting these tests again, I would have emphasized the fact that I would not speak or help the user very much during the test.

Biases Similarly to the biases which may have occurred during the workshop phase, all of my users were interested in attending my usability testing session after we had discussed CLIVE and the issues that Islanders face. Perhaps my results would have been very different had my users been picked completely randomly.

Email Interviews I had a low response rate for my email interviews, though this was expected. Only $50 \%$ of participants responded to my email interview invitation. Even though a low response rate was expected, it is difficult to determine if findings are accurately describing the group. In the future, achieving a higher response rate may be possible if participants are offered more of an incentive to take part. 


\subsection{Conclusions}

Despite global efforts, human-induced climate change is not slowing down. Impacts are being felt all across Canada (with many more in the forecast), affecting our environment, economic sector, and health. According to Natural Resources Canada (2015), it is decidedly important to adapt to global climate change, as the likelihood of stopping these changes is extremely low. To reduce impacts, raise public awareness and to motivate action, we must expand our communication methods away from the typical 'passive' learning programs (such as TV and newspapers) and towards 'active' learning processes, such as geographic visualization (geovisualization) techniques.

The increasing availability of three-dimensional (3D) geovisualization tools has expanded the potential for creating interactive, engaging, informative and effective presentations for communicating geospatial information, including potential and current impacts of global climate change. With its emphasis on immersion and interactivity, geovisualization allows room for knowledge construction (creating knowledge as opposed to revealing it), which is a method of active learning. Despite this, there is a lack of research devoted to understanding the effectiveness of these geovisualization tools.

In the past when they were extremely expensive and time consuming to make, geovisulization tools were created solely to be used by experts in the subject matter of the visualization. With the democratization of geovisualization, now it is more feasible to produce visualizations intended for a much wider audience. This worries geovisualization researchers, with some believing that the process of knowledge construction will not occur with a novice user. Differing target audiences (such as novices and experts in the subject matter of the visualization) can influence the effectiveness of geovisualization tools, and there is a lack of research devoted to this.

Evaluation of the use of geovisualization tools to educate the public about climate change impacts is important to discover whether these pursuits are worthwhile, as well as to support adaptation and effective decision-making within its user base. Usability testing, a very common method used in the Human-Computer Interaction (HCI) research field, is underused and under- 
valued in geovisualization research. It offers a deeper understanding of a system's triumphs and failures when compared to other methods (such as surveys), as shown through my research project, though both are needed.

This thesis outlined the potential and downfalls of 3D geovisualization tools used for communicating climate change impacts, for both novice and expert users. This was completed using a case study focused on the Coastal Impacts Visualization Environment (CLIVE), a 3D geovisualization tool simulating the potential effects of coastal erosion and sea level rise on Prince Edward Island (PEI), a Canadian province currently at risk from these issues. These effects are, in turn, being amplified by global climate change.

Through the use of my case study, it was found that conventional approaches to communicating the effects of climate change can be complemented well by a 3D geovisualization tool, which supports my original hypothesis. In summary, using a combination of workshop surveys and hands-on usability testing, I found that users find CLIVE engaging, educational, and motivating (to a degree). Satisfaction scores were very high, with very few criticisms, showing that users enjoyed the program and were engaged with the issues. Though already very aware of coastal erosion and sea level rise, $15 \%$ of users became more concerned about the issues after the workshops and the usability tests, showing that they learned about the severity of the issues. Many participants decided to take action against the issues, showing that CLIVE's users were becoming motivated.

During the development of these types of geovisualization tools, a lot of consideration is put into target audiences, including what information to include and at what complexity. I fear that a lot of this time and energy is wasted, as shown by my findings: that CLIVE is equally effective at communicating climate change risks to novices and experts in the subject matter of the visualization, which was an unexpected finding when looking back to my original hypothesis relating to novices and experts. Although it is extremely important to considerate the wants and needs of the target audience, I urge developers to not let the worry about target audiences impede the development and distribution of important communication tools such as CLIVE. As long as clear and transparent information is available for the interested user to go looking for it, tools should be released to reach the widest audience possible. The use of an 
Intelligent Agent could help to guide different users through these resources.

Despite the fact that CLIVE helped to engage, educate, and motivate individuals, an hour long session with the tool is not the solution to communicating climate change impacts. This was shown through follow up email interviews with the usability test subjects, with the majority stating that they had forgotten about their intentions to take measures to protect themselves against coastal erosion and sea level rise impacts. This shows that the motivation that CLIVE seemed to conjure in users did not necessarily lead to the willingness to act. This suggests the need for the continued discussion of climate change impacts with the users of CLIVE.

Interface issues are becoming more and more on the forefront of geovisualization research: a visualization's interface is seen as just as important as content. Just like this mindset shift, we must move towards the idea that the development of adaptation measures and solutions are just as (if not more) important than the development of the flashy geovisualization tools associated with them. This research I conducted solidifies the need for this pairing, and follows the investigations of other leading researchers (Lieske 2012; Shepherd 2009; Sheppard et al. 2011).

If the goal is to motivate users to prepare to adapt to climate change impacts, 3D geovisualization tools like CLIVE are only the beginning. CLIVE has started the dialogue surrounding the issues of costal erosion and sea level rise on Prince Edward Island, and the Road Show uncovered a rich depth of information regarding the public's thoughts and opinions regarding climate change. At the moment, the CRL team plans to release a version of CLIVE online, as well as produce localized versions of CLIVE all around the world. The long-term plan is to create a network of these localized versions of CLIVE which will be examined to understand the interplay between climate science communication and community adaptation. Also in the long term plan is to incorporate mixed reality technology for more interaction with climate data (Lonergan and Hedley 2014). But right now, CLIVE is and can only be demonstrated by team members, and the only those lucky enough to attend these demonstrations will benefit from the team's work. As seen with the workshop surveys, most attendees of the CLIVE July 2014 Road Show were already extremely concerned about coastal erosion. 
The Government of Canada stresses the importance of translating and communicating climate science into societal awareness by using novel data visualization techniques, and by enhancing climate change awareness through planned activities such as workshops Natural Resources Canada (2015). While CLIVE and the CRL team certainly respond to this call, the discussion created by CLIVE has been only contained within the walls of the demonstrations. Documention and dissemination of this discussion is necessary, and it must be made available for the public to refer to, educate themselves, and to get informed. With such a resource, the public will be included in the discussion, and will be able to hear each other. All this may keep the issues fresh in users' minds.

Explained further in the following section, I am adding onto the project and attempting to fulfil this need by creating an interactive cybercartographic atlas of climate change impacts, which will incorporate the discussion generated by workshops and usability tests that were conducted in the case study. These narratives will help paint a clearer picture of the attitudes and awareness of Canadians regarding issues of climate change. It will also help to bridge the public, governmental, and academic perspectives on climate change by facilitating the transfer of knowledge and data between all stakeholders.

\subsection{Ideas for Further Research}

\subsubsection{Pilot Atlas}

The following section will outline the importance of cybercartography, as well as the creation of the pilot climate change cybercartographic atlas.

Cybercartography is a multi-sensory, multimedia, online, and map-based form of communication with society, that engages users, is interdisciplinary by nature, and applies to a wide range of topics of interest to society (Taylor 2006, 2005, 1997; Taylor and Lauriault 2014). Cybercartography differs from cartography in that it takes advantage of available technology which allows and empowers people to tell their own stories using online maps, focuses on active and many learning formats, and can present very complex information (Tay- 
lor and Lauriault 2014). Using the six key ideas of the framework, cybercartographic atlases have the capacity to pull together interview findings, survey comments, photographs, and recordings, and present them in a succinct, interactive, and visually pleasing way. Showing these data using atlases (which can be considered as a metaphor for the organization, analysis, and presentation of location based information), allows users to find connections and reveal new spatial patterns, that may be otherwise lost (Taylor and Caquard 2006).

By using the concepts central to cybercartography, building a test pilot atlas is one way to extend the CLIVE project further. This pilot atlas is meant to focus on current and potential impacts of climate change across Canada, as well public opinions of the implications of these impacts. Similar projects exist, such as the Climate Stories Project, an initiative giving voice to climate change impacts through stories, art, and music (Davis and Siperstein 2015). What is unique about the Pilot Climate Change Atlas is that it was conceptualized based on a cybercartographic framework, and was built using the Nunaliit Atlas Framework, open source software built by the Geomatics and Cartographic Research Centre (GCRC) at Carleton University (2012).

To improve future versions of this pilot atlas, it would be prudent to turn to established research groups like Volunteered Geographic Information (VGI) or Participatory GIS (Dunn 2007).

Drawing from recommendations from the usability testing, the key target of this resource is students, who have a greater potential for impact as well as the possibility of a lack experience when it comes to coastal erosion and sea level rise. Resulting from this, one module of this atlas showcases climate change impacts in terms that high school students can understand. This module also includes links to geovisualization tools that depict these impacts, be it sea level rise, coastal erosion, snow line loss, lake levels, and forest fire hazards. These tools, including CLIVE, are spread all across Canada (see Figure 4.1).

The second module of this test atlas highlights public reactions and impressions of potential climate change impacts (see Figures 4.2 to 4.4). For this test run, I focused on coastal and sea level rise on PEI, and the reactions generated from the workshop surveying and usability testing phases I conducted 


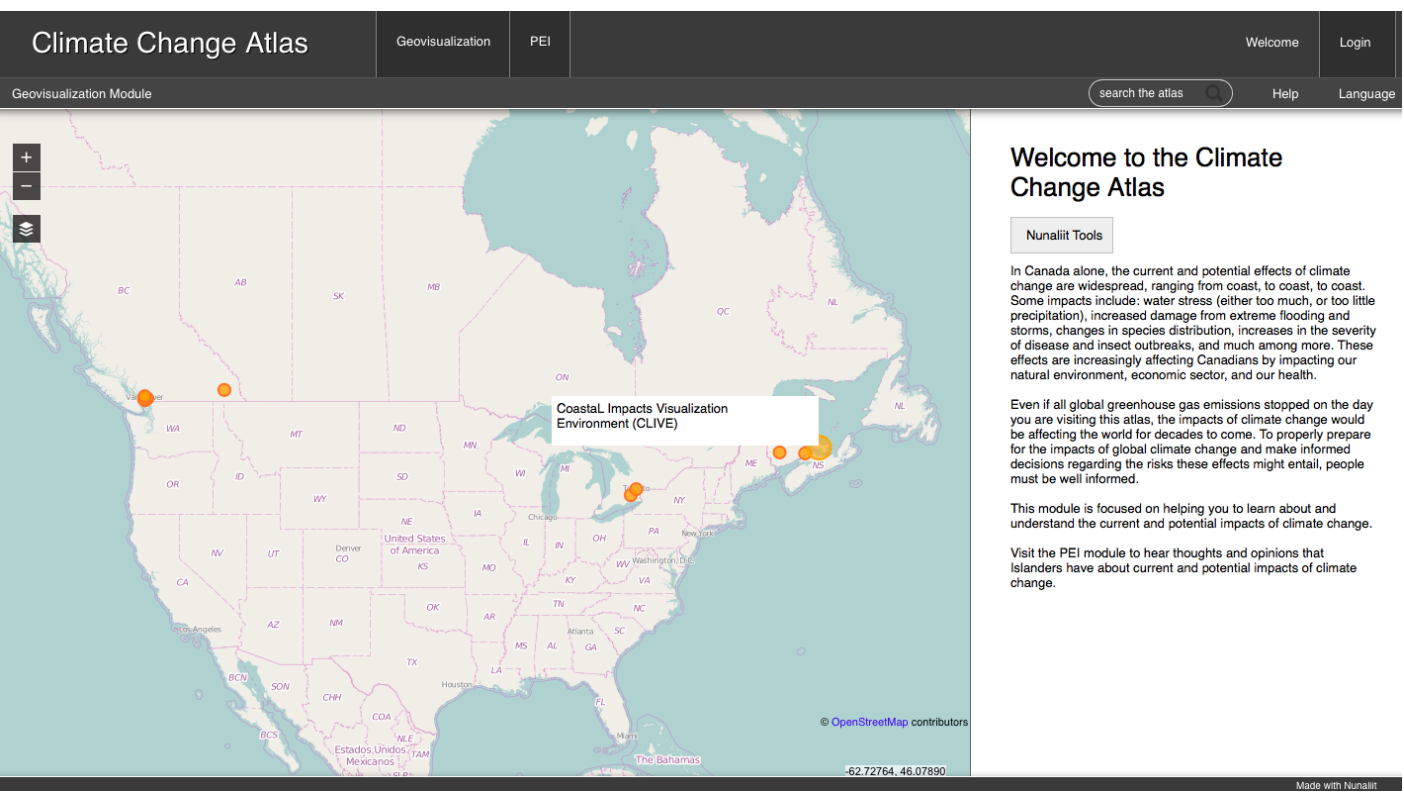

Figure 4.1: Overview of the Geovisualization Module. The cursor is hovering over the geovisualization tool CLIVE.

in July 2014. All comments and media were published as according to the selections made by the participants in their consent release forms. If this pilot atlas was open to the public in the future, users could continue to add their own opinions, and comment on the existing opinions.

When communicating complex spatial problems (like climate change impacts) effectively, it is essential to grab the user's attention in an active and creative way, and combine this tactic with clear and accessible future actions that users can take. Although this pilot atlas does not currently include options for future adaptation, it is another aid to help create lasting change. If this atlas had been set up in in time for the CLIVE Road Show, we could have directed participants to it in order to continue the climate change discussion. As the atlas evolves and develops, more resources can be added, including ways to protect users' property and livelihoods. Perhaps this continued discussion would help to keep the presented issues fresh in participants' minds, and to keep them motivated to act upon them. 


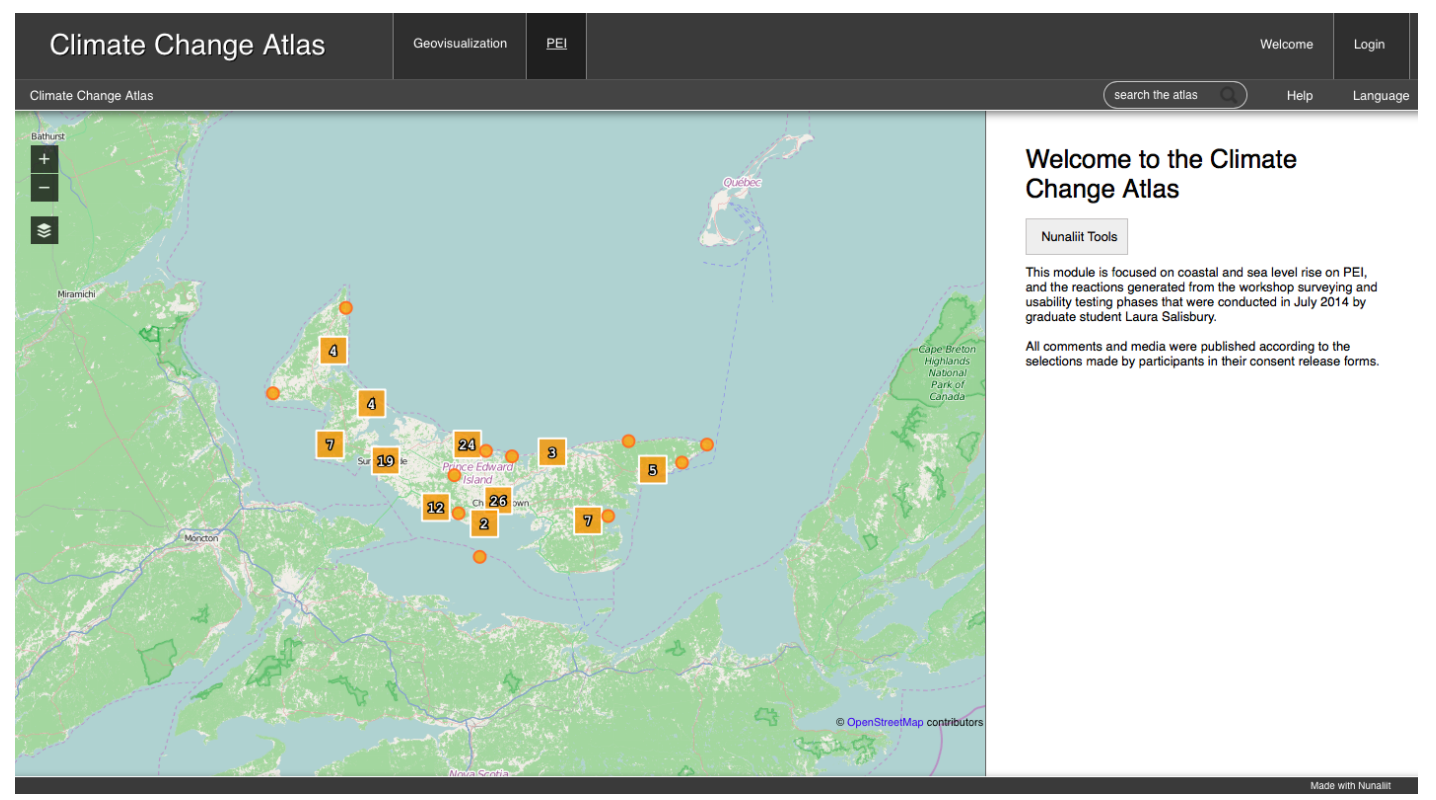

Figure 4.2: Comments made by CLIVE Road Show Participants shown in the PEI Module.

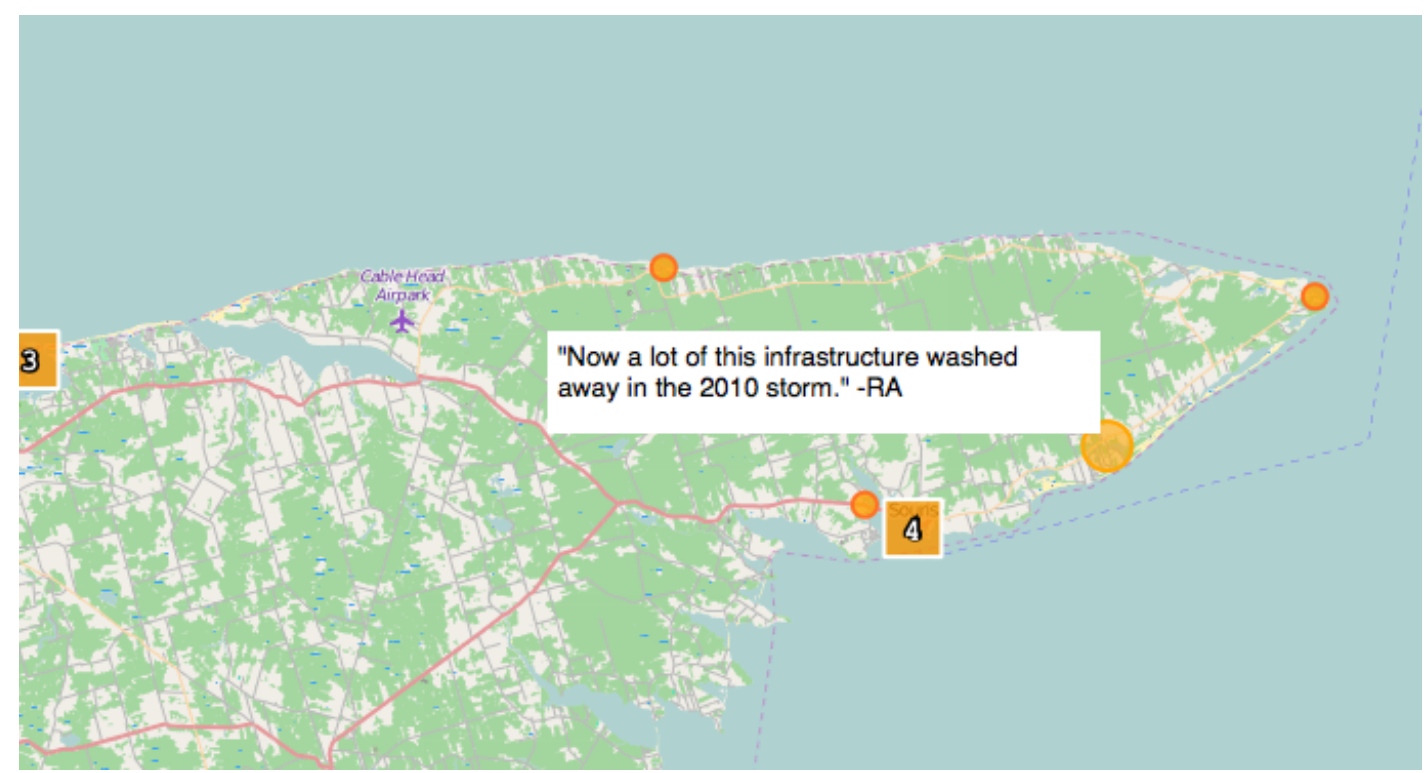

Figure 4.3: Comments near Cable Head. The cursor is hovering over a comment made by user ' $\mathrm{RA}^{\prime}$ ' who is remembering the impacts from storms past. Clustering of comments is seen in this screenshot. 


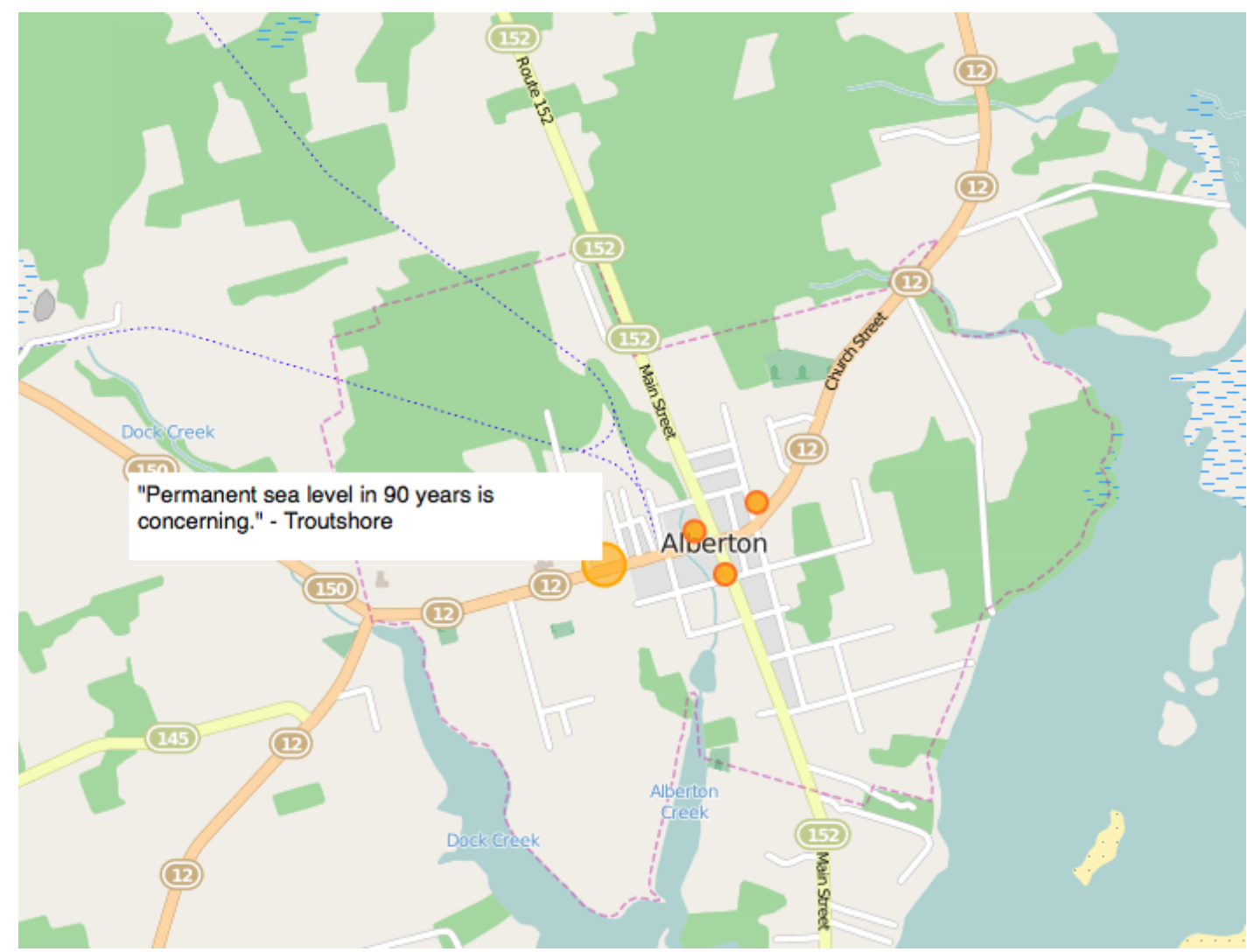

Figure 4.4: Comments in Alberton. The cursor is hovering over a comment made by user 'Troutshore', who is concerned about future impacts of coastal erosion. 


\subsubsection{Other Directions}

As with most research, we end with many more questions than we started with. Future researchers can move forward in many possible directions. Longitudinal studies directly testing changes in the behaviour of participants using 3D geovisualization tools (such as CLIVE) are the next step in truly uncovering the effectiveness of these types of tools. My study was only the first step in what is sure to be a long and complicated journey: one that may include further usability testing, workshops, surveying, a combination of all three, as well as other possible methods. These future studies could examine how different groups perceive CLIVE, or other tools demonstrating impacts of climate change. Depending on the goals of further studies, specific groups may be more worthwhile to target. If looking to make direct change to policies, perhaps politicians or industry groups could be targeted. If looking on more of an advocacy front, those at-risk and those not at-risk could be two groups to study.

I truly believe that as much attention must be placed in the development of geovisualization tools as well as the 'follow up' component of workshops, which is why I developed the Pilot Climate Change Atlas. But as a true geovisualization researcher, I do understand that it is necessary to use usability engineering principles to uncover whether or not an atlas like the one I produced could be used as a complimentary follow up tool in climate change risk awareness. This is a project that future researchers may be interested in.

In a more general sense, the production of these geovisualization tools could be made even more widespread. Lessons on developing these tools could be given directly to advocacy groups, non-governmental organizations, and even government offices. Although the benefits of geovisualization tools can be spread much further than simply climate change impact communication, this is an current and important issue and one that will likely always be important. Continuing the geovisualization democratization process is essential for the creative dissemination of this information. 


\subsection{Final Statements}

When it comes to raising climate change risk awareness, there are many advantages in using 3D geovisualization tools. They are very compelling in part from their novel, dynamic, and interactive nature, they make issues meaningful at a local level by providing a window into the future, and have even been shown to affect policy changes. Not only do they prompt the construction of knowledge, but also engage the user in an otherwise possibly dull subject, allowing them to want to learn as opposed to feeling like they have to learn. Despite all this, collective behaviour change has yet to be seen clearly. It is in the best interest of the geovisualization researcher to devote more time and energy towards the development of materials for after the demonstrations or engagement sessions (such as possible adaptation responses or options) in order to avoid users' inspiration from burning out.

To close, I bring you back towards the quotation in Section 1.3.1.: "When something is visualized (made visible), even if only by illumination in a dark room, the viewer is brought closer to understanding it" (Wood 1994). If an extremely large and complex spatial issue like climate change adaptation is our 'dark room', then 3D geovisualization tools (like CLIVE) is a match, flashing brightly but quickly burning out. And although the importance of investigating different types of matches is essential, it is more important to move towards the search for a suitable candle to illuminate the rest of the room, so we are striving forward in a sustainable manner. 


\section{Bibliography}

Aitken, S. and J. Craine (2006). Guest editorial: Affective geovisualization. Directions Magazine.

Andrienko, G., N. Andrienko, and S. Wrobel (2007). Visual analytics tools for analysis of movement data. ACM SIGKDD Explorations Newsletter 9(2), 38.

Andrienko, N., G. Andrienko, H. Voss, F. Bernardo, J. Hipolito, and U. Kretchmer (2002). Testing the usability of interactive maps in commongis. Cartography and Geographic Information Science 29(4), 325-342.

Atila, U., R. Karas, Ismail, and A. Abdul-Rahman (2013). Integration of citygml and oracle spatial for implementing $3 \mathrm{~d}$ network analysis solutions and routing simulation within 3d-gis environment. Geo-spatial Information Science 16(4), 221-237.

Baig, S. and A. Rahman (2013). Generalization and Visualization of 3D Building Models in CityGML (1st ed.). Springer-Verlag.

Barron, S., G. Canete, J. Carmichael, D. Flanders, E. Pond, S. Sheppard, and K. Tatebe (2012). A climate change adaptation planning process for lowlying, communities vulnerable to sea level rise. Sustainability 4(12), 21762208.

Beccario, C. (2013). Earth: An Animated Map.

Becker, T., C. Nagel, and T. Kolbe (2013). Semantic 3D Modeling of Multi-Utility Networks (1st ed.). Springer-Verlag.

Bhowmick, T., A. C. Robinson, A. Gruver, A. M. MacEachren, and E. J. Lengerich (2008). Distributed usability evaluation of the pennsylvania cancer atlas. International Journal of Health Geographics 7(1), 36. 
Bowen, J. and S. Reeves (2008). Refinement for user interface designs. Electronic Notes in Theoretical Computer Science 208, 5-22.

Brauen, G. (2011). Towards Interactive Audiovisual Cartography: Motivations, Design Strategies, and Methods. Ph. D. thesis, Carleton University.

Bredl, K., A. GroÃ§, J. HÃijnniger, and J. Fleischer (2012). The avatar as a knowledge worker? how immersive $3 \mathrm{~d}$ virtual environments may foster knowledge acquisition. The Electronic Journal of Knowledge Management 10(1), 15-25.

Breunig, M., E. Butwilowski, D. Golovko, P. V. Kuper, M. Menninghaus, and A. Thomsen (2013). Advancing DB4GeO (1st ed.). Springer-Verlag.

Brodersen, L. (2007). Paradigm shift from cartography to geo-communication. International Cartographic Association.

Brown, G., C. Nagel, S. Zlatanova, and T. Kolbe (2013). Modelling 3D Topographic Space Against Indoor Navigation Requirements (1st ed.). SpringerVerlag.

Buchanan, R. and M. Csikszentmihalyi (1991). Flow: The psychology of optimal experience. Design Issues 8(1), 80.

Buecken, A. and J. Rossman (2013). From the Volumetric Algorithm for SingleTree Delineation Towards a Fully-Automated Process for the Generation of Virtual Forests (1st ed.). Springer-Verlag.

Bunch, R. L. and R. E. Lloyd (2006). The cognitive load of geographic information. The Professional Geographer 58(2), 209-220.

Card, S. K., J. D. Mackinlay, and B. Shneiderman (1999). Readings in information visualization. Morgan Kaufmann Publishers.

Cartwright, W. (2006). Linking Geographical Facts with Cartographic Artifacts (1st ed.)., pp. 331-349. Elsevier Ltd.

Cinnamon, J., C. Rinner, M. Cusomano, S. Marshall, T. Bekele, T. Hernandez, R. Glazier, and L. Chipman. Evaluating web-based static, animated and interactive maps for injury prevention. 4 . 
Cormish, L. (2013). Can 4d visioning foster community responses on climate change?

Craine, J. and S. Aitken (2009). The emotional life of maps and other visual geographies (1st ed.). MPG Books Group.

Danahy, J., J. Mitchell, R. Feick, R. Wright, and R. Hoinkes (2015). Multiscale $3 \mathrm{~d}$ geovisualization of urban heat island data for planning dialogue in toronto. Emerging Issues, Challenges, and Opportunities in Urban E-Planning, 166.

Davis, J. and S. Siperstein (2015). Climate stories project.

de Boer, A. (2010). Processing old maps and drawings to create virtual historic landscapes, pp. $66-74$.

Dodge, M., M. McDerby, and M. Turner (2008). Geographic visualization. Wiley.

Dransch, D., H. Rotzoll, and K. Poser (2010). The contribution of maps to the challenges of risk communication to the public. International Journal of Digital Earth 3(3), 292-311.

Dumas, J. and B. Loring (2008). Moderating Usability Tests. Morgan Kaufmann Publishing.

Dumas, J. S. and J. Redish (1993). A practical guide to usability testing. Ablex Pub. Corp.

Dunn, C. E. (2007). Participatory gis a people's gis? Progress in Human Geography 31(5), 616-637.

Dunn, K. (2000). The Interview Process. Oxford University Press.

Dykes, J. (2005). Exploring geovisualization. Elsevier.

Ellis, D. (2014). CLIVE Roadshow Report. UPEI Climate Research Lab.

Ellul, C. (2013). Can Topological Pre-Culling of Faces Improve Rendering Performance of City Models in Google Earth (1st ed.). Springer-Verlag.

Ermi, L. and M. Frans (2005). Fundamental components of the gameplay experience: Analysing immersion. In DiGRA E\#3905 - Proceedings of the 2005 DiGRA International Conference: Changing Views: Worlds in Play. 
Foster, A. (2008). Games and motivation to learn science: Personal identity, applicability, relevance and meaningfulness. Journal of Interactive Learning Research 19(4), 597-614.

Fuhrmann, S., O. Komogortsev, and D. Tamir (2009). Investigating hologrambased route planning. Transactions in GIS 13, 177-196.

Fuhrmann, S. and W. Pike (2005). User-centered design of collaborative geovisualization tools (1st ed.). Elsevier.

Galarneau, L. L. (2005). Authentic learning experiences through play: Games, simulations and the construction of knowledge. SSRN Journal.

Geomatics and Cartographic Research Centre (2012). Nunaliit Atlas Framework.

Google Data Arts Team (2013). WebGL Globe.

Haberling, C., H. BÃd'r, and L. Hurni (2008). Proposed cartographic design principles for $3 \mathrm{~d}$ maps: A contribution to an extended cartographic theory. Cartographica: The International Journal for Geographic Information and Geovisualization 43(3), 175-188.

Harrower, M. (2007). The cognitive limits of animated maps. Cartographica: The International Journal for Geographic Information and Geovisualization 42(4), 349-357.

Hegarty, M., H. S. Smallman, and A. T. Stull (2008). Decoupling of Intuitions and Performance in the Use of Complex Visual Displays, pp. 881-886.

Henriksen, T. (2013). Using Learning Games to Meet Learning Objectives, pp. 273-277. Springer Berlin Heidelberg.

Hudson-Smith, A. (2008). The Visual City. John Wiley \& Sons, Ltd.

Irvankoski, K. (2012). Visualisation of Elevation Information on Maps: An Eye Movement Study. Ph. D. thesis, University of Helsinki.

Jaspers, M., T. Steen, C. Bos, and M. Geene (2004). The think aloud method: a guide to user interface design. International Journal of Medical Informatics 73(11-12), 781-795. 
Johnson, A., J. Leigh, P. Morin, and P. Van Keken (2006). Geowall: Stereoscopic visualization for geoscience research and education. IEEE Computer Graphics and Applications 26(6), 10-14.

Kaden, R. and T. H. Kolbe (2013). City-wide total energy demand estimation of buildings using semantic $3 \mathrm{~d}$ city models and statistical data. ISPRS Annals of Photogrammetry, Remote Sensing and Spatial Information Sciences II-2/W1, 163-171.

Keim, D. A. (2001). Visual exploration of large data sets. Commun. ACM 44(8), 38-44.

Klimke, J., B. Hagedorn, and J. Dollner (2013). A Service-Based Concept for Camera Control in $3 D$ Geovirtual Environments (1st ed.). Springer-Verlag.

Kostelnick, J. C., D. McDermott, R. J. Rowley, and N. Bunnyfield (2013). A cartographic framework for visualizing risk. Cartographica: The International Journal for Geographic Information and Geovisualization 48(3), 200-224.

Koua, E. L. and M. J. Kraak (2005). Evaluating self- organizing maps for geovisualization (1st ed.)., pp. 627-643. Elsevier.

Kraak, M. J. (2009). Geovisualization.

Kraak, M. J. and A. M. MacEachren (2005). Geovisualization and giscience. Cartography and Geographic Information Science 32(2), 67-68.

Kray, C., K. Laakso, C. Elting, and V. Coors (2003). Presenting route instructions on mobile devices, pp. 117-124.

Kushniruk, A. (2002). Evaluation in the design of health information systems: application of approaches emerging from usability engineering. Computers in Biology and Medicine 32(3), 141-149.

Kushniruk, A. and V. L. Patel (2004). Cognitive and usability engineering methods for the evaluation of clinical information systems. Journal of Biomedical Informatics 37(1), 56-76.

Ledoux, H. and M. Meijers (2013). Representing Three-Dimensional Topography in a DBMS with a Star-Based Data Structure (1st ed.). Springer-Verlag. 
Lieske, D. (2012). Toward a framework for designing spatial and non-spatial visualizations for communicating climate change risks. Geomatica 66, 255265.

Lombard, M. and T. Ditton (1997). At the heart of it all: The concept of presence. Journal of Computer-Mediated Communication 3(2), 0-0.

Lonergan, C. and N. Hedley (2014). Flexible mixed reality and situated simulation as emerging forms of geovisualization. Cartographica 49(3), 175-187.

Lowner, M. O. (2013). On Problems and Benefits of 3D Topology on Under-Specified Geometries in Geomorphology (1st ed.). Springer-Verlag.

MacEachren, A. M. (1995). How maps work. Guilford Press.

MacEachren, A. M., M. Gahegan, W. Pike, I. Brewer, G. Cai, E. Lengerich, and F. Hardistry (2004). Geovisualization for knowledge construction and decision support. IEEE Computer Graphics and Applications 24(1), 13-17.

MacEachren, A. M. and D. R. F. Taylor (1994). Visualization in modern cartography. Pergamon.

Maclachlan, J. C., M. Jerrett, T. Abernathy, M. Sears, and M. J. Bunch (2007). Mapping health on the internet: A new tool for environmental justice and public health research. Health \& Place 13(1), 72-86.

Mann, M. E. (2014). Dire Predictions. Dk Pub.

McCormick, B. H. (1988). Visualization in scientific computing. ACM SIGBIO Newsletter 10(1), 15-21.

Montello, D. R. (2009). Cognitive research in giscience: Recent achievements and future prospects. Geography Compass 3(5), 1824-1840.

Morss, R. E., J. L. Demuth, and J. K. Lazo (2008). Communicating uncertainty in weather forecasts: A survey of the u.s. public. Wea. Forecasting 23(5), 974-991.

Moser, S. C. and L. Dilling (2007). Creating a climate for change. Cambridge University Press. 
Natural Resources Canada (2015). Canada in a Changing Climate: Sector Perspectives on Impacts and Adaptation.

Nivala, A. M., T. Sarjakoski, and T. Sarjakoski (2007). Usability methods' familiarity among map application developers. International Journal of HumanComputer Studies 65(9), 784-795.

Norman, K. and E. Panizzi (2006). Levels of automation and user participation in usability testing. Interact Comput 18, 246-264.

O'Neill, S. and S. Nicholson-Cole (2009). "fear won't do it": Promoting positive engagement with climate change through visual and iconic representations. Science Communication 30(3), 355-379.

Pasewaldt, S. (2012). Towards Comprehensible Digital 3D Maps (1st ed.)., pp. 261-66. JobstMedia Management Verlag Wien.

Peake, R. (2012). Mapping Census 2010. Esri Press.

Pennsylvania State University (2010). Penn State Public Broadcasting.

Petrovic, D. and P. Masera (2006). Analysis of user's response on 3D cartographic presentations.

Popelka, S. and A. Brychtova (2011). Visualization of Spatio-Temporal Changes of The Olomouc City.

Popelka, S. and A. Brychtova (2013). Eye-tracking study on different perception of $2 \mathrm{~d}$ and $3 \mathrm{~d}$ terrain visualisation. The Cartographic Journal 50(3), 240246.

Richards, W. and R. Daigle (2011). Scenarios and Guidance for Adaptation to Climate Change and Sea-Level Rise.

Roth, R. E. (2013). Interactive maps: What we know and what we need to know. Journal of Spatial Information Science (6).

Savage, D., E. Wiebe, and H. Devine (2004). Performance of 2D versus 3D Topographic Representations for Different Task Types, pp. 1793-1797.

Sayers, H. (2004). Desktop virtual environments: a study of navigation and age. Interacting with Computers 16(5), 939-956. 
Schobesberger, D. and T. Patterson (2008). Exploring of Effectiveness of 2D vs. 3D Trailhead Maps.

Schroth, O., E. Pond, C. Campbell, P. Cizek, S. Bohus, and S. R. J. Sheppard (2011). Tool or toy? virtual globes in landscape planning. Future Internet 3(4), 204-227.

Schroth, O., E. Pond, and S. R. J. Sheppard (2015). Evaluating presentation formats of local climate change in community planning with regard to process and outcomes. Landscape and Urban Planning.

Semmo, A., M. Trapp, J. E. Kyprianidis, and J. DÃúllner (2012). Interactive visualization of generalized virtual $3 \mathrm{~d}$ city models using level-of-abstraction transitions. Computer Graphics Forum 31(3), 885-894.

Shepherd, I. (2009). Travails in the Third Dimension: A Critical Evaluation of Three-dimentional Geographical Visualization (3rd ed.). Pearson Prentice Hall.

Shepherd, I. and L. Bleasdale-Shepherd (2008). Towards effective interaction in $3 D$ data visualizations: What can we learn from videogames technology?

Sheppard, S. R. and P. Cizek (2009). The ethics of google earth: Crossing thresholds from spatial data to landscape visualisation. Journal of Environmental Management 90(6), 2102-2117.

Sheppard, S. R., A. Shaw, D. Flanders, S. Burch, A. Wiek, J. Carmichael, J. Robinson, and S. Cohen (2011). Future visioning of local climate change: A framework for community engagement and planning with scenarios and visualisation. Futures 43(4), 400-412.

Sheppard, S. R. J., A. S. Flanders, S. Burch, and O. Schroth (2013). Bringing Climate Change Science to the Landscape Level: Canadian Experience in Using Landscape Visualisation Within Participatory Processes for Community Planning. (1st ed.). Taylor and Francis.

Slocum, T. A., C. Blok, B. Jiang, A. Koussoulakou, D. R. Montello, S. Fuhrmann, and N. R. Hedley (2001). Cognitive and usability issues in geovisualization. Cartography and Geographic Information Science 28(1), 6175. 
Slocum, T. A., R. B. McMaster, F. C. Kessler, and H. H. Howard (2009). Virtual Environments (3rd ed.). Pearson Prentice Hall.

Smallman, H. S. and M. St. John (2005). Naive realism: Misplaced faith in realistic displays. Ergonomics in Design 13(3), 6-13.

Statistics Canada (2011). Census Data.

Swienty, O., T. Reichenbacher, S. Reppermund, and J. Zihl (2008). The role of relevance and cognition in attention-guiding geovisualization. The Cartographic Journal 45, 227âĂŞ38.

Taylor, D. R. F. (1997). Maps and Mapping in the Information Era, pp. 1-10.

Taylor, D. R. F. (2005). Cybercartography: Theory and Practice (1st ed.). Elsevier Science.

Taylor, D. R. F. (2006). The Theory and Practice of Cybercartography (1st ed.)., pp. 1-14. Elsevier Ltd.

Taylor, D. R. F. and S. Caquard (2006). Cybercartography: Maps and mapping in the information era. Cartographica: The International Journal for Geographic Information and Geovisualization 41(1), 1-6.

Taylor, D. R. F. and T. P. Lauriault (2014). Developments in the Theory and Practice of Cybercartography: Applications and Indigenous Mapping (2nd ed.). Elsevier Science.

Tobon, C. (2005). Evaluating geographic visualization tools and methods: An approach and experiment based upon user tasks (1st ed.)., pp. 627-643. Elsevier.

Trujillo, A., J. P. Suarez, M. de la Calle, D. Gomez, A. Pedriza, and J. M. Santana (2013). Glob3 Mobile: An Open Source Framework for Designing Virtual Globes on iOS and Android Mobile Devices (1st ed.). Springer-Verlag.

Uden, M. and A. Zipf (2013). Open Building Models: Towards a Platform for Crowdsourcing Virtual 3D Cities (1st ed.). Springer-Verlag.

Unity Technologies (2015). Unity.

van Elzakker, C. and K. Wealands (2007). Use and users of multimedia cartography. Springer. 
Wagner, D., M. Wewetzer, J. Bogdahn, N. Alam, M. Pries, and V. Coors (2013). Geometric-Semantical Consistency Validation of CityGML Models (1st ed.). Springer-Verlag.

Ware, C. (2012). Information visualization. Morgan Kaufmann.

Webster, T. and C. Brydon (2013). Evaluating long-term coastal change on prince edward island using gis-based spatial analysis of coastline orthophotography. Climate Impacts and Adaption Science (3).

Williamson, R. (2013). News. Carbon Management 4(6), 583-585.

Wolff, M., M. J. Wagner, S. Poznanski, J. Schiller, and S. Santen (2015). Not another boring lecture: Engaging learners with active learning techniques. The Journal of Emergency Medicine 48(1), 85-93.

Wood, M. (1994). Visualization in Historical Context (1st ed.). Pergamon. 
Appendices 


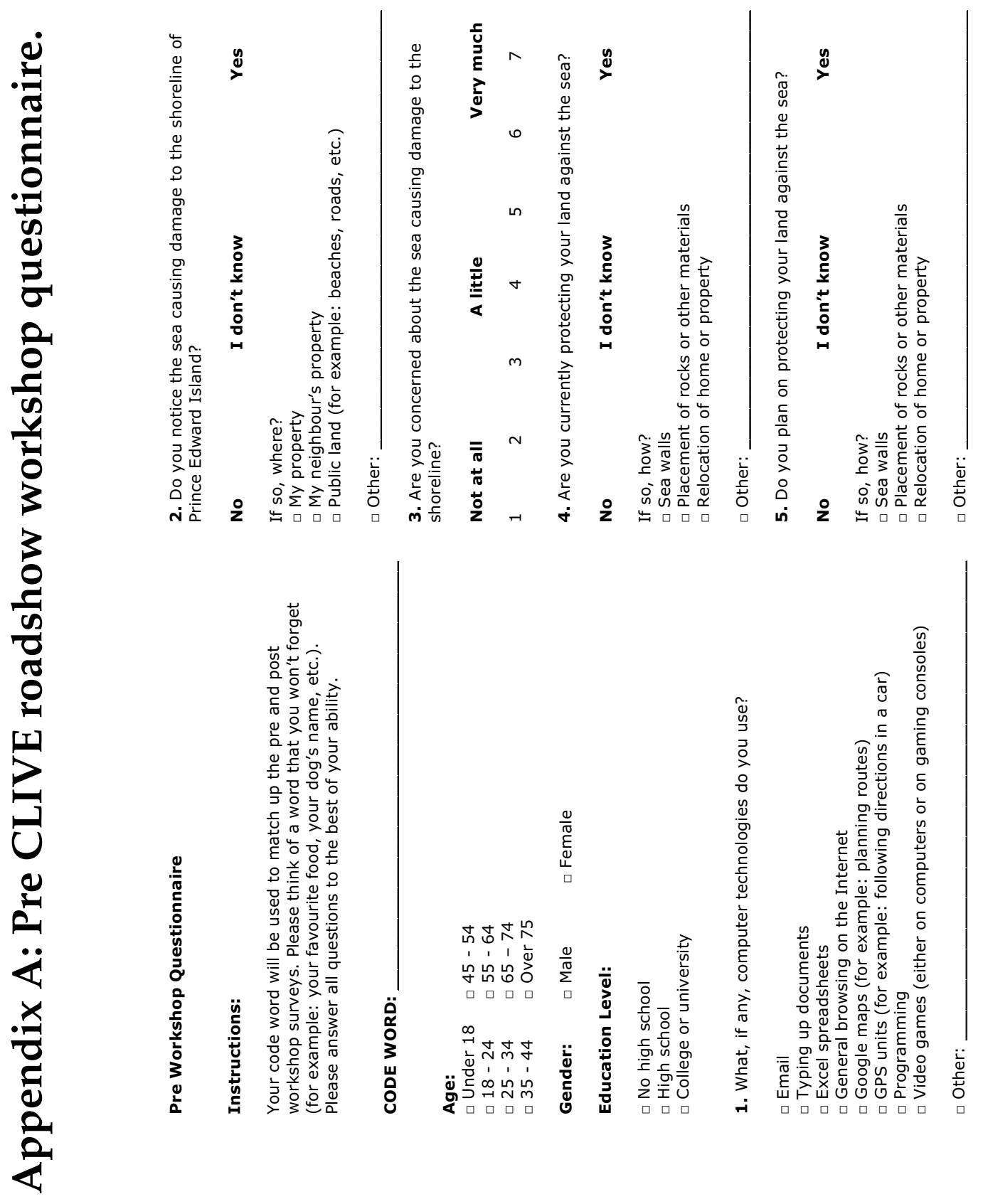




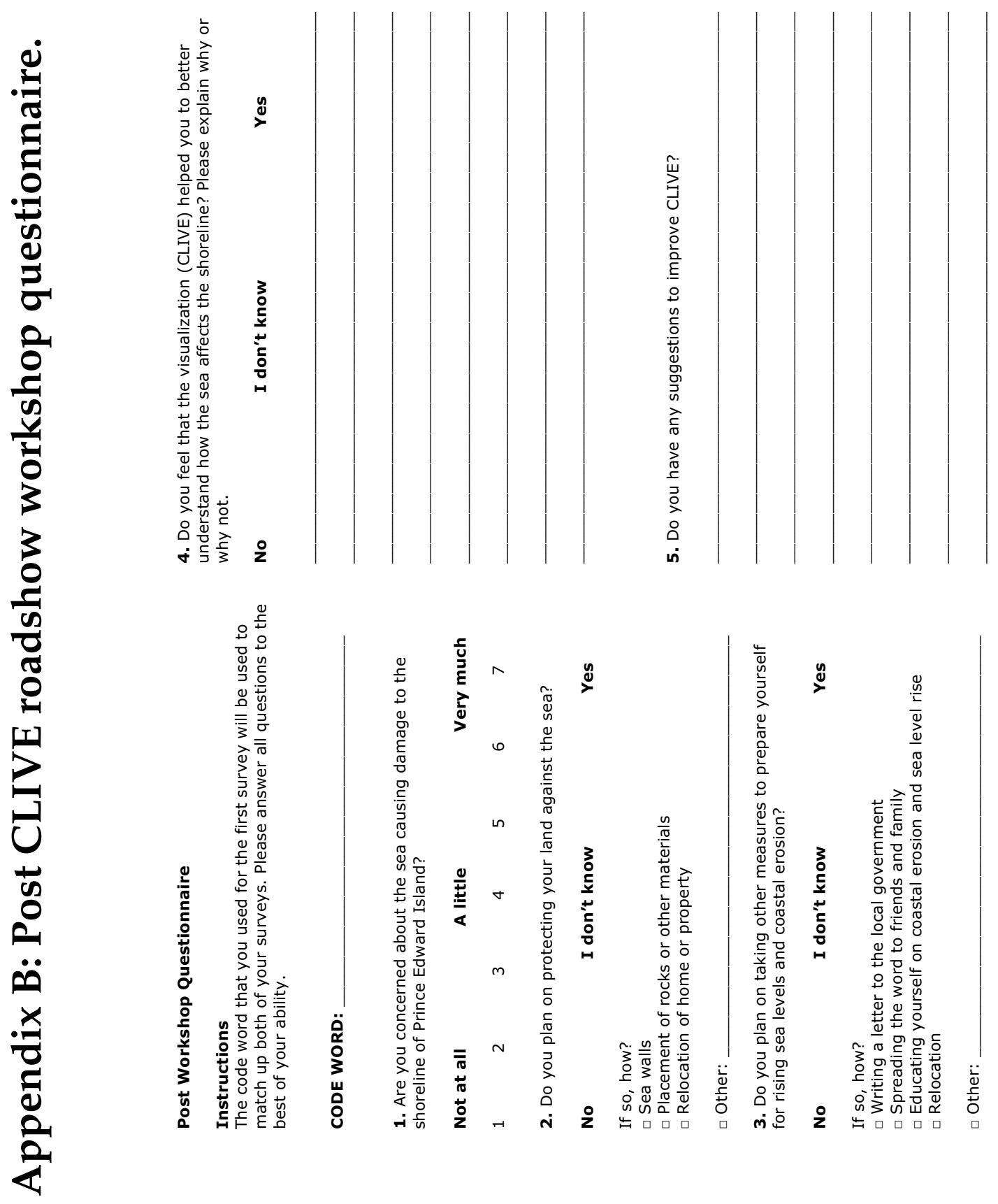




\title{
Appendix C: Email invitation to participate in the usability study - expert user.
}

\begin{abstract}
Hello
My name is Laura Salisbury and I am a Master's student in the Department of Geography \& Environmental Studies at Carleton University. I am working on a research project under the supervision of Dr. Fraser Taylor and Dr. Scott Mitchell at Carleton University, as well as Dr. Adam Fenech of the Climate Research Lab at UPEl.

I am writing to you specifically by the recommendation of Dr. Fenech who pointed to you as an expert in coastal erosion and/or sea level rise. I am also told that you were heavily Involved with the production and development of CLIVE (CoastaL Impact Visualization Environment - http://projects.upei.ca/climate/). For my research project, I am researching the potentials of 3D geographic visualization for raising climate change risk awareness and education. Specifically, I'm looking at how CLIVE is used by novices and experts. You are a perfect candidate for the "expert" group.

I am in Charlottetown for the month of July conducting usability tests with CLIVE, and interviewing both experts and novices in the subject area of coastal erosion. I am stationed at the Climate Research Lab (on the first floor of the Regis and Joan Duffy Research Centre at UPEI). I would really appreciate your participation in a 30 to 45 minute interview, as your insight is very valuable to my work. Interviews will be audio recorded, and can be scheduled at your convenience, though must take place in the Climate Research Lab. You will receive the lab's newly published "trivia calendar" as a token of appreciation for your time (http://news.upei.ca/media/2014/05/13/upei-sclimate-researchlab-launch-2015-pei-weather-trivia-calendar).
\end{abstract}

The ethics protocol for this project was reviewed by the Carleton University Research Ethics Board, which provided clearance to carry out the research. Should you have questions or concerns related to your involvement in this research, please contact the REB Chair, Professor Andy Adler at ethics@carleton.ca or at 613-520-2517.

If you would like to participate in this research project, or have any questions, please contact me at 613-853-8079 or laura.salisbury@carleton.ca .

Thank you so much,

\author{
Laura Salisbury \\ MSc Candidate \\ Department of Geography \& Environmental Studies \\ Geomatics and Cartographic Research Centre \\ Carleton University \\ laura.salisbury@carleton.ca (613) 853-8079
}


Appendix D: Usability study interview consent form. 


\section{Carleton \\ U N I V E R S I T Y}

Canada's Capital University

Interview Consent Form: 3D Geovisualization

Exploring the Differences in Usability and Utility of Three Dimensional Geographic Visualizations between Users with Differing Levels of Expertise and Experience

Date of ethics clearance: June $20^{\text {th }}, 2014$

Ethics Clearance for the Collection of Data Expires: May $31^{\text {st }}, 2015$

I , choose to participate in a study on 3D geovisualization. This study aims to explore how different users react to a geographic visualization depicting sea level rise and coastal erosion risk on Prince Edward Island. The visualization (called Coastal Impact Visualization Environment or CLIVE) has been developed by the Climate research lab at UPEI and is being toured across PEI during the summer of 2014. The researcher for this study is Laura Salisbury in the Department of Geography \& Environmental Studies at Carleton University. She is working under the supervision of Dr. Fraser Taylor and Dr. Scott Mitchell in the Department of Geography \& Environmental Studies at Carleton University.

This study involves one 45 minute to 60 minute interview. With your consent, interviews will be audio-recorded. Once the recording has been transcribed, the audio-recording will be destroyed.

As this project will ask you about your employment, there are some potential professional risks to you if your statements are critical of your employer. While this risk is expected to be minimal, I will take precautions to protect your identity. This will be done by keeping all responses anonymous and allowing you to request that certain responses not be included in the final project. Should you experience any distress during the interview, you will be provided with contact information for counseling services available nearby.

You have the right to end your participation in the study at any time, for any reason, up until September $1^{\text {st }}, 2014$. You can withdraw by phoning or emailing the researcher or the research supervisor. If you withdraw from the study, all information you have provided will be immediately destroyed.

All research data, including audio-recordings and any notes will be encrypted and passwordprotected. Any hard copies of data (including any handwritten notes or USB keys) will be kept in a locked cabinet at Carleton University. Research data will only be accessible by the researcher and the research supervisor.

Once the project is completed, all research data will be securely destroyed. (Electronic data will be erased and hard copies will be shredded.) A written summary report will remain. 


\section{Online Atlas of Workshop Reactions}

In the fall, I will develop an online atlas exploring the effects of climate change. This atlas will be published on the website of the Geomatics and Cartographic Research Centre at Carleton University. In this atlas, I would like to include your written and/or oral reactions from the visualization. These reactions would be linked to your workshop location, age, gender, as well as your photograph if you wish.

You may wish to have your comments published on this site. Please note that by allowing your name or photograph to appear on the website you are waiving your anonymity and your comments will be attributed to you on the site.

Please check the following boxes. If you do not want any of your comments to be published on the online website, check the last box in the list and you will remain an anonymous contributor to the study.
$\square$ Age
$\square$ Gender
$\square$ Name
$\square$ Workshop location
$\square$ Audio recordings
$\square$ Photograph

$\square$ I do NOT want any of my comments to be published on the online website

If you would like a copy of the finished research project, you are invited to contact the researcher to request an electronic copy which will be provided to you.

This project was reviewed by the Carleton University Research Ethics Board, which provided clearance to carry out the research. Should you have questions or concerns related to your involvement in this research, please contact:

\section{REB contact information:}

Professor Andy Adler, Chair

Professor Louise Heslop, Vice-Chair

Research Ethics Board

Carleton University

1325 Dunton Tower

1125 Colonel By Drive

Ottawa, ON K1S 5B6

Tel: 613-520-2517

ethics@carleton.ca

Researcher contact information: Laura Salisbury

Geography \& Environmental Studies

Carleton University

Tel: 613-853-8079

Email: laura.salisbury@carleton.ca

Signature of participant

Signature of researcher

\author{
Supervisor contact information: \\ Dr. Fraser Taylor \\ Geography \& Environmental Studies \\ Carleton University \\ Tel: 613-853-8079 \\ Email: fraser_taylor@carleton.ca
}



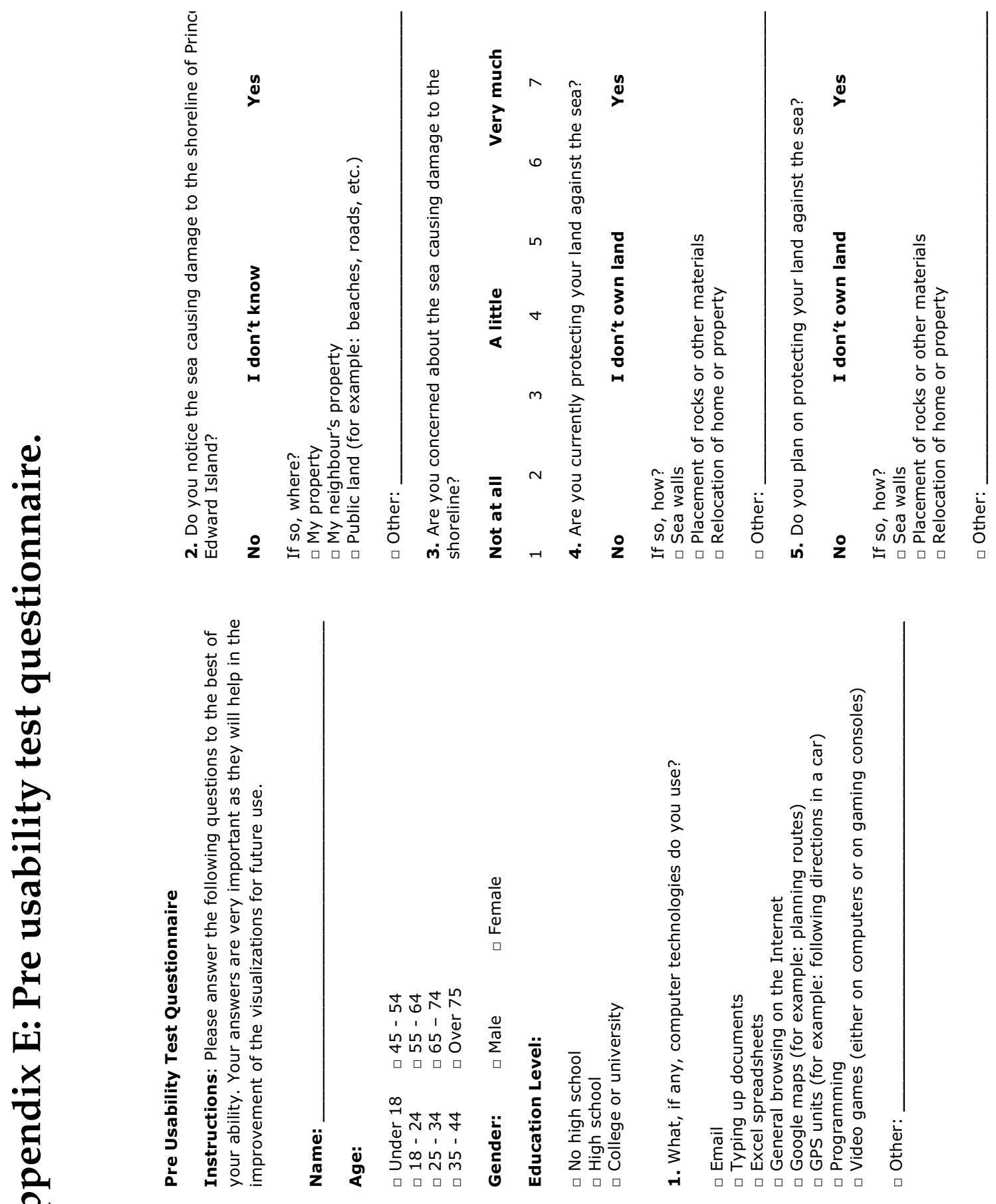
Appendix F: Usability testing notes, tasks, and interview questions. 


\section{Usability Testing Notes - Coastal Impact Visualization Environment (CLIVE)}

(Facilitator: Display the CLIVE visualization on the computer and explain briefly how it works. Ask the participant to examine the page and observe their initial work with the example and their reactions. If they have difficulty with the example, answer their questions but note the difficulties.)

Instructions: Please take a few minutes and play with and explore CLIVE. Remember to think aloud as you explore. I will be asking you a few questions after you have taken some time to explore and get comfortable with CLIVE. You're free to explore, but here are some prompts: use the controller to move around the Island. Change the timeline. Freeze and unfreeze the camera frame

\section{Usability}

\section{Time taken to explore:}

While users explore the map please take notes on the following:

- Are users able to work with visualization?

- Do users understand how the game controller works with regards to the visualization?

- Do users understand how to change the sea level and the coastline?

- Do they require assistance in working with the visualization and, if so, in what ways? 
Usefulness (Instructions: Answer the following questions. Remember to think aloud.)

1. Can you find your home town? (Charlottetown if you are not from PEI)

2. Can you find a local landmark for me? (UPEI if you are using Charlottetown)

3. Place a flag on your landmark of choice. What's the elevation of your landmark?

4. Use the distance tool from your landmark to the coastline. How far is your landmark? 
5) Please change the sea level in 2 ways:

- the "back" buttons

- the "arrow" buttons

6a) Please add all coast lines. Remove them one by one.

b) Add the 1968 coast. Add the 2100 coast. Remove them all. 


\section{General Questions}

1. Do you feel that the visualization helped you to better understand coastal erosion and sea level rise? If so how?

2. After seeing experiencing the visualization, are you more concerned with coastal erosion and sea level rise?

3. Do you think you will take any measures against coastal erosion and sea level rise? 
4. What did you like most about the visualization?

5. What did you least like about the visualization?

6. Do you have any suggestions for improving this visualization?

7. What is your "take home" or "overall" message? 
Appendix G: Post usability test questionnaire. 


\section{Post Usability Test Questionnaire - Coastal Impact Visualization Environment (CLIVE)}

Instructions: Please answer the following questions based on the visualization that you just interacted with. Your answers are very important as they will help in the improvement of the visualizations for future use.

1. Are you concerned about the sea causing damage to the shoreline?

Not at all

1 2 3

A little

4

Very much 5

6 7

2. Your overall experience with the visualization can best be described as:

Terrible

1
2

3

\section{OK}

45
Wonderful 7

3. When answering questions and completing tasks, you generally felt:
Frustrated

1
2
Indifferent

4
5

OK

4
5
Satisfied

6 7
4. In general, the visualization was:
Dull

2
3

Stimulating

7

5. Answering questions based on the visualization was:

Difficult

Moderate

1

2

3

4

5

6

Easy 7

6. The amount of visual information in the visualization is: Inadequate

Adequate 1 3
Too much

6

7
7. The level of interactivity on the visualization as: Inadequate

Adequate 1 2
4
Too much

6 
8. Learning to use the visualization was:

\begin{tabular}{lllllll} 
Difficult & & \multicolumn{3}{c}{ OK } & \multicolumn{3}{c}{ Easy } \\
1 & 2 & 3 & 4 & 5 & 6 & 7
\end{tabular}

9. Interacting with the visualization helped with answering the questions:

\begin{tabular}{ccccccc} 
Not at all & \multicolumn{9}{c}{ A little } & & Very much \\
1 & 2 & 3 & 4 & 5 & 6 & 7
\end{tabular}

10. The amount of visual information was very distracting:

Agree

1

11. Did you learn about the coastal erosion and sea level rise?

No

1

2

3

I don't know
Disagree

$6 \quad 7$

12. If they were interested in the subject matter, would you recommend this visualization to a friend:

No

1

13. Would you use this visualization again?

No

1

1

2

3
Maybe

4

Maybe

4
Yes

6

7

Yes

7

5

Yes

$6 \quad 7$




\title{
Appendix H: Follow up Email interview Questions: 'Expert Template'.
}

\author{
Hi 'Expert',
}

I hope you're well. First I want to thank you again for allowing me to interview you back in July. I learned a lot about PEI and CLIVE, and the CLIVE development team received a lot of feedback to improve their tool.

If you don't mind, I'd like to ask you a few follow up questions. Six months ago, we sat down and worked with CLIVE together. I'm interested in seeing if using CLIVE has made any sort of impact in your life (regarding coastal erosion and sea level rise risks) since then. You should know that I conducted 13 interviews in total.

Don't feel that you have to be positive - I'm also interested in knowing if it has made absolutely no impact on your life or habits in the slightest. Hearing this will help to improve future versions of CLIVE. As you know, I was not involved in the development of the tool at all, so I won't be hurt if you have completely forgotten about CLIVE. I also understand that some of these questions might be hard for you to answer since you have been so heavily involved with the development of CLIVE.

You are under no obligation to take part. If you are interested, please answer the following questions and send them back to this email (laurasalisbury@cmail.carleton.ca). The answers can be as short or as long as you'd like. I can't imagine the whole process taking up longer than 15 or 20 minutes of your time.

1. Since our interview, can you recall having discussed CLIVE with anyone?

2. Since our interview, can you recall having discussed coastal erosion or sea level rise on PEI with anyone? If so, was it because of your experience with CLIVE?

3. Are you currently taking any measures against coastal erosion or sea level rise? This can be anything from protecting your shoreline property, to spreading awareness about the risks of coastal erosion and sea level rise on PEI. 
4. One of the goals of the developers of CLIVE is to motivate users to act and protect themselves against the effects of coastal erosion and sea level rise. Do you have any recommendations to help this process along? We already discussed specific usability issues back in July, but perhaps you have other thoughts on the matter.

Thanks a lot. I really appreciate any insight you have. I hope you're not buried in snow - I've seen some pretty alarming photos!

Thanks again, Laura Salisbury 